\title{
I. Aufbau und Entwicklung der politischen Beziehungen
}

\section{Der mühsame Neubeginn - Die Aufnahme diplomatischer Beziehungen 1949-1952}

Mit der Gründung der Bundesrepublik Deutschland im September 1949 war zwar eine Zäsur im Verhältnis der Deutschen zu den drei westlichen Siegermächten erfolgt, das Prinzip der alliierten Kontrolle galt jedoch weiterhin. Die Alliierte Hohe Kommission (AHK), das höchste Zivilorgan der Westalliierten, nahm auf der Basis des Besatzungsstatuts weitreichende Kontroll- und Vorbehaltsrechte wahr. Diese „versetzten die Westalliierten in die Lage, die außenpolitische und außenwirtschaftliche Orientierung der Bundesregierung vollständig zu steuern "I. Der neue westdeutsche Staat war also in seiner Souveränität zunächst noch beschränkt und de facto ein Protektorat, vor allem fehlte ihm die Kompetenz zur Wahrnehmung der auswärtigen Angelegenheiten. Andererseits war vor dem Hintergrund der globalen Ost-West-Konfrontation, ungeachtet mancher Zweifel der Alliierten an der Demokratiefähigkeit der Deutschen, das Ziel einer kontrollierten und schrittweisen Integration des Landes in das seit 1947/48 Konturen gewinnende westliche Bündnis unumstritten ${ }^{2}$.

Das Petersberger Abkommen vom 22. November $1949^{3}$ bedeutete in seiner Mischung aus Zugeständnissen und Forderungen an die deutsche Seite eine erste Etappe auf dem Weg zur vollen Souveränität Westdeutschlands. Da der Bundesrepublik die außenpolitische Befugnis noch fehlte, war vorläufig nur die Einrichtung konsularischer und wirtschaftlicher Vertretungen im Ausland erlaubt worden. Die Bundesregierung unter Konrad Adenauer konnte aber nunmehr in Absprache mit der Alliierten Hohen Kommission darangehen, erste Schritte zur Wiedergründung des Auswärtigen Dienstes vorzunehmen. Den Kern des künftigen außenpolitischen Apparates bildeten die „Verbindungsstelle zur Alliierten Hohen Kommission“, die seit September 1949 unter Leitung von Herbert Blankenhorn im Bundeskanzleramt bestand, sowie das im November 1949 gebildete „Organisationsbüro für die konsularisch-wirtschaftlichen Vertretungen im Ausland“ unter Wilhelm Haas ${ }^{4}$. Die

1 Herbst, Stil und Handlungsspielräume westdeutscher Integrationspolitik, S. 5.

2 Siehe hierzu Herbst (Hrsg.), Westdeutschland 1945-1955; zur amerikanischen Deutschlandpolitik vgl. Rupieper, Der besetzte Verbündete.

${ }^{3}$ Dazu ausführlich: Lademacher/Mühlhausen (Hrsg.), Sicherheit, Kontrolle, Souveränität.

${ }^{4}$ Das "Organisationsbüro" bildete nach seiner Erweiterung und Umbenennung zur „Dienststelle für Auswärtige Angelegenheiten“ im Juni 1950 den Nukleus der Personal- bzw. Verwaltungsabteilung im späteren Auswärtigen Amt. Haas, der die Personalabteilung bis Ende Juli 1951 leitete, hat diese Anfangszeit eingehend geschildert; vgl. Haas, Beitrag zur Geschichte der Entstehung des Auswärtigen Dienstes der Bundesrepublik, S. 22 ff.; ders., Lebenserinnerungen, S. 210-231. Neben dieser offiziösen Darstellung siehe als erste behördengeschichtliche Untersuchung der Anfänge des neuen Auswärtigen Amts Döscher, Verschworene Gesellschaft. Vgl. Kroll, Deutschlands Weg nach Europa, S. 161-180. Atmosphärisch aufschlußreich die Erinnerungen von Diehl, Zwischen Presse und Politik; Sahm, „Diplomaten taugen nichts"; und von Herwarth, Von Adenauer zu Brandt. 
Arbeit des „Organisationsbüros“ orientierte sich an den Vorgaben des Petersberger Abkommens. Das Hauptaugenmerk galt daher zunächst der Planung von Konsulaten bzw. Handelsvertretungen ohne diplomatischen Status. Blankenhorn und Haas stellten dem Ausschuß für Politische Angelegenheiten der AHK bereits im Januar 1950 die ersten deutschen Überlegungen vor ${ }^{5}$. Danach sollten zunächst innerhalb eines Jahres 42 Konsulate in 34 Ländern eingerichtet werden, allen voran Vertretungen in den USA, Frankreich und Großbritannien, den drei westlichen Besatzungsmächten. Diesen würden dann weitere Missionen in den Ländern folgen, die ihrerseits Vertretungen in Deutschland eingerichtet hätten ${ }^{6}$. Die AHK stimmte den von Haas skizzierten Überlegungen im Grundsatz zu, wies aber einschränkend darauf hin, daß über die Auswahl weiterer Länder in diesem frühen Stadium noch nichts Endgültiges gesagt werden könne. Außerdem betonten die Vertreter der Besatzungsmächte, daß jeder Einzelfall zunächst von der Hohen Kommission zu prüfen sei.

Angesichts seiner traditionellen politischen und wirtschaftlichen Verbindungen zu Deutschland gehörte auch Spanien ${ }^{7}$ zu den 34 Ländern, in denen die ersten Auslandsdienststellen etabliert werden sollten ${ }^{8}$. Neben der konsularischen Tätigkeit für die deutsche Kolonie wurde das Interesse an Spanien vom Bundeskanzleramt mit wirtschaftlichen Motiven, wie dem 1949 abgeschlossenen Handelsabkommen, Verkehrs- und Schiffahrtsfragen sowie der Frage des Auslandsvermögens begründet. Die Mission in Madrid wurde mit einem personellen Umfang von 35 Personen konzipiert und nahm damit in Relation zu den Vertretungen in New York mit 56 und Athen mit 29 Personen eine mittlere Stellung ein ${ }^{9}$. Die bereits im Oktober 1950 begonnenen organisatorischen Vorbereitungen werfen angesichts des zu diesem Zeitpunkt noch existierenden UNO-Boykotts gegen Spanien die Frage auf, inwieweit diese Entwürfe beeinflußt waren durch die wichtige Rolle Franco-Spaniens in der NS-Außenpolitik.

Denn ein Blick auf die internationalen Rahmenbedingungen zeigt, wie sehr gerade das Spanien Francos zu Beginn der 50er Jahre noch im politischen Abseits stand. Von den rechtsgerichteten Diktaturen in Europa war nach dem Ende des Zweiten Weltkrieges neben Portugal ${ }^{10}$ nur das franquistische Spanien übriggeblieben. Die für Francos Sieg im Spanischen Bürgerkrieg maßgebliche Hilfe des nationalsozialistischen Deutschland und

5 Das Gespräch fand am 23.Januar 1950 auf dem Petersberg, dem Sitz der AHK, statt; Aufzeichnung vom 24. Januar 1950, PA/AA, Abt. 2, Bd. 157.

6 Ebenda. Die Vertreter der Besatzungsmächte übergaben Blankenhorn und Haas allerdings eine Liste von 10 weiteren Ländern, die aus ihrer Sicht als unproblematisch galten. Danach konnte die Bundesregierung - ohne den Einspruch der AHK befürchten zu müssen - Vertretungen in den Beneluxstaaten, Dänemark, Griechenland, Italien, Norwegen und der Türkei planen. Hinzu kamen in Übersee die Commonwealth-Länder Kanada und Australien. In Europa kamen hingegen die im Zweiten Weltkrieg neutralen I.änder Schweiz, Schweden, Spanien und Portugal aufgrund der dort beschlagnahmten deutschen Vermögenswerte vorläufig nicht in Frage.

7 Vgl. zu dem differenziert zu betrachtenden Beziehungsgeflecht: Corden, German policy toward neutral Spain 1914-1918; Sepasgosarian, Eine ungetrübte Freundschaft? Vgl. außerdem Volkmann, Politik und ökonomisches Interesse in den Beziehungen der Weimarer Republik zum Königreich Spanien, S. 41-76.

8 Denkschrift über die Organisation der konsularisch-wirtschaftlichen Vertretungen im Ausland und den Aufbau einer zentralen Dienststelle im Bundeskanzleramt, o. D., PA/AA, Nl. Haas, Bd. 22.

9 Ebenda.

10 Vgl. zu Portugals Entwicklung bis 1945 von zur Mühlen, Fluchtweg Spanien-Portugal, S. 115-135. 
des faschistischen Italien sowie Spaniens ideologische und politische Affinitäten zu den „Achsenmächten“ während des Zweiten Weltkrieges" ${ }^{11}$ waren die wesentlichen Ursachen für die internationale Ächtung des Landes. Spanien galt nach der Zäsur des Jahres 1945 als das einzige „faschistische Relikt", das den Weltkrieg unbeschadet überlebt hatte. Das Stigma der Zusammenarbeit mit den „Achsenmächten“ und das zeitweilig gegen die AntiHitler-Koalition gerichtete Handeln führte zu einer Isolierung des franquistischen Spaniens, die nach der auf der Potsdamer Konferenz im Juli 1945 ausgesprochenen Verurteilung 1946 in einer Empfehlung der UNO-Generalversammlung gipfelte, den iberischen Staat diplomatisch zu boykottieren ${ }^{12}$.

Unter dem Eindruck der wachsenden Ost-West-Konfrontation schwanden jedoch bald die antifaschistisch motivierten Vorbehalte. Seine geostrategische Lage verlieh Spanien ein immer größeres Gewicht in den militärischen Überlegungen des Westens - insbesondere der USA. Aber erst der Ausbruch des Korea-Krieges im Juni 1950 machte den Einstellungswandel zugunsten Spaniens international möglich. Im November 1950 hob die UNO ihre Boykottresolution auf. Dies war jedoch nur ein erster Schritt, „salonfähig“ war die Franco-Diktatur damit aber noch nicht geworden. So blieben ihr die Marshallplan-Hilfe und der Weg in die NATO - im Gegensatz zu Portugal - versperrt. Spanien war für die internationale Staatengemeinschaft nach wie vor ein "Stein des Anstoßes"13.

Dies war die Konstellation, in der die Bundesregierung ihre Spanienpolitik entwickeln mußte. Über das Verhältnis des neuen westdeutschen Staates zu Spanien gab es in dieser Phase erster außenpolitischer Gehversuche lediglich ungefähre Vorstellungen. Daß aber die Regierung Adenauer von Beginn an auf das Franco-Regime als verläßlichen antikommunistischen Partner setzte, dokumentiert bereits das beredte Schweigen gegenüber einem Appell der spanischen Exilregierung in Paris, die im Oktober 1949 gefordert hatte, die „neue deutsche Demokratie“ möge sich dem internationalen Druck auf die FrancoDiktatur anschließen ${ }^{14}$. Der Bonner Regierung ging es vielmehr darum, alsbald direkte Verbindungen zu dem isolierten Regime herzustellen. Dabei halfen Privatleute wie Jakob Kindt-Kiefer, der bereits seit 1948 von der Schweiz aus Adenauer mit europäischen Politikern christlich-demokratischer Parteien in Genf zusammengebracht hatte ${ }^{15}$. Mit Wissen

11 Vgl. Ruhl, Spanien im Zweiten Weltkrieg.

12 Vgl. zur internationalen Isolation des Franco-Regimes Portero, Franco aislado.

${ }_{13}$ So der Titel einer zeitgenössischen Studie von Duff, Spanien. Der Stein des Anstoßes.

14 Die an die Bundesminister Erhard, Niklas und Wildermuth übermittelte Deklaration des Vize-Präsidenten der republikanischen Exilregierung in Paris, Fernando Valera, vom 30.9.1949 wurde an das Bundeskanzleramt zur Klärung weitergeleitet. Den Bundesministern erteilte man die Auskunft, es sei nicht beabsichtigt, auf die Schreiben einzugehen. Bundeskanzleramt an Wildermuth, 25.10.1949, BA, B 136, Bd. 6282. Auch bei anderer Gelegenheit, so im Jahre 1955, reagierten deutsche Diplomaten unter Hinweis auf die „freundschaftlichen Beziehungen der Bundesrepublik mit der legalen spanischen Regierung in Madrid" nicht auf Eingaben der Exilregierung in Paris. Botschaft Paris an Auswärtiges Amt, 13. 4. 1955, PA/AA, Ref. 206, Az. 82.00.

${ }_{15}$ Zur Person Jakob Kindt-Kiefers und seinem wechselhaften Verhältnis zu Adenauer vgl. Schwarz, Adenauer. Der Staatsmann, S. 229-231, sowie Der Spiegel, Nr. 46 (1959), S. 15 f. Vgl. zu den informellen Gesprächen europäischer Politiker: Kaiser, Begegnungen christdemokratischer Politiker in der Nachkriegszeit, S. 150-152. Aus der Sicht des Zeitzeugen siehe Dörpinghaus, Die Genfer Sitzungen - Erste Zusammenkünfte führender christlich-demokratischer Politiker im Nachkriegseuropa, S. 538-565. Siehe zu Adenauers Bemühungen, die Verbindungen zum Ausland auch auf diesem Wege wiederherzustellen: Bosmans, Das Ringen um Europa, S. 123-148. 
des Kanzlers trafen im September und November 1950 Kindt-Kiefer und der spanische Außenminister Martín Artajo in Madrid zu Informationsgesprächen über politische und wirtschaftliche Themen zusammen. Mitte November erläuterte der Außenminister den Standpunkt Francos, daß „die deutsch-spanischen Beziehungen jetzt nicht länger in Form von privaten Gesprächen behandelt werden sollten" 16 . Vielmehr sei es sein Wunsch, daß Deutschland unverzüglich einen Botschafter oder, falls dies nicht möglich sei, einen Generalkonsul ernenne. Kindt-Kiefer verwies auf den Widerstand der alliierten Hochkommissare. Nunmehr sei aber nach dem Ende des UNO-Boykotts eine neue Lage eingetreten, die er mit dem Bundeskanzler besprechen werde ${ }^{17}$. Tatsächlich suchte Adenauer nun die Dinge voranzutreiben, indem er bereits am 18. Januar 1951 der Alliierten Hohen Kommission den „Wunsch" der Bundesregierung kundtat, in Spanien ein Generalkonsulat zu eröffnen ${ }^{18}$.

Schon beim Antrittsbesuch des spanischen Gesandten Antonio Aguirre im Bundeskanzleramt war im Oktober 1950 neben wirtschaftlichen Fragen vor allem der beiderseitige Wunsch nach einer deutschen Vertretung in Madrid erörtert worden ${ }^{19}$. Der Leiter der Länderabteilung in der „Dienststelle für Auswärtige Angelegenheiten“, Theodor Kordt, mußte damals gegenüber seinem Gesprächspartner, wie er selbst später vermerkte, mit einem „gewissen Gefühl von Ohnmacht“ einräumen, daß dafür jedoch die Zustimmung der Hohen Kommission erforderlich sei"0. Offenbar traute Kordt aber ausgerechnet dem international stigmatisierten Franco-Regime zu, die westlichen Alliierten positiv beeinflussen zu können. So warb er bei Aguirre vorsichtig um eine Fürsprache Spaniens gegenüber der AHK. Angesichts der ausweichenden Reaktion Aguirres kommentierte Kordt jedoch ernüchtert: „Wir haben also offenbar von seiten der spanischen Regierung mit einer Unterstützung in dieser Hinsicht kaum zu rechnen, vermutlich, weil Spanien sich zu einem derartigen Hinweis auf dem Petersberg noch nicht stark genug fühlt."

Auf dem Petersberg, dem Sitz der Hohen Kommissare, behandelte man die deutsche Anfrage zögerlich. Im April 1951 gab der Leiter der Politischen Abteilung im französischen Hohen Kommissariat, de Guiringaud, einen ersten Zwischenbescheid. Er ließ anklingen, daß es bei der Entscheidung „um eine schwierige politische Frage“ gehe, die noch Zeit benötige ${ }^{22}$. Ob es dabei um Probleme ging, die mit der jeweiligen Spanienpolitik der Alliierten zu tun hatten, oder ob primär das durch die Assoziation Hitler-Franco belastete deutsch-spanische Verhältnis gemeint war, muß offenbleiben. Insbesondere Frankreich bremste das Ansinnen der Bundesregierung. Ein Grund für diese hinhaltende

${ }^{16}$ Aktennotiz Kindt-Kiefer über die Besprechung mit Artajo am 14. 11. 1950, BA, B 136, Bd. 6282.

17 Ebenda.

18 Gesuch von Adenauer an Kirkpatrick, 18. 1.1951, PA/AA, Abt. 2, Bd. 158.

19 In der britischen und amerikanischen Besatzungszone gab es bereits seit 1948 in Hamburg und Frankfurt spanische Konsulate. Die im Dezember 1949 von der AHK genehmigte Gesandtschaft wurde im Mai 1951 in eine Botschaft umgewandelt. Siehe hierzu ausführlich Weber, Spanische Deutschlandpolitik 1945-1958, S. 85-95.

20 Vermerk über den Antrittsbesuch des spanischen Missionschefs Aguirre bei dem Leiter der Länderabteilung der Dienststelle für Auswärtige Angelegenheiten, Theodor Kordt, 20. 10. 1950, PA/AA, 210-03/70, Bd. 1.

${ }^{21}$ Ebenda.

22 Aufzeichnung Dittmann für Staatssekretär, 16. 4. 1951, PA/AA, 210-01/70, Bd. 1. 
Taktik könnte das zu Reparationszwecken herangezogene deutsche Vermögen in Spanien gewesen sein. Da Frankreich zu diesem Zeitpunkt über das alliierte Verbindungsbüro in Madrid die deutschen Interessen in Spanien vertrat, hätte eine Bonner Repräsentanz in der spanischen Hauptstadt unter Umständen störend gewirkt. Erst nachdem die Bundesrepublik einen zeitlichen Vorbehalt der Pariser Regierung akzeptiert hatte, wonach die deutsche Vertretung in Madrid nicht vor September oder Oktober 1951 errichtet werden sollte, fand das Zögern der Alliierten ein Ende. Die AHK genehmigte schließlich am 19. Juni 1951 ein deutsches Generalkonsulat in Spanien ${ }^{23}$.

Nach der zweiten Revision des Besatzungsstatuts vom 6. März 1951 hatte das neue Auswärtige Amt bereits am 15. März seine Arbeit unter Außenminister Adenauer offiziell aufgenommen. Da der Bundesrepublik nun auch der Aufbau diplomatischer Missionen erlaubt war, konnte die deutsche Vertretung in Madrid als Botschaft geplant werden. Obwohl der Errichtung von alliierter Seite nichts mehr entgegenstand, tauchten jetzt auf deutscher Seite Schwierigkeiten auf. Bei der Einrichtung des Auswärtigen Dienstes gab es von Beginn an ein Spannungsverhältnis zwischen dem Entnazifizierungsinteresse der Alliierten und dem Bedarf an ausgebildeten Fachkräften. So wurde der für die personelle Besetzung der Auslandsdienststellen zuständige Organisationsstab unter Wilhelm Haas von der AHK zunächst darauf verpflichtet, „daß niemand, der mit der Nazibewegung in Verbindung gestanden habe, als Konsulatsbeamter oder leitender Wirtschaftsvertreter ins Ausland geschickt würde“24. Um dieses Prinzip zu gewährleisten, sollten der Hohen Kommission vor den Ernennungen die Namen der für den höheren Dienst vorgesehenen Bewerber mitgeteilt werden ${ }^{25}$.

Im Bundeskanzleramt sorgte man sich indes um das Wohl der deutschen Diplomaten im Ausland. Wilhelm Haas befürchtete als Folge der NS-Diktatur politische Anfeindungen. Sein Verständnis für die besondere politisch-psychologische Konstellation zwischen Deutschen und Ausländern wenige Jahre nach Kriegsende blieb allerdings tradierten Feindbildern verhaftet. So warnte er vor der Gefahr, die den Angehörigen der Vertretungen drohe, ,insbesondere von seiten der Linksparteien des Gastlandes, der deutschen Emigration und des ortsansässigen Judentums, das im Wirtschaftsleben des Auslands überall eine groBe Rolle spielt“26. Unabhängig davon, von welchen Kriterien man sich bei der Wiedereinstellung der Diplomaten leiten ließ, entscheidend war die Frage, wie die Bundesrepublik von außen wahrgenommen wurde. Insbesondere für die Missionen in Frankreich, Großbritannien und den USA kam es darauf an, politisch unbelastete Persönlichkeiten zu finden, die das „neue“ Deutschland repräsentieren konnten. Daher lag es nahe, in diesen Fällen auf Berufsdiplomaten des alten Auswärtigen Amts in der Berliner „Wilhelmstraße“ zu verzichten. Seiteneinsteiger wie der Kunsthistoriker Wilhelm Hausenstein, der CDUPolitiker Hans Schlange-Schöningen und der FDP-Politiker Heinz Krekeler sollten als Leiter der wichtigsten Missionen in Paris, London und New York zu einem veränderten

23 Chronologie über den Stand der Errichtung einer Vertretung der Bundesrepublik, 4. 7. 1951, PA/AA, Ref. 110, Bd. 120.

${ }^{24}$ Aufzeichnung vom 24. 1. 1950, PA/AA, Abt. 2, Bd. 157.

25 Ebenda.

${ }^{26}$ Personalbesetzung der Auslandsvertretungen, 8. 12. 1949, PA/AA, Nl. Haas, Bd. 36. 
Deutschlandbild beitragen ${ }^{27}$. Diese diplomatischen Außenseiter, welche als Vertreter der jungen Bundesrepublik einen ersten „Goodwill“ im Gastland schaffen sollten, waren allerdings selbst in diesen Anfangsjahren nur die Ausnahme. Qualifizierte berufsfremde Kräfte waren selten, so daß in der Regel auf die früheren Beamten des alten Auswärtigen Amts zurückgegriffen wurde.

Angesichts des raschen Ausbaus der Auslandsdienststellen ${ }^{28}$ und des damit einhergehenden Personalbedarfs stieß die anti-nationalsozialistische Kontrollpolitik der drei Westmächte schon bald an ihre Grenzen. Auf deutsches Drängen - es wurde mit drohenden personellen Lücken in den Auslandsmissionen argumentiert - lockerte die AHK bereits im September 1950 ihre ursprünglichen Richtlinien, so daß nun auch frühere NSDAPMitglieder grundsätzlich als Diplomaten im Ausland tätig werden konnten ${ }^{29}$. Im Gegensatz zu den meisten Ländern rechnete der Organisationsstab unter Wilhelm Haas in Spanien nicht mit grundsätzlichen Vorbehalten gegenüber deutschen Diplomaten, dort seien „Angriffe gegen unsere Außenvertreter nicht zu befürchten“30. Für den Madrider Posten waren im Jahre 1951 mehrere Namen im Gespräch, unter ihnen der CSU- Bundestagsabgeordnete Fürst Fugger sowie Fürst Salm- Reifferscheidt ${ }^{31}$.

Als aussichtsreichster Kandidat wurde in Bonn der bereits dem alten Auswärtigen Amt angehörende Karrierediplomat Peter Pfeiffer genannt. Die Idee, den seit Ende 1949 für die Ausbildung des diplomatischen Nachwuchses verantwortlichen Beamten nach Madrid zu entsenden, stieß allerdings bei der französischen Regierung auf heftigen Widerspruch. Der stellvertretende Hohe Kommissar Frankreichs, Armand Bérard, erläuterte Ministerialdirektor Blankenhorn im August 1951 die Bedenken gegen eine Verwendung Pfeiffers im Ausland. Wegen seines Wirkens als deutscher Generalkonsul in Algier während des Zweiten Weltkriegs war Pfeiffer in Paris zur unliebsamen Person geworden. Ihm wurde vorgehalten, er habe einer Politik gedient, die die „Auflösung Frankreichs“ als Ziel verfolgt habe: „Eine solche Persönlichkeit sollte heute nicht deutsche Interessen auf einem Posten wie Madrid vertreten." Blankenhorn wiegelte ab und verwies darauf, daß eine Entschei-

27 Daß bei der Ernennung von Außenseitern für Adenauer auch häufig innenpolitische Erwägungen den Ausschlag gaben, veranschaulicht nicht nur das Beispiel des CDU-Politikers und früheren Reichsministers für Ernährung und Landwirtschaft in der Weimarer Republik Schlange-Schöningen. Die Ernennungen von Friedrich Holzapfel (Bern 1952) und Leo Wohleb (Lissabon 1952) zeigen, daß diplomatische Posten als ein Mittel angesehen wurden, um sich mißliebiger Parteifreunde zu entledigen. Den herausgehobenen Stellenwert innenpolitischer Überlegungen in der Personalpolitik Adenauers bestätigt rückblickend auch Haas, Lebenserinnerungen, S. 220 f. Vgl. Kroll, Deutschlands Weg nach Europa, S. 161-180. Zu den Erfahrungen eines Kunsthistorikers und Schriftstellers im diplomatischen Dienst siehe: Hausenstein, Pariser Erinnerungen; Lappenküper; Wilhelm Hausenstein - Adenauers erster Missionschef in Paris, S. 635-678; Reuss, Die Mission Hausenstein (1950-1955).

${ }^{28}$ Außer den Vertretungen in Frankreich, Großbritannien und den Vereinigten Staaten genehmigte die AHK im Jahre 1950 weitere deutsche Missionen in Australien, Belgien, Dänemark, Griechenland, Italien, Kanada, Luxemburg, den Nicderlanden, Norwegen, Schweden, der Schweiz, Südafrika und der Türkei, später in Brasilien, Chile, Ägypten, Indien, Indonesien, im Iran, Irland und Pakistan sowie in Kolumbien, Mexiko, Panama, Peru und Venezuela. Vgl. PA/AA, Abt. 2, Bd. 157.

29. Aufzeichnung Haas vom 13. 9. 1950, PA/AA, Abt. 2, Bd. 157.

30 Als unproblematische Länder wurden weiter die Türkei und mit Einschränkung auch Frankreich [sic!] genannt. Vgl. Aufzeichnung Haas, 8. 12. 1949, PA/AA, Nl. Haas, Bd. 36 (Anm. 26).

31 Diese Namen finden sich ohme weitere Erklärungen in den persönlichen Aufzeichnungen von Staatssekretär Hallstein, 25.4. 1951, BA, Nl. Hallstein, Bd. 121. Fürst Fugger wurde in der Öffentlichkeit zudem als Kandidat für den Botschafterposten beim Heiligen Stuhl genannt. 
dung noch nicht getroffen sei. Außerdem werde nicht "ernsthaft" an eine Kandidatur Peter Pfeiffers gedacht ${ }^{32}$.

Die unerwartete französische Intervention verzögerte die beabsichtigte Einrichtung der deutschen Botschaft. Da der Wunschkandidat nicht durchsetzbar schien, mußte das Auswärtige Amt notgedrungen nach Alternativen suchen. Bald zeigte sich, daß ein derartiges Personalproblem in der Frühzeit des Amtes nicht so rasch zu lösen war. Blankenhorn reagierte auf die von spanischer Seite gestellte Forderung nach der „dringenden“ Entsendung eines deutschen Botschafters ratlos, indem er klagte: „Wenn wir nur eine geeignete Persönlichkeit wüssten." ${ }^{33}$ Im deutsch-spanischen Verhältnis verschärfte sich angesichts des eingetretenen Stillstands die Tonlage. Am Rande der vorbereitenden Konferenz über die Bildung der Europäischen Verteidigungsgemeinschaft (EVG) Ende Oktober 1951 in Paris teilte der spanische Botschafter in Bonn, Aguirre, dem Mitglied der deutschen Delegation General a. D. Hans Speidel den „Unwillen“ und die „Besorgnis“ seiner Regierung mit, daß die Bundesrepublik noch keinen diplomatischen Vertreter nach Madrid entsandt habe. Daher erwäge die spanische Regierung zwar nicht seine Abberufung, aber seine baldige Zurückziehung ${ }^{34}$.

Auch von anderer Seite erfolgte Kritik an der als hinhaltend empfundenen Politik des Auswärtigen Amtes. Die für das Spanienbild in der westdeutschen Öffentlichkeit maßgeblichen deutschen Pressekorrespondenten in Spanien meldeten sich mit kritischen Berichten über die Untätigkeit der Bundesregierung zu Wort und versuchten damit, Druck auszuüben $^{35}$. Unzufriedenheit zeigte sich gleichfalls in Kreisen der bundesdeutschen Wirtschaft, die bereits seit Ende 1950 durch Eingaben an das Bundeskanzleramt bzw. das Bundeswirtschaftsministerium für eine deutsche Vertretung in Madrid geworben hatten. Es ging ihnen dabei um die generelle politische Unterstützung des Spanien-Geschäfts, den Ausbau der Handelsbeziehungen und das Problem des konfiszierten deutschen Vermögens. So wies der stellvertretende Präsident der Deutschen Handelskammer in Madrid, Victor Bucz, darauf hin, „daß die deutschen Interessen in weit größerem Maße gefördert werden könnten, wenn eine bundesstaatliche Vertretung in Madrid tätig wäre. Dies bezieht sich nicht nur auf die handelspolitischen Belange z. B. in der Durchführung des Handelsvertrages, sondern auch auf kulturpolitische, konsularische und sonstige Fragen" $" 36$. Am Spanienhandel interessierte Geschäftsleute wie Otto Wolff von Amerongen übermittelten der Bundesregierung die wachsende Empörung spanischer Regierungskreise. Als beispielhaft führte Wolff die Bemerkung von Außenhandelsminister Planell an: „Herr

32 Gesprächsnotiz Blankenhorn, 9. 8. 1951 (dem Bundeskanzler vorzulegen), BA, Nl. Blankenhorn, Bd. 7a. Peter Pfeiffer gehörte dem Auswärtigen Amt seit 1926 an (Mitglied der NSDAP seit 1940). Pfeiffer war zwischen 1941 und 1942 Generalkonsul in Algier. Nach der Besetzung Algiers durch alliierte Streitkräfte geriet er in Gefangenschaft, aus der er 1944 entlassen wurde.

${ }^{33}$ Vermerk Blankenhorn über ein Gespräch mit dem spanischen Botschafter Aguirre, 17.9. 1951, BA, Nl. Blankenhorn 351, Bd. 7a.

${ }^{34}$ Vermerk Speidel für Blank über ein Abendessen beim spanischen Militär-Attaché in Paris, 3. 11. 1951, BA-MA, Dienststelle Blank, BW 9, Bd. 3256.

3.5 Dabei folgten dic in Madrid akkreditierten Korrespondenten weitgehend der grundsätzlichen Linie der Franco-Regierung. Während bis Mai 1951 noch das Verständnis für die Zurückhaltung in Bonn überwog, wurde danach die Unzufriedenheit über das anhaltende Vakuum sehr vicl deutlicher artikuliert. Vgl. u. a. SZ vom 26. Mai und 27. Oktober 1951.

36 Bucz an Adenauer, 9. 11. 1951, PA/AA, Ref. 110, Bd. 12. 
Franco habe sich von Herrn Hitler nicht alles gefallen lassen und werde sich daher auch von der Bundesregierung nicht alles gefallen lassen." ${ }^{\text {"37 }}$

Das Auswärtige Amt beantwortete derartige Interventionen meist mit dem stereotypen Hinweis auf die Vielzahl der neu einzurichtenden Auslandsmissionen und der daraus folgenden Personalknappheit. Inzwischen suchte selbst Madrid dem Bonner Personaldilemma beizukommen. Namen wie Herbert Blankenhorn oder der DP-Politiker Hans-Joachim von Merkatz wurden u. a. gegenüber Bundeskanzler Adenauer - allerdings ohne erkennbare Resonanz - in die Diskussion gebracht ${ }^{38}$. Um den als unhaltbar empfundenen $\mathrm{Zu}-$ stand zu beenden, entschloß sich das für die iberische Halbinsel zuständige Länderreferat im Februar $1952 \mathrm{zu}$ einem dringlich formulierten Appell an die politische Führung des Auswärtigen Amtes. In einem gemeinsam mit anderen Abteilungen - Handel, Recht, Kultur - erstellten Papier wurde Staatssekretär Walter Hallstein gebeten, unverzüglich Entscheidungen im Hinblick auf die Wiedereinrichtung diplomatischer Vertretungen in Spanien und Portugal zu treffen ${ }^{39}$.

Das Memorandum bündelte die zentralen politischen, wirtschaftlichen und völkerrechtlichen Interessen der Bundesrepublik an Spanien. Danach hätten sich die politischen Rahmenbedingungen grundlegend verändert. Die internationale Position des FrancoRegimes sei durch das Ende des UNO-Boykotts „wesentlich“ gestärkt worden. Daher müsse das Fehlen der Bundesrepublik in Madrid um so mehr auffallen.

Eine fortdauernde Vakanz verschlechtere das zwischenstaatliche Verhältnis und führe außerdem dazu, daß in Spanien lebende Deutsche aus dem rechtsextremen Spektrum ungehindert zu einem Zerrbild Westdeutschlands beitragen: „Besonders in Spanien fehlt ein politisches Gegengewicht gegen das Auftreten der zahlreichen deutschen Nazis, die sich dort ständig oder vorübergehend aufhalten, von den offiziellen Kreisen auf Grund alter Beziehungen herzlich aufgenommen und vor allem über die Leistungen der Bundesregierung ungünstig und absprechend berichten werden." ${ }^{40}$ Offenbar war aber die Sorge um das durch die Nazi-Aktivitäten in Spanien gefährdete Image der Bundesrepublik im westlichen Ausland für die Beamten im Auswärtigen Amt weniger wichtig. Entscheidend war für sie offenbar der drohende Ansehensverlust der Bonner Regierung in Madrid, da sie dem Einfluß nationalsozialistischer Aktivisten vor Ort nichts entgegensetzen konnte ${ }^{41}$. Für

37 Aufzeichnung Böhm über ein Gespräch mit Otto Wolff von Amerongen, 28. 4. 1952 (dem Bundeskanzler vorzulegen), PA/AA, 210-02/70, Bd. 1.

38 Aguirre an Adenauer, 17. 1. 1952, PA/AA, Büro Staatssekretär, Bd. 272. Die von Botschafter Aguirre an Adenauer übermittelte Vorschlagsliste führte außerdem den Wirtschaftsexperten und späteren Leiter der Handelspolitischen Abteilung im Auswärtigen Amt, Freiherr von Maltzan, den CDU-Bundestagsabgeordneten Carl Spiecker und den konservativen Publizisten Josef Winschuh auf. Ob es sich hierbei um eine Eigeninitiative der Franco-Regierung oder eine von Bonn gewünschte Hilfestellung handelte, konnte nicht geklärt werden.

39 Etzdorf an Hallstein, Wiedereinrichtung diplomatischer Vertretungen in Spanien und Portugal, 18. 2. 1952, PA/AA, Abt. 2, Bd. 158. Schon im Mai 1951 hatte das Spanien-Referat Argumente für die Errichtung einer deutschen Botschaft zusammengetragen. Vgl. 31.5. 1951, PA/AA, 210-02/70, Bd. 1.

40 Ebenda.

41 Allerdings hat sich die Botschaft in Madrid später mit der NS-Vergangenheit der 1952 ca. 10000 Personen zählenden deutschen Kolonie in Spanien nicht beschäftigt. Charakteristisch war im Verhältnis zwischen Botschaft und Kolonie, daß man über dieses tabuisierte Thema schwieg. Auch von der Zentrale selbst wurde die Vertretung anscheinend nicht dazu angehalten, darüber zu berichten. Abgesehen von möglichen einzelnen Einlassungen im Gesamtkontext des bilateralen Verhältnisses war es dem früheren 
die Mahnung, den Propagandisten des „Dritten Reiches“ nicht allein das Feld der politischen Meinungsbildung über Westdeutschland zu überlassen, gab es Anfang 1952 zwar keinen unmittelbaren Anlaß. Jedoch waren die Präsenz und die Aktivitäten der dort lebenden Nazis seit dem Ende des Zweiten Weltkrieges ein in der deutschen und ausländischen Presse immer wieder diskutiertes Problem, für das stellvertretend die Namen Léon Degrelle und Otto Skorzeny standen ${ }^{42}$.

Der handelspolitische Teil der Aufzeichnung griff die Argumente der deutschen Wirtschaft auf und erinnerte an die „umfangreichen“ Industrialisierungspläne der spanischen Regierung. Daher sei es für die deutsche Exportwirtschaft von "größter Bedeutung“, sich in diese Vorhaben einzuschalten, wobei die errungene Marktposition deutscher Firmen in Spanien ohne eine amtliche Mission nicht zu halten wäre. Als ein weiterer Grund wurde das enteignete deutsche Vermögen genannt. Allein die bloße Anwesenheit eines deutschen Diplomaten könne auf die Haltung spanischer Stellen verändernd wirken. Die Länderabteilung spekulierte angesichts der weit fortgeschrittenen Liquidation des deutschen Vermögens über die Einflußmöglichkeiten eines „starken“ Botschafters. Dieser könne, „vorausgesetzt, daß er sich persönlich eine gute Stellung bei den maßgebenden Persönlichkeiten an Ort und Stelle zu verschaffen weiß, die Aussicht bieten, wenigstens Teile der noch nicht liquidierten Werte vor der Verschleuderung zu bewahren "43. Insgesamt kam man zu dem Schluß, daß es nicht mehr tragbar sei, die Errichtung einer Botschaft in Madrid weiter hinauszuschieben.

Trotz dieses Anstoßes der Fachressorts dauerte es noch einige Zeit, bis Staatssekretär Hallstein und Bundeskanzler Adenauer der Iberischen Halbinsel ihre Aufmerksamkeit schenkten. In einer Gesamtschau westdeutscher Außenpolitik zählte sie zu den nachgeordneten Feldern. Denn zwischen 1951 und 1952 ging es in Gesprächen und Verhandlungen mit den westlichen Alliierten um den künftigen Standort der Bundesrepublik im internationalen System. Da Hallstein mit den Verhandlungen über den Deutschland- und EVG-Vertrag überlastet war, blieb im Auswärtigen Amt vieles liegen, was der Kanzler und Außenminister, der letztlich die Personalentscheidungen auf Botschafterebene traf, in einem Hintergrundgespräch mit Journalisten Ende Mai 1952 auch selbstkritisch einräum-

Botschaftsrat Rupprecht von Keller nicht mehr erinnerlich, daß die Botschaft zwischen 1954 und 1956 über die Problematik der in Spanien verbliebenen Nazis auch nur cinen zusammenfassenden Gesamtbericht an das Auswärtige Amt gefertigt hätte. Vgl. die schriftliche Auskunft von Kellers an den Verfasser, 2. 1. 1991. Symptomatisch für dieses beredte Schweigen war die Haltung des ersten deutschen Botschafters Prinz Adalbert von Bayern, der sich während seiner Amtsführung vorgenommen hatte, sich nicht um die politische Einstellung seiner Landsleute zu kümmern. Vgl. Adalbert von Bayern, Erinnerungen, S. 557.

42 Der in Abwesenheit zum Tode verurteilte belgische NS-Kollaborateur Degrelle hatte sich nach dem Ende des Zweiten Weltkriegs ebenso wie der sogenannte Mussolini-Befreier Skorzeny in die Obhut des franquistischen Spanien begeben. Vgl. hierzu die Diskussion zwischen Spanien und den westlichen Alliierten um die Auslieferung von Nationalsozialisten in den Jahren 1945-1948 bei Weber, Spanische Deutschlandpolitik 1945-1958, S. 47-60, die auf der Grundlage von spanischem Quellenmaterial diese bislang in der Literatur vernachlässigte Grauzone auszuleuchten sucht. Außerdem Collado Seidel, Zufluchtsstätte für Nationalsozialisten?, S. 131-157, und ders.: Angst vor dem „Vierten Reich“, S. $25-147$. Ebenso wie Petra-Maria Weber verweist Collado Seidel auf die vielfältige Protektion, die diese Personen durch das Franco-Regime erfahren haben.

${ }^{43}$ Wiedereinrichtung diplomatischer Vertretungen in Spanien und Portugal, 18. 2. 1952, PA/AA, Abt. 2, Bd. 158 . 
te $^{44}$. Angesprochen auf den zukünftigen Botschafter für Spanien, eine, so Adenauer, sehr eilige Sache, verwies er darauf, wie schwierig die Suche nach einer geeigneten Persönlichkeit für Madrid sei, und beschrieb die notwendigen Voraussetzungen des Kandidaten: „Natürlich muß er gut katholisch sein, zweitens darf er nicht zu weit links stehen, ferner darf er nicht zu weit rechts stehen, sonst schreien die Deutschen; also muß er mit großer Sorgfalt ausgesucht werden." 45 Die Personalabteilung des Auswärtigen Amtes schien in diesen Tagen bereits die passende Persönlichkeit gefunden zu haben. Ihr Favorit war der katholische Berufsdiplomat Peter Pfeiffer ${ }^{46}$, der wenige Monate zuvor schon einmal als Botschafter für Madrid gehandelt worden war. Damals war seine Entsendung nach Spanien am Veto Frankreichs gescheitert. Es bleibt offen, ob die Personalabteilung die französischen Bedenken nun bewußt ignorieren wollte. In jedem Fall setzte sie sich aber mit ihrem Votum über ein schwebendes Untersuchungsverfahren hinweg.

$\mathrm{Zu}$ diesem Zeitpunkt war nämlich die Personalpolitik des Auswärtigen Amtes insgesamt Gegenstand öffentlicher Diskussionen im In- und Ausland. Ausgelöst durch eine Artikelserie der „Frankfurter Rundschau“ vom September 1951 wurde die bisherige Personalauswahl beim Aufbau des Auswärtigen Dienstes scharf kritisiert. Im Kern ging es dabei um den Vorwurf einer personellen Restauration des alten Auswärtigen Amts aus der Berliner Wilhelmstraße durch die bevorzugte Wiederbeschäftigung von ehemaligen Karrierediplomaten mit nationalsozialistischer Vergangenheit ${ }^{47}$. Ein schließlich auf Antrag der SPD-Fraktion eingesetzter Untersuchungsausschuß des Bundestages beschäftigte sich seit Oktober 1951 mit der NS-Vergangenheit der von der „Frankfurter Rundschau“ inkriminierten 21 Diplomaten. Davon war namentlich auch Peter Pfeiffer betroffen, gegen den Vorwürfe erhoben wurden, die seine seit 1940 bestehende Mitgliedschaft in der NSDAP und ein von ihm mit „Sieg Heil Führer und Deutschland“ unterzeichnetes Diensttelegramm aus dem Jahre 1942 zum Inhalt hatten. Der Untersuchungsausschuß kam im Juni 1952 zu dem Schluß, daß Pfeiffer zwar grundsätzlich für den Auswärtigen Dienst geeignet sei, empfahl aber einschränkend, für die Dauer eines Jahres von einer Auslandsverwendung abzusehen ${ }^{48}$.

${ }^{44}$ Nach Unterzeichnung der Verträge am 26. bzw. am 27. Mai 1952 wies Adenauer auf cleren Priorität hin: „Ich habe leider seit Wochen mich mit sozusagen nichts anderem beschäftigen können als mit diesem Vertragswerk. Dahinter mußte alles andere zurückstehen." Adenauer, Teegespräche 1950-1954, S. 286.

${ }^{45}$ Ebenda.

46 Der Vorschlag der Personalabteilung erfolgte am 5. Mai 1952 ohne weitere Angabe von Gründen, so daß die Kriterien der Auswahl und die Frage der Affinität Peter Pfeiffers zu Spanien unbeantwortet bleiben müssen. Personalakte Peter Pfeiffer laut mündlicher Auskunft des Politischen Archivs im Auswärtigen Amt. 47 Vgl. dazu Döscher; Verschworene Gesellschaft. Sein wohl insgesamt zutreffendes Fazit: „Bundeskanzler Adenaucr hat sich der traditionellen Funktionseliten aus der Berliner ,Wilhelmstraße' bedient, um nach 1949 einen baldmöglich funktionsfähigen Auswärtigen Dienst für die Bundesrcpublik Deutschland aufzubauen. Dabei hat er die Ansprüche der Berufsdiplomaten auf Wiederverwendung im angestammten Beruf weitgehend berücksichtigt, zugleich aber hat er sie sich in Kenntnis ihrer nationalsozialistischen Vergangenheit zur Loyalität verpflichtet. Die ,schwankenden Gestalten' hat Adenauer nicht nur hingenommen, weil er auf deren Professionalität angewiesen war, sondern auch integriert, um sich eine potentielle Opposition gegen seine Außenpolitik zu ersparen", vgl. S. 312. Bei Döscher ist die zwischen dem 1. und 6. September 1951 veröffentlichte fünfteilige Folge der FR über Mißstände im Auswärtigen Amt vollständig nachgedruckt, vgl. S. 156-165.

48 Vgl. Bericht des Untersuchungsauschusses 47 vom 18. Juni 1952; abgedruckt bei Haas, Beitrag zur Geschichte der Entstehung des Auswärtigen Dienstes der Bundesrepublik, S. 282-339. Das Votum zu Peter Pfeiffer wird im einzelnen bcgründet S. 325-328. Seiner Karriere war dies nicht abträglich. Fr wurde noch im selben Jahr zum Leiter der Personalabteilung im Auswärtigen Amt ernannt. Mit Pfeiffer gab es insge- 
Nun mußten neue Überlegungen angestellt werden. Da die Zeit drängte, war das Auswärtige Amt für jedwede Anregung empfänglich, die einen Ausweg aus dem Personaldilemma weisen konnte. Zum ernsthaftesten Anwärter für den Madrider Posten wurde jetzt unverhofft Prinz Adalbert von Bayern, der wohl von den beiden CSU-Politikern Schäffer und Strauß gegenüber Adenauer ins Spiel gebracht worden war ${ }^{49}$. Seine engen verwandtschaftlichen Beziehungen zum spanischen Königshaus, die Kenntnis spanischer Kultur, Sprache und Geschichte ließen den Historiker und Schriftsteller ${ }^{50}$ geeignet erscheinen, die Beziehungen zu diesem Lande als erster Botschafter nach dem Zweiten Weltkrieg wieder anzuknüpfen.

Nachdem die spanische Regierung Ende Juni 1952 trotz gewisser Vorbehalte - sie hätte gern einen Wirtschaftsfachmann in Madrid gesehen - ihr Einverständnis mit Prinz Adalbert signalisiert hatte, sollte Blankenhorn im Auftrage des Kanzlers sondieren, ob der bereits im Pensionsalter stehende Wittelsbacher bereit sei, die Aufgabe zu übernehmen. Abgesehen von der vornehmlich repräsentativen Funktion als Vorsitzender der DeutschSpanischen Gesellschaft, die seit 1950 in München bestand, führte Prinz Adalbert ein eher zurückgezogenes Leben als Privatgelehrter und Autor. Vermutlich hat das Engagement für die Deutsch-Spanische Gesellschaft in Bonn die Idee befördert, ihn für den Botschafterposten vorzusehen. Wie weit er dem Zeitgeschehen und den innenpolitischen Verhältnissen der Bundesrepublik entrückt war, zeigt seine verwunderte Reaktion auf den angekündigten Besuch von Blankenhorn: „Bis dahin wußte ich von der Bundesregierung nur, daß Heuss Präsident und Adenauer Kanzler waren." ${ }^{51}$

samt sieben Personen, bei denen man eine eingeschränkte Verwendung empfahl. In vier Fällen wurde die Eignung für den Auswärtigen Dienst der Bundesrepublik prinzipiell verneint. Ein wirkliches personalpolitisches Revirement blieb aus. Die Grenzen eines personellen Neubeginns wurden deutlich, als Bundeskanzler Adenauer in der anschließenden parlamentarischen Debatte im Oktober 1952 eingestand, daß ca. $66 \%$ der leitenden Beamten des Auswärtigen Amtes ehemals Mitglieder der NSDAP gewesen seien. Er war zwar nicht glücklich über die Einstellungspraxis, nahm sie aber um der Effizienz. willen hin. Döscher, Verschivorene Gesellschaft, S. 455. Ferner: Schwarz, Adenauer. Der Aufstieg, 1876-1952, S. 664; Köhler, Adenauer - Eine politische Biographie, S. 731-735. Auch die drei Besatzungsmächte schauten den Vorgängen im Auswärtigen Amt offenbar „eher unbeteiligt - bisweilen sogar verständnislos - zu“. Vgl. Brochhagen, Nach Nürnberg, S. 195. Klaus-Dietmar Henke kommt allgemein zu dem triftigen Schluß, daß trotz der hohen moralischen und politischen Kosten die Integration der „Ehemaligen“ angesichts „einer durch und durch nationalsozialistisch kontaminierten Gesellschaft wie der deutschen" nicht anders vorstellbar war „als ein mit Skandalen gepflasterter Prozeß der Amalgamierung“. Henke, Die Trennung vom Nationalsozialismus - Selbstzerstörung, politische Säuberung, „Entnazifizierung“, Strafverfolgung, S. 65.

${ }^{49}$ Einer Anckdote zufolge soll Adenauer im Gespräch mit Schäffer und Strauß die vielfältigen Verbindungen von Prinz Adalbert nach Spanien mit den Worten kommentiert haben: „Dann wäre er ja eigentlich ein prächtiger spanischer Botschafter für Bonn"; Gespräch des Verfassers mit Max Schulze-Vorberg am 11. 4. 1989 in Bonn. Schulze-Vorberg war zwischen 1948-1965 Korrespondent des Bayerischen Rundfunks in der Bundeshauptstadt.

50 Adalberts Mutter, Maria de la Paz, war dic Tochter der Königin Isabella II. von Spanien. Sein ältester Bruder, Ferdinand von Bayern und Infant von Spanien, lebte in Madrid. Der 1886 geborene Prinz Adalbert wurde, wie in der Familie üblich, zunächst bayerischer Offizier. Nach dem 1. Weltkrieg studierte er Geschichte und Kunstgeschichte. Seine Dissertation erweiterte er 1927 zu einer Monographic über das "Ende der Habsburger in Spanien“.

51 Adalbert von Bayern, Erinnerungen, S. 535. Die aus dem Nachlaß veröffentlichten Memoiren Prinz Adalberts erlauben cinen weitgehend unverstellten Blick auf sein Denken, da das (nur) für die Familie bestimmte Manuskript ohne Bearbeitung des Verlags veröffentlicht wurde. Vgl. Schriftwechsel zwischen dem Verlag Langen Müller und Botschafter a. D. Rupprecht von Keller vom 19. 3. 1991, von dem Herr von Kcller dem Verfasser freundlicherweisc eine Kopie zur Verfügung stellte. 
Ebenso erstaunt zeigte sich Prinz Adalbert über die ihm angetragene Position eines Botschafters der Bundesrepublik. Gegenüber Blankenhorn verwies er am 1.Juli darauf, daß er für eine derartige Tätigkeit nur wenige Voraussetzungen mitbringe und von Diplomatie nichts verstehe. Des weiteren führte der 66jährige Prinz sein fortgeschrittenes Alter abwehrend ins Feld, was Blankenhorn aber mit dem Hinweis auf den zehn Jahre älteren Regierungschef Adenauer nicht gelten lassen mochte.

Prinz Adalbert wollte seine endgültige Entscheidung in jedem Fall von der Zustimmung des Chefs des Hauses Wittelsbach, Kronprinz Rupprecht von Bayern, abhängig machen, da er ohne dessen Genehmigung ein solches Amt nicht übernehmen durfte ${ }^{52}$. Dieser kommentierte die Neuigkeit mit der sarkastischen Bemerkung, „die Bundesrepublik müsse wenig Auswahl an Botschaftern haben, wenn sie auf einen Prinzen verfalle " 53 . Nach seiner ersten Überraschung fühlte sich Prinz Adalbert augenscheinlich doch sehr umworben und war nach kurzem Zögern bereit, Adenauers Angebot anzunehmen. Kronprinz Rupprecht ging es dann nur noch darum, der Bundesregierung mitzuteilen, daß diese Genehmigung ,in keiner Weise eine Anerkennung der republikanischen Staatsform in Bayern "54 beinhalte. Nachdem dieser Vorbehalt zu Protokoll gegeben war, erfolgte schließlich das Agrément der spanischen Regierung für Prinz Adalbert von Bayern am 16. Juli 1952.

Es stellt sich die Frage, was Prinz Adalbert bewogen haben könnte, diese in seiner Lebensplanung nicht vorgesehene Position zu übernehmen. Er wußte nicht, daß er ein Verlegenheitskandidat war, und hatte wohl den Eindruck gewonnen, daß Bonn gerade ihn aufgrund seiner Herkunft und Bildung für das Amt wie niemanden sonst für berufen hielt. Das mußte ihm schmeicheln. In der Wahl seiner Person sah er gleichsam eine natürliche Lösung der Frage. Wer, wenn nicht er, hätte aufgrund seiner Vita in der Lage sein können, die seit 1945 unterbrochenen diplomatischen Verbindungen zwischen Deutschland und Spanien wieder in Gang zu bringen. Prinz Adalbert stand für eine Kontinuität der Beziehungen, die im Dynastischen wurzelte und von den gesellschaftspolitischen Umbrüchen des Jahrhunderts unberührt geblieben war. Er begriff sich selbst als Wegbereiter für andere, welche nachfolgen sollten, wenn das „Feld bestellt“ sei. Hinzu kam für ihn der in der Welt protokollarischer Feinheiten aufgewachsen war - ein gewisser Reiz am Absurden seiner mit der Botschafterrolle verbundenen gesellschaftlichen Position. In seinen Erinnerungen betonte er denn auch, „daß ich nämlich als Sohn der Infantin Paz eine Republik bei einer Monarchie vertrat, bei Franco akkreditiert, obwohl ich direkter Onkel des spanischen Kronprätendenten Don Juan bin" ${ }^{" 55}$.

So nimmt es nicht wunder, daß Prinz Adalbert sich in seinem „neuen Beruf“ primär als Botschafter sui generis verstand. Das demonstrierte er schon dadurch, daß er im Bundeskanzleramt vorstellig wurde, um für sich die Wiedereinführung einer Immediatbericht-

52 Vgl. zum Gespräch Blankenhorn mit Prinz Adalbert von Bayern: BA, Nl. Blankenhorn 351, Bd. 13, 1. 7. 1952. Siehe außerdem: Adalbert von Bayern, Erinncrungen, S. 535-537.

53 Ebenda, S. 537.

54 Kronprinz. Rupprecht von Bayern an Adenauer, 8. 7. 1952, BA, Nl. Blankenhorn 351, Bd. 13. Vgl. dazu auch: Der Spiegel, 16. 7. 1952 („Das Königshaus zuerst“).

55 Adalbert von Bayern, Erinnerungen, S. 536. Spanien war durch das Gesetz über die Nachfolge in der Staatsführung vom 26. 7. 1947 zur Monarchie erklärt worden. Das Königreich Spanien blieb jedoch bis zu Francos Tod im Jahre 1975 ohne Monarchen. 
erstattung an den Regierungschef $z u$ erreichen ${ }^{56}$. Ähnlich wie sein Freund Wilhelm Hausenstein, der seit 1950 die junge Bundesrepublik in Frankreich vertrat, sah sich Prinz Adalbert als Repräsentant des konservativen Kultur- und Geisteslebens. Von dem Staat, den er zukünftig in Spanien vertreten sollte, wußte er nicht viel. Erst bei der Vorbereitung auf seinen Madrider Posten lernte der gebildete, aber politikferne Aristokrat die Zahl und die Namen der Bundesländer kennen ${ }^{57}$. Auch Spanien, sein „zweites Heimatland“, war ihm seit der Zweiten Republik zu Beginn der dreißiger Jahre mehr und mehr fremd geworden. Selbst den Bürgerkrieg zwischen 1936 und 1939 nahm Prinz Adalbert nur gleichsam am Rande wahr ${ }^{58}$, so daß er im nachhinein vor allem die Arbeit in der Deutsch-Spanischen Gesellschaft als Vorbereitung seines Botschafteramts empfand, hatte er sich doch dadurch mit dem Spanien nach 1931 und dem ihm weitgehend unbekannten Regime Francos vertraut machen können ${ }^{59}$. Aus all dem verdichtet sich der Eindruck, daß Prinz Adalbert in einer schwierigen personalpolitischen Konstellation, die rasches Handeln erforderte, eher zufällig zum Botschafter wurde, dabei aber sozusagen als ideale Verlegenheitslösung galt. Es wäre verfehlt, die Entscheidung für den Wittelsbacher primär als Ausdruck einer bewußt zurückhaltenden Spanienpolitik der Bundesregierung zu begreifen.

Welche Erwartungen verband nun das Auswärtige Amt mit der Entsendung des ersten Nachkriegsbotschafters in das franquistische Spanien? Worin sah man die Schwerpunkte westdeutscher Spanienpolitik und an welche Traditionen knüpfte sie an?

Die untergeordnete Bedeutung, die dem Verhältnis zu Franco-Spanien in der Gesamtperspektive bundesdeutscher Außenpolitik vom Auswärtigen Amt zu diesem Zeitpunkt eingeräumt wurde, kommt auch in der Instruktion für den neuen deutschen Botschafter in Madrid zum Ausdruck. In einem nur sehr allgemein gehaltenen Schreiben vom Oktober 1952 an Prinz Adalbert formulierte Staatssekretär Hallstein die generelle Weisung: „Als Botschafter der deutschen Bundesrepublik in Spanien bitte ich Sie, Ihre Aufgabe vornehmlich darin zu erblicken, die Beziehungen der Bundesregierung zur Spanischen Regierung und zu den maßgebenden Kreisen in Spanien so freundschaftlich als möglich zu gestalten und für die deutschen Interessen nach besten Kräften einzutreten. "60 Im bilateralen Rahmen galt das besondere Augenmerk dem Problem des in Spanien enteigneten deutschen Vermögens, über das Adalbert „alsbald“ nach seinem Eintreffen Verhandlun-

\footnotetext{
56 Der ehemalige Diplomat Lothar Lahn berichtet in seinen Memoiren jedenfalls über einen derartigen Vorstoß Prinz Adalberts bei Staatssekretär Globke im Bundeskanzleramt. Globke lchnte ab und empfahl dem neuen Botschafter statt dessen: „Schauen Sie Durchlaucht, wenn Sie erreichen wollen, daß Ihre, Spanien betreffenden Ausführungen auch zur Kenntnis des ,Alten' gelangen, gibt es nur einen sicheren Weg: Aus Madrid berichtet regelmäßig und gut der dortige Korrespondent der Neuen Zürcher Zeitung, Silvius Schädler. Sagen Sie ihm, was er schreiben soll, - und wenn er's tut, seien Sie sicher, daß Adenauer das liest. Er zieht die Neue Zürcher jedem diplomatischen Botschafter-Bericht vor." Lahn, Jedermann auf der Weltbühne, S. 114.

57 Vgl. Adalbert von Bayern, Erinnerungen, S. 538.

${ }_{58}$ Jedenfalls fanden die Ereignisse in Spanien offenbar nur wenig Aufmerksamkeit bei Prinz Adalbert. Zwar spricht er in seinen Memoiren vom „Aufstand Francos“, aber ein tiefergehendes Interesse an den dortigen politischen Vorgängen ist nicht zu erkennen. Gan\% im Gegensatz zu seiner Mutter: „Sobald Francos Sender ,Radio Verdad“ eingerichtet war, lauschte ihm meine Mutter täglich beim Abendessen bis zum Sieg Francos." Ebenda, S. 377.

59 Ebenda, S. 531.

Gallstein an Adalbert, 10.10. 1952 (Einleitendes Schreiben zur Instruktion für Prinz Adalbert von Bayern), PA/AA, 210-02/70, Bd. 1.
} 
gen aufnehmen sollte ${ }^{61}$. Im übrigen hatte die Botschaft wie andernorts auch, die Aufgabe, die innenpolitische und wirtschaftliche Entwicklung in Spanien sowie das Verhältnis Spaniens zu anderen Staaten zu beobachten. Insgesamt kam die mit 110 Seiten voluminös ausgefallene Instruktion über weite Strecken aber eher einer Einführung in die spanische Landeskunde gleich.

Die Perzeption der zukünftigen politischen Beziehungen war einerseits geprägt von $\mathrm{Zu}$ rückhaltung und Unsicherheit über die eigene außenpolitische Rolle in der europäischen Politik. Andererseits war dem Auswärtigen Amt aber daran gelegen, gegenüber Madrid die wachsende Bedeutung herauszustellen, die mit der ,allmählichen Rückkehr Deutschlands" auf die europäische Bühne einherging. Deshalb verwies man darauf, daß der für Spaniens Außenpolitik noch unbekannte Faktor Bundesrepublik, „insbesondere im Hinblick auf den gemeinsamen französischen Nachbarn und auf die Fragen der europäischen Verteidigung in dem außenpolitischen System Spaniens eine wichtige Rolle spielen " ${ }^{\prime 2} 2$ werde. Dem nur kurzen Blick in die Zukunft folgte ein etwas längerer Blick zurück in die Geschichte der seit langen Jahren „freundschaftlichen Beziehungen“, an die man unverändert anknüpfen wollte.

In einem historischen Rückblick wurde, ausgehend von der Neutralität Spaniens im Ersten Weltkrieg, der Vorrat an politischen Gemeinsamkeiten bemüht. Da das nach dem Ende des internationalen Boykotts inzwischen wieder gefestigte Franco-Regime als zukünftiger Partner gesehen wurde, hielt es das Auswärtige Amt für zweckmäßig, die deutsche Waffenhilfe für Franco im Spanischen Bürgerkrieg herauszustreichen. Daß dies jedoch nicht allein auf taktischem Kalkül beruhte, sondern Ausdruck von Denkmustern war, welche die NS-Zeit überdauert hatten, zeigt die Wortwahl und undifferenzierte Interpretation der deutschen Intervention: „Bei Beginn des Spanischen Bürgerkrieges im Jahre 1936 waren es deutsche Transportflugzeuge, die Francos afrikanische Truppen auf das Festland gebracht und damit nicht weniger zum Gelingen der nationalen Erhebung beigetragen haben als die aus deutschen Freiwilligen zusammengestellte Legion Condor. Diese Waffenhilfe ist im spanischen Volke nicht vergessen. "63 Trotz der politischen Zäsur des Jahres 1945 war in der Gedankenwelt des Auswärtigen Amtes manches beim alten geblieben.

Vor dem Hintergrund des sich verschärfenden Ost-West-Gegensatzes sah man in der Franco-Diktatur einen bereits im Zweiten Weltkrieg bewährten Verbündeten im Kampf gegen den „Bolschewismus“. Während die internationale Staatengemeinschaft noch wenige Jahre zuvor das „faschistische Relikt“ Spanien infolge seiner ideologischen Nähe zum "Dritten Reich“ und der ambivalenten Haltung in der Frage des Kriegseintritts geächtet hatte, suchte die deutsche Diplomatie vor allem an diese Bindungen anzuknüpfen. Nach Auffassung des Auswärtigen Amtes wurde das beiderseitige Verhältnis auch in Spanien nach wie vor im Lichte der sogenannten Waffenbrüderschaft gesehen, die für die leitenden spanischen Politiker und Militärs immer noch ein Vertrauenskapital bilde, von dem Deutschland zehren könnte. Es klingt sogar Bedauern über die damalige spanische Haltung an, wenn es hieß: „Die im Jahre 1940 mit der Spanischen Regierung geführten Ver-

\footnotetext{
61 Vgl. ebenda. Daß diese Thematik als besonders wichtig angesehen wurde, zeigen auch die mit 19 Seiten recht umfangreich ausgefallenen Ausführungen innerhalb der Instruktion.

62 Ebenda, S. 20.

${ }^{63}$ Ebenda, S. 20-20a.
} 
handlungen wegen einer aktiven Beteiligung am Kriege auf Seiten der Achsenmächte scheiterten teils an den großen Forderungen, die die Spanische Regierung für ihre Beteiligung stellte, teils an der zögernden Haltung Francos. Immerhin stellte er die ,Blaue Division' unter der Führung des jetzigen Kriegsministers, General Muñoz Grandes, zur Verfügung, die im Osten Schulter an Schulter mit den deutschen Divisionen kämpfte und erst gegen Kriegsende unter dem Druck der Alliierten wieder zurückgezogen wurde. "64

Insgesamt bestimmte vor allem das alte und neue Feindbild Sowjetunion den Blick auf die durch ihren Antikommunismus legitimierte Franco-Diktatur. Eine Reflexion über das von der nationalsozialistischen Propaganda ideologisch eingefärbte Spanienbild der dreiBiger und vierziger Jahre ${ }^{65}$ erfolgte nicht. Der Neubeginn in den deutsch-spanischen Nachkriegsbeziehungen fand unter alten Vorzeichen statt.

Der mit diesem historischen Kapital versehene Prinz Adalbert reiste Ende Oktober nach Madrid, wo bereits am 8. Oktober die Kanzlei der Botschaft eröffnet worden war. Dem diplomatischen Novizen zur Seite gestellt war als Botschaftsrat Oskar Schlitter. Als Berufsdiplomat sollte er den Botschafter politisch beraten und die innere Organisation der deutschen Vertretung aufbauen.

Bei seinem Antrittsbesuch fühlte sich Prinz Adalbert vom spanischen Staatschef, General Franco, herzlich aufgenommen ${ }^{66}$. In dem von nostalgischer Rückschau dominierten Gespräch erinnerte Franco daran, daß Deutschland ihm zu Beginn des Bürgerkrieges mit der Lieferung von Flugzeugen das Übersetzen von Marokko nach Spanien überhaupt erst ermöglicht habe. Deshalb zeigte er sich erfreut, nun wieder einen offiziellen deutschen Vertreter begrüßen zu können, zumal ihn der „unglaublich“ schnelle Wiederaufstieg der Bundesrepublik beeindrucke. Das Gespräch mit Franco bestätigte Prinz Adalbert nur das vom Auswärtigen Amt gezeichnete Bild der deutsch-spanischen Beziehungen und unterstrich die Bedeutung Deutschlands im Welt- und Geschichtsbild des Diktators.

Aber der neue Botschafter wurde auch mit den Schattenseiten konfrontiert, die den Vertreter eines besiegten Landes einholten. So kam dem an Repräsentanz gewohnten Aristokraten Prinz Adalbert von Bayern, der sich selbst als Überbleibsel einer „versunkenen Epoche" ${ }^{67}$ empfand, die Unterbringung der Botschaft in einfachen und beengten Räumlichkeiten als eine Zumutung vor. Angesichts der äußeren Umstände räsonierte er larmoyant über den Machtverlust Deutschlands, welches von seinem politischen Gewicht her momentan mit einer „Bananenrepublik“ gleichzusetzen sei: „Ich fand mein Fräulein Angermair in einem fensterlosen Raum mit zwei anderen Schreibkräften vor. Deutlicher hätte ich bei einem Vergleich mit den großen Botschaften nicht darauf gestoßen werden können, daß unser aus bedingungsloser Kapitulation hervorgegangenes halbes Deutschland seinen früheren Rang in der Welt nicht mehr einnahm. Wir konnten uns bestenfalls mit Honduras vergleichen, das im gleichen Haus über uns hauste. "68

\footnotetext{
${ }^{64}$ Ebenda, S. 20a.

65 Vgl. Bernecker, Das nationalsozialistische Spanienbild und Hitlers Eingreifen in den Spanischen Bürgerkrieg, S. 25-54.

${ }_{66}$ Bericht von Prinz Adalbert von Bayern an das Auswärtige Amt (Bundeskanzler Adenauer vorzulegen), 11. 11. 1952, PA/AA, 210-02/70, Bd. 1.

${ }^{67}$ Adalbert von Bayern, Erinnerungen, S. 565.

${ }^{68}$ Ebenda, S. 551.
} 


\section{Die Enteignung deutschen Vermögens als Hypothek der Nachkriegs- beziehungen}

Das für die Bonner Regierung zunächst drängendste Problem in ihrem Verhältnis zum Franco-Regime war die Frage des enteigneten deutschen Vermögens in Spanien. Auf der Potsdamer Konferenz hatten Großbritannien, die UdSSR und die USA im August 1945 beschlossen, die deutschen Vermögenswerte im Ausland für Reparationszwecke zu verwenden ${ }^{69}$. Ein weiteres Motiv mag dabei auch der Strafgedanke gewesen sein. Die Enteignung sollte nicht nur das Reichseigentum sondern auch das Privateigentum wie auch das geistige Eigentum an Patenten, Marken- oder Warenzeichen betreffen. Anders als nach dem Ersten Weltkrieg wurde im Pariser Reparationsabkommen vom 14.Januar 1946 auch der deutsche Auslandsbesitz in den im Zweiten Weltkrieg neutral gebliebenen Staaten in den Reparationsanspruch der westlichen Siegermächte einbezogen. Daher begannen die Alliierten alsbald Verhandlungen mit der Schweiz, Schweden, Portugal ${ }^{70}$ und Spanien $^{71}$, die im Fall Spanien am 10. Mai 1948 zum Abschluß des Madrider Abkommens führten.

Der singuläre Charakter dieser Übereinkunft lag darin, daß Spanien den Alliierten Kontrollrat - vertreten von den drei Westmächten - als rechtmäßige Regierung Deutschlands anerkannt hatte. Um Spanien gegen zukünftige deutsche Entschädigungsansprüche abzusichern, garantierte Artikel 15, daß die Alliierten jede künftige deutsche Regierung veranlassen würden, die getroffenen Vereinbarungen zu bestätigen. Ferner sah das Madrider Abkommen vor, daß Spanien am Liquidationserlös ein Anteil von 20 bis 30 Prozent als Ausgleich seiner Forderungen an Deutschland ${ }^{72}$ überlassen wurde, während der restliche Betrag der „Interalliierten Reparationsagentur“ (IARA) zur Verfügung gestellt werden sollte. Damit fand eine Entwicklung ihren vorläufigen Abschluß, die sich bereits in den Jahren zuvor abgezeichnet hatte. In einer Zeit, in der das Franco-Regime als Überbleibsel der faschistischen Ära um seine Zukunft fürchten mußte, lag es nahe, sich den Grundsätzen der alliierten Feindvermögenspolitik umgehend anzuschließen. Bereits seit dem 5. Mai

69 Im Potsdamer Abkommen war die Verteilung der Reparationen zwischen den Westmächten einerseits und der Sowjetunion sowie Polen andererseits festgelegt worden. Demnach fielen die deutschen Vermögenswerte in Bulgarien, Finnland, Rumänien, Ungarn und dem östlichen Teil Österreichs der Sowjetunion zu, während den westlichen Alliierten die deutschen Vermögen in allen übrigen Staaten überlassen wurden; vgl. dazu Fisch, Reparationen nach dem Zweiten Weltkrieg, S. 69-80.

${ }^{70}$ Einen Überblick über die jeweilige Enteignungsregelung in den neutralen Ländern bietet die völkerrechtliche Studie von Benter, Deutsches Vermögen im neutralen Ausland.

${ }^{71} \mathrm{Zu}$ den spanisch-alliierten Auseinandersetzungen um das deutsche Eigentum siehe Collado Seidel, Angst vor dem „Vierten Reich“. Der Autor vernachlässigt allerdings die sich wandelnde Interessenlage der Westmächte sowie die eigenständige Politik der Bundesrepublik, die hier vor allem als „Störenfried“ erscheint.

72 Die Bundesrepublik hat die spanischen Ansprüche aus der Zeit bis 1945 stets bestritten. Nach Durchsicht der spanischen Akten kommt Petra-Maria Weber zu dem Schluß, daß diese Forderungen "frisiert" worden seien. Vgl. dazu Weber, Spanische Deutschlandpolitik 1945-1958, S. 72 f. Um das spanische Interesse an einer möglichst umfangreichen Liquidation zu befördern, hatten dic Alliierten eine progressiv ansteigende Skala vorgeschlagen. Im Madrider Abkommen war festgelegt worden, daß Spanien von den ersten 100 Mio. Ptas $20 \%$ erhalten sollte, von den zweiten $22,5 \%$ usw. bis $z u 30 \%$ bei einem Betrag über 400 Mio. Ptas. 
1945 waren damit sämtliche Vermögenswerte der Achsenmächte, also auch die Deutschlands, blockiert. Schon vor dem formalen Abschluß des Madrider Abkommens war durch das spanische Gesetzesdekret über die „zwangsweise Enteignung“ vom 23. April 1948, das die innerstaatliche Rechtsgrundlage für die Übereinkunft mit den westlichen Besatzungsmächten bildete, die Liquidation privater deutscher Vermögenswerte eingeleitet worden. Davon ausgenommen blieb allerdings das Privatvermögen der am Stichtag (6. Mai 1948) in Spanien ansässigen Deutschen ${ }^{73}$.

An den Bestimmungen des spanisch-alliierten Abkommens von 1948 und vor allem der Enteignungspraxis entzündete sich zwischen der Bundesrepublik und Spanien eine jahrelange Kontroverse. Da der westdeutsche Staat außenpolitisch noch nicht handlungsfähig war und die westlichen Alliierten sich im Rahmen des Besatzungsstatuts ausdrücklich die Verfügungsgewalt über das deutsche Auslandsvermögen vorbehalten hatten, konnte das Problem erst nach einer Neuordnung des deutsch-alliierten Verhältnisses grundsätzlich geregelt werden. Vor diesem Hintergrund war es der Bundesregierung zunächst nur möglich, auf informellem Wege auszuloten, ob der betreffende Staat überhaupt die Bereitschaft zu zweiseitigen Gesprächen zeigte.

An das Verhalten der Franco-Regierung legte sie dabei besondere Maßstäbe an. Nur so wird die Enttäuschung über das als sehr rigoros empfundene spanische Vorgehen bei der Enteignung erklärbar. Bonn registrierte empört, daß der „traditionelle Freund Deutschlands“ sich selbst sogar öffentlich rühmte, die deutschen Vermögenswerte besonders schnell liquidiert zu haben ${ }^{74}$. Bezeichnend ist die Kritik am spanischen Liquidationsverfahren durch den für das Auslandsvermögen zuständigen Referatsleiter in der Dienststelle für Auswärtige Angelegenheiten, Generalkonsul Schellert ${ }^{75}$. In einem Gespräch mit dem österreichischen Vertreter in Bonn, Generalkonsul Schöner, über die Situation des deutschen Eigentums im Ausland räsonierte Schellert im Februar 1951, daß die Lage in Spanien im Vergleich zu anderen Staaten am schlimmsten sei: „Herr Schellert geriet in sichtbare Erregung, als er schilderte, wie Spanien uneingedenk der einstigen ,Waffenbrüderschaft ${ }^{\star}$ das deutsche Eigentum viel vollständiger liquidiert habe, als die meisten Feindstaaten. Deutsche Firmen seien um einen Peso Nominale verkauft worden und die Kor-

${ }^{73}$ Gleichzeitig wurde die Beschlagnahme aufgehoben. Dies galt jedoch nur für Personen, die keinen Ausweisungsbefehl erhalten hatten. Vgl. Weber, Spanische Deutschlandpolitik 1945-1958, S. 70.

${ }_{74}$ Dic spanische Pressc hatte am 26. Mai 1950 eine Meldung der amtlichen Nachrichtenagentur EFE verbrcitet, in der die "Interalliierte Reparationsagentur" der spanischen Regierung ein ausdrückliches Lob für dic rasche Liquidierung des deutschen Eigentums ausgesprochen hatte. Vgl. Aufzeichnung über das deutsche Vermögen in Spanien, 1.3.1952, PA/AA, Ref. 412, Bd.91.

75 Das Thema des deutschen Auslandsvermögens wurde anfänglich im Bundeskanzleramt, später in einem eigenen Referat (506 bzw. 507) in der Rechtsabteilung des Auswärtigen Amtes bearbeitet. Obwohl die Federführung zunächst beim Bundesfinanzministerium lag, beschränkte es sich in der Praxis auf die technische Seite der diplomatischen Kontakte. Nachdem die AHK Bonn für das Jahr 1954 einen größeren Verhandlungsspielraum in Aussicht gestellt hatte, übertrug Bundeskanzler Adenauer im Januar die Kompetenzen auf das Auswärtige Amt; vgl. PA/AA, Ref. 110, Bd. 39, 23. 2. 1954. Die Interessen der betroffenen Eigentümer vertrat seit 1948 die in Bremen ansässige „Studiengesellschaft für privatrechtliche Auslandsinteressen“. Diese „pressure group" arbeitete eng mit der Bonner Ministerialbürokratie zusammen. Siehe dazu Kreikamp, Deutsches Vermögen in den Vereinigten Staaten, S. 44 ff. Detaillierten Aufschluß über die Aktivitäten der Interessengemeinschaft gibt ihr im Bundesarchiv Koblenz vorhandener Aktenbestand, BA, B 184. 
ruption bei der Veräußerung einstigen deutschen Besitzes sei unvorstellbar. "76 Dieser Gestus hilfloser Entrüstung bestimmte zunächst die deutsche Sicht der Eigentumsproblematik.

\section{Vom Bittsteller zum Verhandlungspartner}

Auf der politischen Ebene ging es vorrangig darum, die weitere Liquidation von Vermögensobjekten zu verhindern. Die spanische Seite reagierte aber auf den deutschen Wunsch, das Thema bei den Handelsvertragsverhandlungen im April 1951 zu erörtern, ausweichend bis ablehnend. Der spanische Gesandte in Bonn, Aguirre, verwies Schellert im Februar auf die Vereinbarungen mit den Alliierten, an die man gebunden sei, worauf sein Gesprächspartner nur ins Felde führen konnte, das spanische Vorgehen habe angesichts „der traditionellen deutsch-spanischen Freundschaft besondere Bitterkeit in der deutschen Öffentlichkeit ausgelöst"77. Da die spanische Regierung, auf Wahrung ihres Vorteils bedacht, sich hier dem „Wert“ solch historischer Reminiszenzen gegenüber wenig aufgeschlossen zeigte und an den realpolitischen Gegebenheiten orientiert blieb, konnte Bonn nur darauf setzen, den Emanzipationsprozeß von den Besatzungsmächten möglichst schnell voranzutreiben.

Bereits ein Jahr später konnten die Verhandlungen über die Ablösung des Besatzungsstatuts zwischen den westlichen Alliierten und der Bundesrepublik mit der Unterzeichnung des Deutschland- und EVG-Vertrages am 26. bzw. 27. Mai 1952 abgeschlossen werden. In dem Dreieck Bundesrepublik, Spanien, Alliierte hatten sich die Koordinaten damit zugunsten der Bundesrepublik verschoben. Der das Reparationsproblem behandelnde Überleitungsvertrag räumte ihr im Hinblick auf das deutsche Eigentum im Ausland erstmals gewisse Handlungsmöglichkeiten ein. Der Bundesrepublik war darin (Sechster Teil, Art. 4, Abs. 4) zugestanden worden, nach Absprache mit den Drei Mächten zweiseitige Verhandlungen über die Liquidation des deutschen Vermögens führen zu dürfen.

Gestärkt durch diesen Erfolg, konnte die Bundesregierung nun ihr Nahziel, Spanien zu einem Liquidationsstopp zu bewegen, mit größerem Nachdruck verfolgen. Bei den Handelsvertragsverhandlungen in Madrid nutzte die deutsche Delegation im Herbst 1952 die Gelegenheit zu einem entsprechenden Vorstoß. Dem war ein interner Klärungsprozeß der beteiligten Ressorts aus den Bundesministerien für Wirtschaft, Justiz und Finanzen sowie dem Auswärtigen Amt über Strategien und Ziele in der Eigentumsfrage vorausgegangen.

Nachdem sich in der Vergangenheit gezeigt hatte, daß die spanische Seite auf bevorstehende Handelsvertragsverhandlungen stets mit einer Verlangsamung ihrer Konfiskationen reagierte ${ }^{78}$, sollten jetzt handelspolitische Zusagen als Druckmittel eingesetzt werden,

76 Bericht Schöners über deutsches Eigentum im Ausland, 28. 2. 1951, Außenministerium Wien (AAW II-Pol 1951). Freundlicher Hinweis von Dr. Matthias Pape (Bonn). Schellert spielte auf den Umstand an, daß die ehemaligen deutschen Firmen in der Regel weit unter Preis verkauft wurden, aber eine „Zwischengebühr“ an den „Nationalen Forschungsrat“ Spaniens ging. Dadurch flossen Spanien neben dem anteiligen Kaufpreis noch weitere Gelder zu. Vgl. Denkschrift zu den deutsch-spanischen Vermögensabkommen, Bundesrat, Drucksache 294/1958, S. 21.

77 Aufzeichnung Schellert, 23. 2. 1951, PA/AA, Ref. 506, Bd. 59. Zu diesem Zeitpunkt war es der Bundesregierung infolge des Besatzungsstatuts nicht möglich, offiziell an Spanien heranzutreten. Daher wies Schellert ausdrücklich darauf hin, dies sei ein nur inoffiziell zu verstehendes Gespräch gewesen.

${ }_{78}$ Vgl. Aufzeichnung Mosler, 10. 1. 1952, PA/AA, Ref. 506, Bd.55. Prof. Hermann Mosler war zu diesem Zeitpunkt Leiter der Rechtsabteilung im Auswärtigen Amt. 
um einen Beschlagnahme- und Liquidationsstopp herbeizuführen. Obwohl die eigene Position aufgrund der für Spanien „dringend notwendigen“ Exporte von Zitrusfrüchten übereinstimmend als sehr günstig angesehen wurde ${ }^{79}$, erschien aber ein direktes Junktim weder durchsetzbar noch wünschenswert.

Gleichwohl sollte, während die deutsche Spanienpolitik mit der Aufnahme voller diplomatischer Beziehungen ihr Instrumentarium gerade entscheidend erweiterte, vermieden werden, „das wirtschaftliche und politische Verhältnis zu Spanien in einer für die künftige Arbeit der Botschaft unerträglichen Weise zu belasten“80. Die angestrebten konservatorischen Maßnahmen ${ }^{81}$ waren aber lediglich als ein erster Schritt zu künftigen Verhandlungen gedacht.

Als Fernziel wurde die Erwartung formuliert, daß der franquistische Staat bereit sein werde, über die wechselseitigen Forderungen aus der Zeit bis $1945 \mathrm{zu}$ verhandeln. Nach Bonner Auffassung entbehrten nämlich die von den Alliierten akzeptierten spanischen Ansprüche an Deutschland jeder Grundlage, so daß auch die daraus abgeleiteten spanischen Anteile aus dem Liquidationserlös als unrechtmäßig angesehen wurden. Das Auswärtige Amt warf Spanien in einem internen Memorandum explizit vor, in doppelter Hinsicht Nutzen aus der Feindvermögenspolitik der Alliierten gezogen zu haben. So hätte die Franco-Regierung vor dem Hintergrund eines deutschen Aktivsaldos im Jahre 1945 und der wirtschaftlichen Unterstützung durch die NS-Diktatur im Spanischen Bürgerkrieg damit rechnen müssen, daß der Alliierte Kontrollrat als de-facto-Regierung Deutschlands diese Forderungen seinerseits gegenüber Spanien geltend machen könne ${ }^{82}$. Daher sei Spanien auf die Lösung verfallen, einerseits die deutschen Ansprüche ganz und gar zu bestreiten und andererseits fiktive Kriegsschadensansprüche gegen das ehemalige Deutsche Reich in Höhe von rund 200 Millionen Peseten anzumelden. Diese wurden von den Alliierten anerkannt und boten die Grundlage für die 20-30\%ige Beteiligung Spaniens am Liquidationserlös deutscher Vermögenswerte, was im Auswärtigen

\footnotetext{
79 Auszug aus der Niederschrift über die Sitzung des Handelspolitischen Ausschusses vom 9.9. 1952 (Geheim), PA/AA, Ref. 203, Bd. 473. Nach cinem Antrag des Verfassers auf Offenlegung der Spanien betreffenden Verschlußakten im Auswärtigen Amt wurden einige Schriftstücke herabgestuft und in dem vorgenannten Aktenband zusammengefaßt.

80 Ebenda.

81 Außerdem forderte Bonn von der spanischen Regierung Auskünfte über die bislang gegen das deutsche Eigentum gerichteten Schritte. Über diese Mindestwünsche hinaus sollte die Rückgabe der kulturellen und diplomatischen Objekte verlangt werden. Vermerk über die Frage des deutschen Vermögens im Rahmen der Handelsvertragsverhandlungen, 28. 8. 1952, BA, B 102, Bd. 24870.

${ }^{82}$ Im einzelnen begründete das Auswärtige Amt den deutschen Aktivsaldo vor allem mit den nach wie vor offenen Bürgerkriegsschulden Spaniens, über die es noch im Jahre $1944 \mathrm{zu}$ Verhandlungen gekommen sei. Ohne sich vertraglich geeinigt zu haben, sei aber ein Vergleich in Höhe von 371,89 Mio. Reichsmark (RM) zustande gekommen. Ferner habe das Deutsche Reich Entschädigungsansprüche in Höhe von 45 Mio. RM sowie 21 Mio. RM an Zinsen geltend gemacht. Schließlich existiere aus der Verrechnung der gegenseitigen Forderungen für die „Legion Condor" und die „Blaue Division" noch ein deutsches Plus von 15 Mio. RM, was insgesamt einen Betrag von 452, 89 Mio. RM ergebe. Demgegenüber wurden die spanischen Zahlungen und Forderungen unter Einschluß des Clearingsaldos von 117,6 Mio. RM insgesamt mit nur 273,9 Mio. RM angegeben. 7um Zeitpunkt des „Zusammenbruchs“ verbleibe also cin deutscher Aktivsaldo von etwa 180 Mio. RM. Vgl. dazu: Instruktion für Prinz Adalbert von Bayern, PA/AA, 210-02/70, Bd. 1, S. 53, und Anlage 3, S. 61 f. Auch Ruhl, Spanien im Zweiten Weltkrieg, gibt die Höhe der spanischen Bürgerkriegsschulden mit 372 Mio. RM an, vgl. S. 233.
} 
Amt mit bitteren Worten kommentiert wurde: „Daß Spanien politisch nach dem Zusammenbruch der beiden Achsenmächte gezwungen war, mit allen erreichbaren Mitteln die Verbindung mit den Siegermächten herzustellen bzw. zu festigen, mag verständlich erscheinen. Jedoch kann sich Spanien weder mit seinen politischen Notwendigkeiten von 1945, geschweige denn mit der Art der Durchführung der Maßnahmen gegen das deutsche Vermögen, die bis heute praktiziert werden, entschuldigen. Spanien hat sich durch sein Verhalten ganz außerhalb der Reihe der Neutralen gestellt und durch seinen ,Eifer' selbst alliierte Mächte in den Schatten gestellt. Es ist immer zu beachten, daß das spanische Interesse an der Liquidation des deutschen Vermögens außer an der Errechnung des Aktivsaldos für 1945 20-30 Prozent des Erlöses wert war."83 Der nachhaltige Eindruck, vom ehemaligen Verbündeten Spanien übervorteilt worden zu sein, bestimmte Anfang der 50er Jahre maßgeblich die Überlegungen und das Handeln der Bundesregierung.

Am Rande der im September 1952 beginnenden Handelsgespräche in Madrid konnte Bonn nun seine Hoffnungen auf eine gestärkte Verhandlungsposition testen. Ohne daß die Bundesregierung die Alliierten vorab über ihre Absichten informiert hatte, kam es zu informellen Besprechungen über die Vermögensfrage. Dabei wies der deutsche Delegationschef, Vollrath Freiherr von Maltzan, Leiter der Abteilung Außenhandel im Bundeswirtschaftsministerium, mit Nachdruck darauf hin, es würde in Deutschland nicht mehr verstanden werden, wenn bei der inzwischen eingetretenen Entwicklung hin zur Souveränität „deutsche Rechte in Spanien weiter geschmälert würden “84. Ihm komme es jetzt darauf an, eine klare Zusage für einen sofortigen Liquidationsstopp zu bekommen, überdies müßten Schritte zugunsten deutscher Vermögenswerte erfolgen.

Diese bei Unterstaatssekretär Navasqüés vom spanischen Außenministerium vorgebrachten Wünsche bewirkten mit der mündlichen Zusage eines vorläufigen Liquidationsstopps $^{85}$ ein erstes Einlenken der Madrider Regierung. Allerdings war zu diesem Zeitpunkt der größte Teil der deutschen Unternehmen in Spanien bereits liquidiert worden, so daß das spanische Entgegenkommen letztlich nur eine wohlfeile Geste darstellte.

Im Anschluß an das Madrider Abkommen von 1948 waren nach Angaben der betroffenen Eigentümer etwa 90 Prozent der Firmen einschließlich ihrer Patente, Warenzeichen und Marken mit einem effektiven Wert von rund 150 Millionen DM zwangsweise veräuBert worden ${ }^{86}$. Die Investitionen der über 70 enteigneten Filial- bzw. Tochterunternehmen $^{87}$ verteilten sich sektoral vor allem auf die chemische Industrie (IG-Farben) und die Elektroindustrie (AEG, Siemens, Osram etc.).

83 Instruktion für Prinz Adalbert von Bayern, PA/AA, 210-02/70, Bd. 1, S. 54.

84 Bericht über die in Madrid geführten Gespräche über die Fragen des deutschen Vermögens in Spanien, 17. 10. 1952, BA, B 126, Bd. 12460.

85 Bericht Maltzan an das Auswärtige Amt über seine Besprechungen in Madrid, 22. 10. 1952, BA, B 126, Bd. 12460. Navasqüés hatte die spanische Delegation in den Vermögensverhandlungen mit den Alliierten geleitet. Siehe hierzu detailliert Weber, Spanische Deutschlandpolitik 1945-1958, S. $64 \mathrm{ff}$.

86 So jedenfalls äußerten sich 1958 die durch die Enteignung geschädigten Wirtschaftskreise auf der Jahrestagung der Studiengesellschaft für privatrechtliche Auslandsinteressen; vgl. Benter, Deutsches Vermögen im neutralen Ausland, S. 134.

${ }^{87}$ Die Zahl der enteigneten Firmen wird in den Quellen unterschiedlich mit 75, 76 bzw. 78 angegeben. In Presseberichten ist sogar von 79 bzw. 83 Unternehmen die Rede, FR, 29.5. 1957, und Bremer Nachrichten, 4.8. 1955 . 
Neben den privaten Vermögenswerten muß in eine Gesamtbilanz auch das öffentliche Eigentum (Botschafts- und Konsulatsgebäude, Grundstücke, deutsche Schulen ${ }^{88}$, Einrichtungen der NSDAP etc.) einbezogen werden. Nach dem Ende des „Dritten Reiches“ wurde das staatliche Vermögen, zu dem auch der quasi-staatliche Sofindus-Konzern ${ }^{89}$ gehörte, den westlichen Alliierten überstellt und liquidiert.

Die materielle Dimension insgesamt war selbst für die Experten im Bundesfinanzministerium und im Auswärtigen Amt nur schwer quantifizierbar. Zuverlässige Zahlen über den Wert des deutschen Vermögens standen nicht zur Verfügung. Daher sind die auf Schätzungen beruhenden Angaben über die finanzielle Größenordnung mit Vorbehalt zu sehen. Das Auswärtige Amt bezifferte den Gesamtverlust Mitte der 50er Jahre auf ca. 155 Millionen $\mathrm{DM}^{90}$.

Nachdem der bilaterale Diskussionsprozeß nun in Gang gebracht war, nahm die Bundesregierung an, die spanische Seite werde direkten Verhandlungen zukünftig nicht mehr ausweichen und Lösungen seien schon bald erreichbar ${ }^{91}$. Wie weit diese optimistische Prognose von der politischen Realität entfernt war, zeigte sich allerdings sehr bald. Der „besetzte Verbündete“ Bundesrepublik (Rupieper) hatte mit seiner eigenmächtigen Sondierung in Madrid politisches und völkerrechtliches „Niemandsland“ betreten, worauf die Westalliierten verärgert reagierten.

Das von der Bundesrepublik auch anderen Staaten gegenüber eingeschlagene Verfahren, die Vermögensproblematik durch einen nicht vorher mit den Alliierten abgesprochenen bilateralen Meinungsaustausch voranzutreiben, wurde unmißverständlich zurückgewiesen. So erinnerte der Generalsekretär der Alliierten Hohen Kommission, Golay, in einer an Staatssekretär Hallstein gerichteten Note vom 5. Februar 1953 unter Hinweis auf das Besatzungsstatut daran, daß der Bundesregierung direkte Verhandlungen über deutsche Auslandswerte nach wie vor nicht gestattet seien ${ }^{92}$. Trotz der im Vorjahr erfolgten Paraphierung des Generalvertrages war die Zeit der Kontrolle im deutsch-alliierten Verhältnis

\footnotetext{
${ }^{8 \pi}$ Die zwölf deutschen Schulen waren Eigentum örtlicher deutscher Schulvercine, somit juristisch gesehen kein staatliches Eigentum; jedoch galten sie den Alliierten als Träger der nationalsozialistischen Ideologie. Mit einer Ausnahme wurden sie der Franco-Regierung überlassen.

${ }^{89}$ Die in der seit 1938 bestehenden Sofindus-Holding zusammengefaßten reichseigenen Gesellschaften Hisma und Rowak organisierten mit teilweise rabiaten Methoden von 1936 an im Interesse der NS-Diktatur nahezu monopolistisch den deutsch-spanischen Warenaustausch. Als Kompensation für die deutsche Militärhilfe wickelte Hisma-Sofindus vor allem die Beschaffung von Rohstoffen wie Schwefelkies oder Kupfererz ab. Aus rüstungswirtschaftlichen Gründen erwarb die Hisma in den Jahren 1937 und 1938 erhebliche Kapitalbeteiligungen an spanischen Minenkonzessionen. Siehe zusammenfassend: Bernecker, Krieg in Spanien, S. $58 \mathrm{ff}$. Vgl. außerdem: Volkmann, Die NS-Wirtschaft in Vorbereitung des Krieges, S. 317 ff.; Whealey, Hitler and Spain.

${ }_{90}$ Vgl. Aufzeichnung betr. deutsches Vermögen in Spanien, 7. 7. 1955, PA/AA, Ref. 206, Bd. 20. Nach Angaben der Alliierten wurden als Liquidationserlös 335 Mio. Ptas (dies entsprach nach offiziellem Wechselkurs etwa 33,5 Mio. DM) an die Interalliicrte Reparationsagentur weitergeleitet. Weitere 142 Mio. Ptas waren Gegenstand späterer Verhandlungen. Vgl. Deutsches Vermögen in Spanien (Anlage zur Kabinettsvorlage), 20. 12. 1956, PA/AA, Ref. 506, Bd. 712.

91 In diesem Sinne äußerte sich Maltzan in einem resümierenden Bericht an das Auswärtige Amt, 22. 10. 1952, BA, B 126, Bd. 12460.

92 Note der AHK an Staatssekretär Hallstein, 5. 2. 1953, PA/AA, Abt. 2, Bd. 31. Genannt wurden die Beispiele Portugal, Schweden, Spanien und Österreich. Die Hohe Kommission bekräftigte damit erneut ihren Bundeskanzler Adenauer bereits am 28.4.1951 erläuterten Standpunkt, wonach bilaterale Verhandlungen der Bundesregierung abgelehnt wurden.
} 
nicht beendet. Darüber konnte auch das Zugeständnis der Westmächte nicht hinwegtäuschen, von Fall zu Fall ein Verhandlungsersuchen der Bundesregierung prüfen zu wollen. Die Alliierten wollten also unverändert den weiteren Gang der Dinge steuern. Damit waren der Regierung Adenauer vorläufig die Hände gebunden.

Zu Beginn des Jahres 1954 hatte sich die Lage im deutsch-alliierten Verhältnis jedoch soweit verändert, daß die Frage des Auslandsvermögens nunmehr in den fortschreitenden Normalisierungsprozeß einbezogen wurde. Aufgrund des langwierigen Ratifikationsverfahrens beim Vertrag über die Europäische Verteidigungsgemeinschaft (EVG) ${ }^{93}$, an den der Deutschlandvertrag gekoppelt war, hatte sich ein auf Dauer unhaltbarer Schwebezustand ergeben. Um diese als nicht mehr zeitgemäß empfundene Situation zumindest auf einem Nebenschauplatz zu entschärfen, orientierten die Alliierten sich nun stärker an einer konzilianteren Politik in der Eigentumsfrage, „die den praktischen Gegebenheiten der Lage entspricht und die eine Hilfe für die Bundesregierung bedeuten würde" ${ }^{\text {"94. Dem- }}$ entsprechend räumten die Drei Mächte der Regierung Adenauer am 21. Januar 1954 die Möglichkeit von Verhandlungen ein. Diese Konzession war aber insofern begrenzt, als die Abkommen zwischen den Westalliierten und den neutralen Staaten dadurch grundsätzlich nicht in Frage gestellt werden konnten ${ }^{95}$. In der Sache ging die angebotene Verhandlungsfreiheit nicht über die im Generalvertrag eingeräumten Zugeständnisse hinaus, antizipiert wurde lediglich für diesen Teilbereich sein Inkrafttreten.

Im Hinblick auf das deutsche Vermögen in Spanien konnte also nur noch der Status quo als Basis einer deutsch-spanischen Übereinkunft gelten. Die ursprünglichen Hoffnungen auf eine grundlegende Revision des Madrider Abkommens waren damit zunichte gemacht. Gleichwohl spekulierte man innerhalb der Bonner Ministerialbürokratie auf ein weiterreichendes Entgegenkommen der Franco-Regierung. In einer Analyse zum augenblicklichen Stand der Vermögensfrage befand der zuständige Referent des Bundeswirtschaftsministeriums, Grosdidier, im September 1954, es werde aber dennoch erwartet, „daß die spanische Regierung - wenn auch ohne formalrechtliche Verpflichtung - sich auf eine Verhandlung auch der bereits abgeschlossenen Enteignungen und Liquidationen einläßt und diesen Komplex gegebenenfalls mit einer autonomen Maßnahme zur Zufriedenheit der Bundesregierung regelt" ${ }^{\text {"96 }}$.

Nach dem bisherigen Verlauf der deutsch-spanischen Kontakte überrascht die hier gezeigte Zuversicht. Denn seit dem von Spanien im November 1952 gewährten Liquidationsstopp $^{97}$ war nichts geschehen, was auf eine veränderte Haltung des Franco-Regimes hätte schließen lassen. Dem unablässigen Drängen Bonns war Madrid stets mit dem Hinweis auf

93 Zur Entwicklung der EVG vgl. Rupieper, Der besetzte Verbündete, S. $381 \mathrm{ff}$. Die militärischen Aspekte betont stärker Maier, Die Auseinandersetzung um die EVG als curopäisches Unterbündnis der NATO 1950-1954, S. 447-474.

94 Schreiben des geschäftsführenden Vorsitzenden der Hohen Kommission, Hoyer Millar, an Bundeskanzler Adenauer, 21. 1. 1954, PA/AA, 245-03/70, Bd. 1, S. 2.

95 Ebenda, S. 3. Außerdem behielten sich die Alliierten als Treuhänder der internationalen Vereinbarungen ein Eingriffsrecht vor. Dies sollte dann gelten, wenn sie von einem Staate, der nicht zu Verhandlungen bereit sei, darum gebeten würden.

9; Vermerk Grosdidier über den augenblicklichen Stand der Verhandlungen in der Frage der beschlagnahmten deutschen Vermögen in Spanien, 17. 9. 1954, BA, B 102, Bd. 110888.

97 Ebenda. Der Liquidationsstopp galt offiziell seit dem 6. November 1952, dem Tag der Eröffnung der deutschen Botschaft in Madrid. 
das Vermögensabkommen mit den Alliierten begegnet, das zwar eine Notstandshandlung gewesen sei, die Frage aber doch abschließend geregelt habe. Als Konsequenz der unvereinbaren Positionen erstarte die von deutscher Seite bei jeder offiziellen und inoffiziellen Begegnung initiierte Diskussion zur ritualisierten Routine. Allerdings veränderte sich die deutsche Tonart. Ende 1954 wurde Botschafter Prinz Adalbert von der Bonner Zentrale angewiesen, in einem Gespräch mit Staatschef Franco zu betonen, daß die bevorstehende Unterzeichnung des Kulturabkommens vor dem Hintergrund der ungelösten Enteignungsfrage eine „bewußte Vorleistung“ sei. Aufgrund des liquidierten kulturellen Eigentums müsse nämlich mit erheblicher Kritik von Öffentlichkeit und Parlament gerechnet werden ${ }^{98}$.

Erst 1955 kam tatsächlich Bewegung in den stockenden Enteignungsdialog. Während noch zwei Jahre zuvor der spanische Handelsminister Arburúa seinen von der Bundesregierung gewünschten Besuch abgesagt hatte, weil er befürchtete, auf das Vermögensproblem angesprochen zu werden ${ }^{99}$, ergriff jetzt die Franco-Regierung überraschend die Initiative. Der für die Materie entscheidende Akteur im spanischen Außenministerium, Unterstaatssekretär Emilio Navasqüés, setzte bei seinem Besuch in Bonn im Juli 1955 einen grundlegend neuen Akzent. In einem Gespräch mit dem kurz zuvor ernannten Bundesaußenminister Heinrich von Brentano erklärte er erstmals die Verhandlungsbereitschaft Spaniens, ohne dabei jedoch konkrete Vorstellungen zu entwickeln. Brentano begrüßte das Entgegenkommen, machte aber gleichzeitig deutlich, „daß es kein guter Ausgangspunkt sei, wenn man von Deutschland erwarte, daß es alles, was geschehen ist, unbesehen gutheiße"100. Beide Seiten stimmten in dem Wunsch überein, dieses Kapitel der deutschspanischen Beziehungen bald abzuschließen. Die Motive für den plötzlichen Sinneswandel Spaniens dürften vor allem in der inzwischen veränderten politischen Landschaft zu suchen sein. Anders als in den zurückliegenden Jahren konnte das Franco-Regime den Wünschen der gerade in die Souveränität entlassenen Bundesrepublik nun nicht mehr ohne weiteres ausweichen.

Die Westmächte waren inzwischen um einen Ausgleich bemüht, der die „Altlast“ Auslandsvermögen im Sinne ihrer übergeordneten außenpolitischen Interessen bereinigen sollte $^{101}$. Hinzu kam, daß das politisch und wirtschaftlich erstarkte Westdeutschland für den

${ }_{98}$ Entwurf eines Telegramms an den Missionschef in Madrid, 8. 12. 1954, PA/AA, Ref. 506, Bd.56. Auf das Kulturabkommen und seine Genese wird an anderer Stelle eingegangen.

99 Vermerk von Waldheim über die Besprechung mit Pirkham von der Süddeutschen Bank, 18. 11. 1954, PA/AA, Ref. 506, Bd. 56. Dies sei der eigentliche Grund für seine Absage gewesen, räumte Arburúa 1954 in einem Gespräch mit Dr. Pirkham von der Süddeutschen Bank ein. Arburúa war 1953 anläßlich der Eröffnung der Banco Español in Frankfurt von Bundeswirtschaftsminister Erhard nach Bonn eingeladen worden. Offiziell wurde damals die Absage mit Problemen bei der Durchführung der spanischamerikanischen Stützpunktverträge begründet. Vgl. Bericht der Botschaft Madrid, 4. 12. 1953, PA/AA, 752-05/70, Bd. 1.

${ }^{100}$ Aufzeichnung über Unterredung Brentano mit Navasqüćs, 11.7. 1955, PA/AA, Abt. 2, Ministerbüro, Bd. 155. Navasqüés war inzwischen zum Inspekteur der spanischen Auslandsmissionen avanciert.

${ }^{101}$ Im Februar 1956 äußerten Vertreter der Drei Mächte im Auswärtigen Amt, sie seien der Ansicht, daß die Eigentumsfrage gegenüber beiden Ländern der iberischen Halbinsel „endlich" geregelt werden müsse, "da sie der auch von den 3 Mächten angestrebten Bereinigung der Atmosphäre und der Verstärkung der freundschaftlichen Beziehungen der Bundesrepublik zu diesen Ländern hindernd im Wege stände". Aufzeichnung über die Besprechung mit den Vertretern der Drei Mächte über das deutsche Vermögen in Portugal und Spanien, 6. 2. 1956, PA/AA, Ref. 506, Bd. 774. 
iberischen Staat mit seinen großen ökonomischen Problemen zunehmend an Attraktivität gewann. In dieser Umbruchsphase setzte die Bundesrepublik ihre finanziellen Ressourcen gezielt als Druckmittel ein. Es ist sicherlich kein Zufall, daß der Besuch von Hermann Josef Abs in Madrid Ende April 1955 unmittelbar vor der Neuorientierung Spaniens in der Konfiskationsfrage stattgefunden hatte. Durch seine Gespräche mit Handelsminister Arburúa und insbesondere mit Staatschef Franco half der einflußreiche Bankier, der das Vertrauen Adenauers besaß, den Boden für offizielle Verhandlungen zu bereiten. Von Spanien gewünschte Investitionen in einem Umfang von etwa 40 bis 50 Millionen DM machte er davon abhängig, daß vorher das Problem des Alteigentums geregelt sein müsse ${ }^{102}$.

Auf Regierungsebene spann Landwirtschaftsminister Heinrich Lübke, der als erster deutscher Minister im Oktober 1955 Spanien besuchte, den Faden weiter, indem auch er den Enteignungskomplex in den Mittelpunkt seiner Gespräche mit der Franco-Regierung rückte. Über seinen persönlichen Vorschlag hinaus, die Probleme um das kulturelle Vermögen vorweg zu lösen, stellte Lübke den von Spanien erhofften Besuch Bundeskanzler Adenauers nach Klärung aller offenen Fragen in Aussicht ${ }^{103}$.

Dem Auswärtigen Amt kam diese Eigeninitiative Lübkes zu jenem Zeitpunkt jedoch eher ungelegen. Denn der nach der Deutschlandreise von Navasqüés inzwischen vorgelegte spanische Lösungsvorschlag erwies sich als völlig inakzeptabel. Das spanische Ansinnen, die Bundesrepublik solle als Rechtsnachfolger des Alliierten Kontrollrats in das Madrider Abkommen von 1948 eintreten bzw. es bestätigen, war für Bonn nicht annehmbar ${ }^{104}$. Zudem hatte die Franco-Regierung Kriegsschadensansprüche angemeldet und gefordert, von allen Entschädigungsansprüchen freigestellt zu werden. An der Reaktion der Bundesregierung läßt sich die veränderte Grundlage der Spanienpolitik deutlich ablesen. Während zu Beginn der 50er Jahre die Bundesrepublik nur aus einer Bittstellerposition heraus an das Wohlwollen ihres Gegenüber appellieren konnte, vertrat sie nun uneingeschränkt ihre Interessen.

Zwar hatte man im Auswärtigen Amt mittlerweile die geschaffenen Tatsachen akzeptiert und ging davon aus, das „Rad der Geschichte“ nicht um Jahre zurückdrehen zu können: „Außerdem würden bei Aufrollung des Problems ab Mai 1945 unübersehbare Schwierig-

102 Vermerk von Waldhcim über Unterredung mit Abs, 4. 5. 1955, PA/AA, Ref. 506, Bd. 56. Abs nahm als Vorstandsmitglied der Süddeutschen Bank in Madrid $u$. a. an der Generalversammlung der Banco Espanol cn Alemania teil, an dem seine Bank mit 15\% des Aktienkapitals beteiligt war. Aufgrund seiner guten Verbindungen nach Spanien - der spanische Handelsminister Arburúa saß gemeinsam mit Abs im Verwaltungsrat der Banco Español en Alemania - hatte der Bankier dem Auswärtigen Amt bereits früher seine Hilfe angeboten, die dort dankbar aufgenommen wurde; vgl. Schreiben Berger (Leiter der Rechtsabteilung) an Abs, 22. 12. 1956, PA/AA, Ref. 506, Bd. 711. Auch an anderer Stelle bemühte sich Abs maßgeblich um die Freigabe des deutschen Auslandsvermögens. $\mathrm{Zu}$ seinen Aktivitäten innerhalb der deutsch-amerikanischen Beziehungen siehe die Studie von Kreikamp, Deutsches Vermögen in den Vereinigten Staaten, S. 91 ff. Zu Abs' Vermittlung bei den deutsch-österreichischen Vermögensverhandlungen siehe Pape, Ungleiche Brüder, S. $361 \mathrm{f}$.

${ }_{103}$ Bericht Botschaft Madrid über Gegenbesuch des Bundesministers Lübke in Madrid, 11. 10. 1955, PA/AA, Ref. 506, Bd.56. Lübke weilte auf Einladung seines Amtskollegen Cavestany in Spanien, der im Mai 1954 den Anfang im deutsch-spanischen Ministerdialog gemacht hatte. Adenauer war von der spanischen Regierung am 14.7. 1955 offiziell eingeladen worden.

${ }^{104}$ Neben den politischen Bedenken gab es prinzipielle rechtliche Einwände, da die Bundesrepublik sich nicht als Nachfolgerin des ehemaligen Alliierten Kontrollrates für Deutschland verstand und somit auch nicht Partei des spanisch-alliierten Abkommens vom 10.5.1948 sein konnte. 
keiten auftreten, die die ganze Atmosphäre vergiften und wahrscheinlich eine Lösung unmöglich machen würden." ${ }^{105}$

Der Rechtsabteilung im Auswärtigen Amt war auch bewußt, daß Spanien infolge seiner angespannten Finanz- und Wirtschaftslage für eine Entschädigung der betroffenen deutschen Eigentümer nicht aufkommen wollte und konnte ${ }^{106}$. Ein Eingehen auf derartige Forderungen hätte aus Bonner Sicht aber eine eigene Entschädigungsverpflichtung beinhaltet, die aus prinzipiellen Überlegungen unbedingt vermieden werden sollte ${ }^{10 \tau}$. Besonders im Hinblick auf die parallel laufenden Gespräche mit anderen im Zweiten Weltkrieg neutral gebliebenen Staaten wie Portugal und Schweden ${ }^{108}$ befürchtete man eine präjudizierende Wirkung, zumal vorauszusehen war, daß die dort erwarteten Ergebnisse wesentlich günstiger für die Bundesrepublik ausfallen würden.

Vor diesem Hintergrund empfahl die Rechtsabteilung ${ }^{109}$ die Verhandlungen mit Spanien zu vertagen, bis die Vermögensverhältnisse mit den anderen neutralen Staaten geklärt seien. Daher paßten individuelle Versuche wie der von Lübke unternommene Vorstoß in dieser Phase nicht in das Konzept: „Spanien sollte vielmehr der letzte der drei neutralen Staaten sein, mit dem eine Vereinbarung über die Vermögensfrage abgeschlossen wird."

Noch während des Diskussionsprozesses innerhalb der beteiligten Fachressorts verschärfte Spanien die Lage dadurch, daß ein von Landwirtschaftsminister Cavestany 1954 in Bonn angekündigtes „Geschenk" in Form eines Grundstücks für den Neubau der deutschen Botschaft plötzlich von der vorherigen Anerkennung des spanisch-alliierten Vertrages von 1948 abhängig gemacht wurde. Dieser weitere taktische Schachzug, dargelegt in einer Note vom 9. November 1955, kam für das Auswärtige Amt völlig überraschend und löste Empörung aus: „Diese von Spanien nachträglich eingefügte Bedingung, von der weder bei dem Besuch Cavestanys in Bonn noch bei dem Besuch Bundesministers Lübke in Madrid die Rede war, stellt nicht nur einen Affront, sondern auch einen durchsichtigen Versuch dar, die Bundesrepublik an den Verhandlungstisch zu zwingen."

Entsprechend fiel die Reaktion der Bundesregierung aus. In einem Erlaß an die Vertretung in Madrid formulierte Staatssekretär Hallstein im Januar $1956^{111}$ den Bonner Standpunkt. Um das deutsch-spanische Verhältnis nicht über Gebühr zu belasten, sollte Außen-

${ }^{105}$ Aufzeichnung über die Ressortbesprechung Spanien am 16.8.1955, PA/AA, Ref. 506, Bd.56. Der spanische Entwurf für eine deutsch-spanische Vereinbarung war am 4. 8. vorgelegt worden.

${ }^{106}$ Aufzcichnung Berger (Leiter der Rechtsabteilung) an den Minister, 26. 10. 1955, PA/AA, Ref. 506, Bd. 56 .

1nt Diescr Vorbehalt war von grundsätzlicher Natur. Im Unterschied zu den Alliierten betrachtete dic Bundesrepublik die von ihr in Art. 5 des Überleitungsvertrages eingegangene Entschädigungsverpflichtung nicht als endgültige Reparationsregelung, die crst ein Friedensvertrag leisten könne. Vgl. dazu Kreikamp, Deutsches Vermögen in den Vereinigten Staaten, S. 53 f. Im Fall Spanien erfolgte daher auch keine Entschädigung der betroffenen Eigentümer.

108 Vgl. zu den Vermögensabkommen mit Schweden (22. 3. 1956) und Portugal (3.4. 1958) die Untersuchung von Benter, Deutsches Vermögen im neutralen Ausland, S. $67 \mathrm{ff}$. bzw. S. $40 \mathrm{ff}$. Mit der Schweiz konnte im Einklang mit den Westmächten bercits am 26.8. 1952 eine Regelung getroffen werden. Die Bundesrepublik löste die Ansprüche der Alliierten durch die Zahlung von 121,5 Mio. sfr ab.

109 Aufzeichnung Berger (Leiter der Rechtsabtcilung) an den Minister, 26. 10. 1955, PA/AA, Ref. 506, 13d. 56. Hier auch das Folgende.

110 Buch (Rechtsabteilung) an Staatssekretär Hallstein, 2. 12.1955, betr. deutsches Vermögen in Spanien, PA/AA, Ref. 206, Bd. 38.

11 Hallstein an Botschaft Madrid, 11. 1. 1956, PA/AA, Ref. 506, Bd. 57. 
minister Artajo nur mündlich darüber unterrichtet werden, daß die Bundesrepublik unter diesen Umständen Verhandlungen mit Portugal und Schweden Vorrang einräume und daran gedacht sei, nach Rücksprache mit den Drei Mächten einen deutschen Gegenvorschlag zu präsentieren. Damit war klar, daß an keine Lösung des Enteignungskonflikts zu denken war, solange Spanien auf einer "Generalabsolution “ beharrte, die lediglich die geschaffenen Tatsachen zementiert hätte. Die deutsch-spanischen Gespräche waren also zum wiederholten Male in eine Sackgasse geraten.

In diese Zeit des Stillstands fiel der von der Bundesregierung seit längerem geplante Botschafterwechsel in Madrid. Der bisherige Missionschef, Prinz Adalbert von Bayern, hatte bereits im Herbst 1955 durch Staatssekretär Hallstein von seiner bevorstehenden Ablösung erfahren. Auf die offizielle Begründung, Adenauer achte genauestens auf die Einhaltung der Altersgrenze, reagierte der Botschafter offenbar erstaunt, war doch der Bundeskanzler selbst gut zehn Jahre älter als er. In seinen Memoiren bemerkte Prinz Adalbert dazu lakonisch : „Außerdem hatte ich diese schon hinter mir, als er mich zum Botschafter ernannte." 112

Der eigentliche Grund für das Revirement war die Unzufriedenheit der Bonner Zentrale mit der politischen Inaktivität ihres Vertreters in Spanien, der es nicht vermocht habe, mit den „politisch entscheidenden Kreisen“ des Landes ins Gespräch zu kommen ${ }^{113}$. Darin implizit enthalten war wohl der Vorwurf, Prinz Adalbert denke zu sehr in dynastischen Zusammenhängen und spiele eher eine dekorative als politische Rolle. Dies war nicht neu. Schon sein damaliger Stellvertreter, Botschaftsrat Schlitter, hatte sich 1953 kritisch zu dessen Amtsverständnis geäußert: „Prinz Adalbert unterhält aber einen regelmäßigen privaten gesellschaftlichen Verkehr mit seinen Verwandten und Freunden aus dem monarchistischen Lager. Gegen diesen Verkehr könnte nach meiner Auffassung an sich nichts eingewendet werden, wenn nach der Seite der Pflege dienstlicher Beziehungen ein größeres Gegengewicht gegeben wäre." 114

Abgesehen von der Unzufriedenheit mit der persönlichen Amtsführung des Botschafters lag das Ausscheiden der Außenseiter im diplomatischen Dienst im Trend. Denn die Zeit der berufsfremden außenpolitischen Repräsentanten der ersten Stunde war allenthalben vorüber, sie hatten ihre Aufgabe erfüllt. Mit der 1955 erreichten Souveränität begann eine neue Etappe westdeutscher Außenpolitik, in deren Gefolge auch Hausenstein in Paris und Schlange-Schöningen in London durch Berufsdiplomaten ersetzt wurden ${ }^{115}$.

\footnotetext{
112 Adalbert von Bayern, Erinnerungen, S. 640.

113 Vermerk Berger über deutsches Vermögen in Spanien, 31.7.1956, PA/AA, Ref. 506, Bd. 57. Auch Franz Josef Strauß, der Prinz Adalbert 1952 bei Adenauer vorgeschlagen hatte, war rückblickend mit seiner Wahl ganz und gar nicht zufrieden. Gegenüber Außenminister Brentano sprach er harsch von dem „persönlich ehrenwerten, aber sachlich ebenso unfähigen Botschafter Prinz Adalbert". Strauß an Brentano, 14. 8. 1958, BA, Nl. von Brentano, Bd. 181.

114 Schlitter an Hallstein, 4. 8. 1953, ADL, Nl. Dehler (N 1), DA 0252. Schlitter hatte mit diesem Schreiben Staatssekretär Hallstein um eine andere Verwendung gebeten, da die Entwicklung der persönlichen Zusammenarbeit keine andere Möglichkeit zulasse. Als sein Nachfolger ging der Berufsdiplomat Rupprecht von Keller 1954 nach Madrid.

${ }_{115}$ Auch der im März 1955 verstorbene Gesandte in Lissabon, Leo Wohleb, muß strenggenommen in diese Aufzählung hineingenommen werden. Wohleb war im Dezember 1954 in Bonn über seine bevorstehende Demissionierung informiert worden. Vgl. Adalbert von Bayern, Erinnerungen, S. 618. Zwar ist eine Rotation nach 3-4 jähriger Verweildauer ein im diplomatischen Dienst durchaus übliches Verfahren. Ein solch weitreichendes Revirement ist aber dennoch ungewöhnlich.
} 


\section{Der Botschafterwechsel - Bewegung im Eigentumskonflikt}

In Madrid gab es einen Generations- und Stilwechsel. Auf den politisch unerfahrenen Prinz Adalbert folgte im Oktober 1956 der zwanzig Jahre jüngere Volkswirt Karl Heinrich Knappstein, der zuvor in Chicago als Generalkonsul sechs Jahre Erfahrungen im auswärtigen Dienst hatte sammeln können. Knappstein, wie sein Vorgänger ein „Seiteneinsteiger“, hatte zunächst die Journalistenlaufbahn eingeschlagen und von 1936 bis 1943 als Wirtschaftsredakteur für die renommierte „Frankfurter Zeitung ${ }^{\text {"116 }}$ gearbeitet. Gemeinsam mit Heinrich von Brentano war Knappstein nach dem Kriege einer der Mitbegründer der hessischen CDU gewesen. Vita und Persönlichkeit ließen ihn in den Augen Außenminister Brentanos prädestiniert erscheinen, den schwierigen deutsch-spanischen Beziehungen neue Impulse zu verleihen ${ }^{117}$. Dies galt vor allem für die Vermögensfrage. Der Knappstein nach Madrid vorausgeeilte Ruf, ein persönlicher Vertrauter - ja das Alter ego - des Außenministers zu sein, verschaffte ihm dort ein günstiges Entree ${ }^{118}$.

Bei seinem ersten Gespräch mit Außenminister Artajo brachte der neue Botschafter ohne besondere Präliminarien sogleich die Rede auf das Eigentumsproblem. Er reklamierte, „daß man aus dem Stadium rhetorischer Feststellungen über die Notwendigkeit der Bereinigung dieses Problems nun wirklich zu konkreten Verhandlungen [...] kommen müsse"119. Wenige Tage später untermauerte Knappstein in einem von Artajo angeregten Detailgespräch mit dem „Enteignungsexperten“ Navasqüés den Wunsch nach Fortschritten, in dem er erstmals Eckpunkte eines deutschen Verhandlungsprogramms skizzierte.

Demnach ging es der Bundesregierung vor allem um die Rückgabe der noch nicht liquidierten Unternehmen, die Möglichkeit des Wiedererwerbs durch die früheren Besitzer sowie die Rückgabe des kulturellen Vermögens ${ }^{120}$. Der informelle Meinungsaustausch verlief insofern ermutigend, als nach Navasqüés „privater“ Einschätzung alle Punkte bis auf einen konsensfähig seien. Das uneingeschränkte Rückkaufrecht allerdings wies er als nicht verhandelbar zurück, da das spanische Industrieschutzgesetz von 1939 eine nur 25\%ige Beteiligung ausländischer Investoren an spanischen Firmen zulasse. Insgesamt registrierte Knappstein bei seinen ersten Gesprächen auf spanischer Seite den Willen zur Verständigung, beklagte aber, wie unverbindlich die Äußerungen nach wie vor seien ${ }^{121}$.

Immerhin hatte der neue Botschafter, der in der Klärung der Eigentumsfrage seine vorrangige Aufgabe sah, das Thema wieder auf die bilaterale Tagesordnung gesetzt. Die Dinge

116 Vgl. Gillessen, Auf verlorenem Posten.

117 Der Katholik Knappstein war von Brentano zunächst auch als Botschafter beim Vatikan ins Auge gefaßt worden. Die Entscheidung für Madrid fiel dann im Juni 1956. Knappstein selbst hätte die Aufgabe beim Vatikan aus inhaltlichen wie sprachlichen Gründen Madrid vorgezogen. Vgl. Knappstein an Brentano, 6. 4. 1956, BA, Nl. von Brentano, 239, Bd. 165.

118 Diese Charakterisierung Knappsteins stammte von Brentano. Bei einem Treffen mit dem spanischen Außenminister Artajo in London hatte sich der Bundesaußenminister entsprechend geäußert. Nach seinen ersten Gesprächen in Madrid hob Knappstein die positive Wirkung hervor. Knappstein an Brentano, 5. 10. 1956, ebenda.

119 Bericht Knappsteins an das Auswärtige Amt, 10. 10. 1956, PA/AA, Ref. 506, Bd. 57.

120 Ebenda, S. 6. Als weitere Punkte nannte Knappstein die Rückgabc des noch vorhandenen spanischen Anteils am Liquidationserlös und das von Spanien bereits angebotene Grundstück für cinen Botschaftsneubau in Madrid.

121 Knappstein an Brentano, 5. 10. 1956, Nl. Brentano, Bd. 165. 
gerieten nun mehr und mehr in Fluß. Auch die Alliierten drängten jetzt auf eine Bereinigung dieses zunehmend als lästig empfundenen Problems. Im Oktober 1956 war es auf Initiative der drei Westmächte während der deutsch-portugiesischen Vermögensverhandlungen in Lissabon auch zu deutsch-spanischen Sondierungen gekommen, bei denen vereinbart wurde, die Gespräche in Madrid fortzusetzen. Darüber hinaus konnte in der portugiesischen Hauptstadt bereits das bislang größte Hindernis auf dem Wege zu direkten Verhandlungen - die Frage des Eintritts der Bundesrepublik in das Madrider Abkommen - beiseite geräumt werden: Um Spanien die Furcht vor späteren Entschädigungsansprüchen zu nehmen, bereitete man auf deutscher Seite eine Erklärung vor, die von den Westmächten als Vertragspartner des Madrider Abkommens gegenüber Spanien abgegeben werden sollte. Darin bekräftigte die Bundesregierung noch einmal ausdrücklich, daß sich die im Überleitungsvertrag (6. Teil, Art. 3) abgegebene „Hinnahmeerklärung“ auch auf die Enteignungsmaßnahmen in Spanien beziehe ${ }^{122}$. Da bei den Lissaboner Gesprächen die Westalliierten mittlerweile ihr Einverständnis mit der Auflösung des Madrider Abkommens signalisiert hatten, stand der von der Bundesregierung gewünschten Dreieckslösung eigentlich nichts mehr entgegen ${ }^{123}$. Insgesamt schienen also die Voraussetzungen für die Aufnahme von bilateralen Verhandlungen gegeben zu sein.

In Madrid wurde die deutsche Delegation im November jedoch überraschend mit Ansprüchen konfrontiert, die überwiegend Reparationscharakter hatten und nun mit der Eigentumsfrage verknüpft wurden. Die Spanier machten im einzelnen geltend:

1. „Schadensersatzforderung für im Weltkrieg versenkte Schiffe;

2. Schadensersatzforderung für Schäden der Wehrmacht an spanischem Vermögen im Kriegsgebiet;

3. Wiedergutmachungsforderungen zugunsten der auf dem Balkan lebenden sog. sephardischen Juden, die erst nach dem Kriege das spanische Bürgerrecht verliehen erhalten haben;

4. Versorgungsansprüche für Angehörige der ,Blauen Division';

5. Einräumung der Meistbegünstigung für Spanier auf dem Gebiet des Lastenausgleichs"124.

${ }^{122}$ Deutsches Vermögen in Spanien, Aufzeichnung Berger für den Minister, 24.11. 1956, PA/AA, Ref. 506, Bd. 711. Hier auch das Folgende.

${ }^{123}$ Dieses Verfahren, bei dem die Drei Mächte Spanien gegenüber in die Aufhebung des Madrider Abkommens einwilligen, war aus deutscher Sicht unabdingbar, weil das spanisch-alliierte Abkommen ein ausdrückliches Rückerwerbsverbot vorsah.

${ }^{124}$ Deutsches Vermögen in Spanien, Aufzeichnung Berger für den Minister, 24. 11. 1956, PA/AA, Ref. 506, Bd.711. Die spanische Position war in einer Note vom 31.10.1956 enthalten. Bei den sephardischen Juden handelte es sich um die in den Balkan-Ländern lebenden spanischsprachigen Spaniolen. Mit der deutschen Besetzung waren die dort lebenden Juden in die Gefahr geraten, in die Vernichtungslager deportiert zu werden. Im Februar 1943 hatte die NS-Diktatur angeboten, die Juden spanischer Herkunft von der Deportation auszunehmen, wenn Portugal und Spanien sich zur Aufnahme bereit fänden. Erst auf den energischen Druck der westlichen Alliierten und des Vatikans war das Franco-Regime zu dieser humanitären Geste bereit gewesen. Insgesamt handelte es sich um etwa 500 Personen, von denen eine Gruppe von 365 Spaniolen aufgrund des spanischen Zögerns bereits im Konzentrationslager Bergen-Belsen gewesen war. Siehe dazu ausführlich von zur Mühlen, Fluchtweg Spanien-Portugal, S. $109 \mathrm{f}$. Zum Verhältnis Franco-Spaniens zu den Juden im Zweiten Weltkrieg umfassend Rother, Spanien und der Holocaust. 
Im Auswärtigen Amt wies man diese Forderungen aus finanziellen, rechtlichen wie präjudiziellen Gründen als völlig indiskutabel zurück ${ }^{125}$.

Da es aus Bonner Sicht unklar war, inwieweit die Franco-Regierung nicht nur aus verhandlungstaktischen Gründen initiativ geworden war, wurde Botschafter Knappstein aufgefordert, Außenminister Artajo einerseits den deutschen Standpunkt in der Reparationsfrage unmißverständlich darzulegen und andererseits die Ernsthaftigkeit der spanischen Absichten auszuloten.

Knappstein wies den spanischen Außenminister Anfang Dezember 1956 darauf hin, daß das Auswärtige Amt grundsätzlich bereit sei, gemeinsam zu einer großzügigen politischen Lösung zu kommen. Die Liste mit Reparationsforderungen stelle deshalb eine „unangenehme Überraschung“ dar, welche die von beiden Seiten gewünschte rasche Einigung gefährde. Deswegen schlug er Artajo vor, daß von deutscher Seite auf eine detaillierte Erörterung der einzelnen Liquidationen verzichtet werde und Spanien seinerseits die geforderten Restitutionen als gegenstandslos betrachten solle. Ohnehin seien Reparationsforderungen für die Bundesrepublik grundsätzlich nicht annehmbar ${ }^{126}$. Vor dem Hintergrund der umfassenden Enteignung des deutschen Vermögens seien die spanischen Wünsche auch innenpolitisch niemandem in der Bundesrepublik zu vermitteln. So sah er es als völlig ausgeschlossen an, „daß das deutsche Parlament, nachdem fast das ganze deutsche Vermögen in Spanien verloren sei, zusätzliche Beträge bewilligen würde“127.

Außenminister Artajo zeigte sich gegenüber dem von Bonn angedeuteten Weg einer politischen Lösung aufgeschlossen und kündigte umgehend einen neuen Vorschlag an. Nach dem Eindruck von Knappstein beharrte die Franco-Regierung nicht mehr strikt auf ihren Reparationsansprüchen, so daß er Verhandlungen bereits im Januar 1957 für möglich hielt. Gestützt auf diese eher positive Einschätzung wurde daraufhin im Auswärtigen Amt eine Kabinettsvorlage ausgearbeitet, die der deutschen Delegation Richtlinien für die erwarteten Gespräche an die Hand geben sollte ${ }^{128}$. Um so enttäuschender wirkte schließlich die am 28. Dezember überreichte spanische Note. Inhaltlich ging das Memorandum, das abermals deutsche Reparationsleistungen mit der Eigentumsfrage verknüpfte, sogar über die im Oktober definierten Ansprüche hinaus und konterkarierte damit erneut die deutschen Hoffnungen auf eine bevorstehende Einigung.

Während in der deutschen Presse darüber geklagt wurde, daß Madrid den „Bogen zu weit gespannt“ habe und die deutsch-spanische Freundschaft einer „neuen Prüfung“ aussetze $^{129}$, reagierte das Auswärtige Amt eher nüchtern auf diesen Rückschlag. Bonn bekräf-

125 Siehe dazu zusammenfassend das Schreiben von Ministerialdirektor Berger an Bundesminister Lübke, 29. 11. 1956, PA/AA, Ref. 206, Bd. 20.

126 Bericht Knappsteins an das Auswärtige Amt, 7. 12. 1956, PA/AA, Ref. 206, Bd. 20. Zwar wurde im Auswärtigen Amt eingeräumt, daß das Londoner Schuldenabkommen (Art. 5, Abs. 3) rechtlich durchaus die Möglichkeit eröffne, Forderungen aus dem Zweiten Weltkrieg im Kontext von Abkommen über deutsche Auslandswerte zu regeln; im Falle Spanien sei dies infolge seiner rigiden Enteignungspraxis aber nicht vertretbar. Vgl. Deutsches Vermögen in Spanien. Anlage zur Kabinettsvorlage, 20. 12. 1956, PA/AA, Ref. 506, Bd. 712.

127 Bericht Knappstein, ebenda.

128 Kabincttsvorlage betr. deutsches Vermögen in Spanien, 20.12. 1956, PA/AA, Ref. 506, Bd. 711 und Anlage Bd. 712.

129 So kommentierte jedenfalls Die Welt im Januar 1957 das spanische Vorgehen. Vgl. die Ausgabe vom 30. 1. 1957 . 
tigte als Ergebnis einer „Krisensitzung“ Anfang Januar 1957 seine Weigerung, auf Reparationsansprüche einzugehen; der nächste Schritt müsse jetzt unter veränderten Vorzeichen von Madrid ausgehen ${ }^{130}$. In der internen Diskussion gab es jedoch sehr verschiedene Einschätzungen:

So wurde einerseits die spanische Haltung mit den aus dem „deutschen Wirtschaftswunder" abgeleiteten Hoffnungen auf ein großzügiges Entgegenkommen Bonns durchaus verständnisvoll in den Kontext der letzten Jahre gestellt ${ }^{131}$. Wie gering aber andererseits das Vertrauen in die Zuverlässigkeit des Franco-Regimes war, zeigen Stimmen aus Bankkreisen, die die Befürchtung äußerten, Madrid könne sich ersatzweise an deutschen Neuinvestitionen nach 1945 schadlos halten, die in einer rechtlichen Grauzone stattgefunden hatten. Gemeint war damit die mögliche Verstaatlichung von Unternehmen, die mit stillschweigender Billigung und Wissen spanischer Regierungskreise das Industrieschutzgesetz unterlaufen hatten, welches ausländische Beteiligungen nur bis zu einer Höhe von 25 Prozent zuließ.

Insbesondere größere Firmen, wie AEG oder die Nachfolgeunternehmen der IG Farben, waren nämlich mittlerweile dazu übergegangen, ihre Altbeteiligungen bzw. Niederlassungen unter der Hand wiederzuerwerben. Nach Ansicht der Bank deutscher Länder boten allein die bereits erfolgten Gesetzesverstöße den spanischen Behörden jederzeit die Möglichkeit, die entsprechenden Betriebe zu blockieren. Dieser Argumentation schloß sich auch der Vertreter der Süddeutschen Bank an, der darauf hinwies, „daß die deutschen Großfirmen fast ausnahmslos bei ihren Neuinvestitionen sich nicht um die spanische Industriegesetzgebung gekümmert hätten und sich nur oberflächlich mit Strohmännern oder zwischengeschalteten spanischen Firmen getarnt hätten "132. Daß diese Sorge letztlich doch übertrieben war, zeigte die spanische Reaktion auf die eindeutige Ablehnung aller Reparationsansprüche durch Bonn. Spanien ließ jetzt die Reparationsforderungen endgültig fallen und machte ein neues Angebot, das auch von Bonn als Basis für die im März 1957 anberaumten Verhandlungen akzeptiert wurde.

Die ersten Gespräche in Madrid verliefen jedoch wenig verheißungsvoll. Mit dem Verhandlungsführer, Botschafter Navasqüés, traf die von Ministerialdirektor Berger geleitete deutsche Delegation auf einen Gegenspieler, der in der Vergangenheit gerade die Enteig-

130 Aufzeichnung über die Ressortbesprechung betreffend beschlagnahmtes deutsches Vermögen in Spanien am 4. 1. 1957, PA/AA, Ref. 506, Bd. 712.

131 Diese Position nahm der Leiter der Rechtsabteilung Berger ein. Ebenda.

132 Bericht über die Ressortbesprechung im Auswärtigen Amt am 4. 1.1957, Historisches Archiv der Deutschen Bundesbank (HA), Frankfurt a. M., Bd. 4638. Das gesamte Ausmaß derartiger in einer Grauzone vorgenommenen Konstruktionen - mit unsicherem Kapital- und Gewinntransfer - konnte aus den amtlichen Quellen nicht erschlossen werden. Die AEG wollte jedenfals 1955 nach Angaben ihres Chefsyndikus Hellenbroich unter der Hand eine Minderheitsbeteiligung zurückerwerben. Vgl. Vermerk von Waldheim über sein Gespräch mit Hellenbroich, 17.10.1955, PA/AA, Ref. 506, Bd.56. Im Fall der IG Farben teilte Bundesminister Lübke nach seinem Spanienbesuch 1955 dem Auswärtigen Amt mit, das Unternehmen habe sich „bereits mit der spanischen Regierung geeinigt und verdiene ausgezeichnet“. Vgl. Aufzeichnung von Wclck (Leiter der Iänderabteilung) über sein Gespräch mit Lübke, 19. 10. 1955, PA/AA, Ref. 506, Bd. 56. Welche der Nachfolgegesellschaften, u. a. BASF, Bayer, Hoechst, der seit 1952 in Liquidation befindlichen IG Farben damit gemeint waren, muß offenbleiben. Die Gesamtsumme der nach dem Kricg erfolgten deutschen Neuinvestitionen in Spanien wurde im Mai 1958 vom Bundeswirtschaftsministerium mit 44 Mio. DM angegeben. Vermerk Masserer zum Besuch des spanischen Handelsminister Ullastres, 31.5. 1958, PA/AA, Ref. 206, Bd. 166. 
nungspolitik entscheidend mitgestaltet hatte und sich nun in der Sache wie im Ton entsprechend unbeweglich verhielt. Dies galt vor allem für das zentrale Anliegen Bonns, nach der Auflösung des Madrider Abkommens den von der Enteignung betroffenen Unternehmen die Chance auf einen unbegrenzten Wiedererwerb zu ermöglichen ${ }^{133}$. Das hätte allerdings an einem Grundprinzip der isolationistischen Wirtschaftspolitik Spaniens gerüttelt, nämlich der als Schutz vor Auslandsinvestitionen konzipierten 25-Prozent-Klausel des Industrieschutzgesetzes. So lag es zwar nahe, daß Navasqüés eine bevorzugte Behandlung früherer deutscher Eigentümer kategorisch zurückwies, aber als selbst der Vorschlag einer wohlwollenden Behandlung einzelner Anträge auf Wiederbeteiligung von über 25 Prozent abgelehnt wurde, gerieten die Verhandlungen in eine Sackgasse.

Einen neuen Impuls erhielten die festgefahrenen Gespräche jedoch schon bald durch die im Februar erfolgte Umbildung der spanischen Regierung. Knappstein nutzte seinen Antrittsbesuch bei dem neuen Außenminister Fernando María Castiella, um den bisherigen Mangel an spanischer Kompromißbereitschaft zur Sprache zu bringen. Castiella ließ erkennen, daß die augenblickliche Verhandlungslinie vom früheren Kabinett vorgegeben worden sei und er das Problem nun mit „neuen Augen“ betrachten wolle ${ }^{134}$. Ein erstes Indiz für eine mögliche Kurskorrektur war die kurz darauf erfolgte Ablösung des aus deutscher Sicht untragbar gewordenen Delegationsleiters Navasqüés. Der Wechsel in der Verhandlungsführung wurde von Knappstein erleichtert aufgenommen. Ihm erschien er eine „Gewähr“ dafür zu sein, „daß künftig auch auf spanischer Seite mit Kompromißbereitschaft verhandelt wird, während sich in der ersten Periode der Verhandlungen die deutsche Delegation einem völlig starren Partner gegenüber sah"135.

Auf Navasqüés folgte Ende März der Vizepräsident der Banco de España, Salmones. Da der neue Verhandlungsführer sich zunächst orientieren und die spanische Regierung ihre Position überprüfen wollte, wurden die Verhandlungen nach nur dreiwöchiger Dauer erst einmal unterbrochen. In den folgenden Monaten ging es Knappstein darum, in Vorgesprächen mit Salmones die Grenzen der spanischen Konzessionsbereitschaft auszuloten.

\section{Bonn arrangiert sich mit Madrid}

Mit positiven Eindrücken im Gepäck reiste der Botschafter schließlich im September 1957 zur Berichterstattung nach Bonn, wo eine Zwischenbilanz gezogen und das weitere Vorgehen abgestimmt werden sollte. In dieser Situation griff die Länderabteilung im Auswärtigen Amt mit einem Positionspapier in die Diskussion ein. Es zeigte sich, daß der Konflikt um das deutsche Eigentum, der bisher die bilateralen Beziehungen bestimmt hatte, dort inzwischen nur noch als ein „lästiges“ Hindernis für eine angestrebte intensivere politische Kooperation angesehen wurde. Deshalb drängte die Abteilung auf einen möglichst raschen Abschluß der Vermögensverhandlungen, da er „erst die Voraussetzung für eine

\footnotetext{
${ }^{133}$ Nach dem Vorschlag der Bundesregierung sollte den früheren Eigentümern das Recht auf vollständigen Wiedererwerb eingeräumt werden. Vgl. Telegramm von Berger und Knappstein an Auswärtiges Amt, 21. 3. 1957, PA/AA, Ref. 600, Bd. 197. Petra-Maria Weber schreibt irrtümlicherweise, die Bundesrepublik habe in den Verhandlungen von vornherein die $25 \%$-Quote akzeptiert und keine weiterreichenden Forderungen gestellt. Siehe dies., Spanische Deutschlandpolitik 1945-1958, S. 158.

134 Knappstein an Auswärtiges Amt, 25. 3. 1957, PA/AA, Ref. 506, Bd. 713.

135 Knappstein an Auswärtiges Amt, 4. 4. 1957, PA/AA, Ref. 506, Bd. 713.
} 
engere deutsch-spanische Zusammenarbeit [schaffe], an der auch deutscherseits starkes Interesse besteht" ${ }^{\text {"136. }}$.

Ausschlaggebend für diesen Perspektivenwechsel der Bonner Spanienpolitik war einerseits wohl die eigene außenpolitisch konsolidierte Position und andererseits der am UNOBeitritt Spaniens 1955 ablesbare internationale Statusgewinn der Franco-Diktatur. Mit dem Ende des UNO-Boykotts 1950 war ein Rehabilitationsprozeß eingeleitet worden, der sich zunächst in dem Stützpunktabkommen mit den USA und dem Konkordat mit dem Vatikan im Jahre 1953 ausgedrückt hatte. Davon ermutigt, betonte der Verfasser des Memorandums, Ministerialdirektor von Welck, wie unerläßlich es aus deutscher Sicht sei, Spanien jetzt in den militärischen und politisch-wirtschaftlichen Integrationsproze $\beta$ in Europa einzubinden.

Wichtiger als gewisse Interessengegensätze in der Eigentumsfrage war für Bonn die Bedeutung Madrids als antikommunistischer Partner im Ost-West-Konflikt. Der westdeutschen Diplomatie galt diese ideologische Gemeinsamkeit beider Staaten trotz der „autoritären Regierungsform“ in Spanien als mögliches Gegengewicht gegen Desintegrationstendenzen im westlichen Bündnis, die von den starken kommunistischen Parteien in Italien und Frankreich ausging. Der „zuverlässige“ Verbündete Spanien war wegen seiner geographischen Lage als „südwestlicher Eckpfeiler Europas“ auch in den Blickpunkt der militärstrategischen Überlegungen im Auswärtigen Amt gerückt. Obwohl der franquistische Staat durch die Militärabkommen mit den USA seit 1953 bereits indirekt mit dem Nordatlantikpakt verbunden war, formulierte die Politische Abteilung ihr Interesse an einer künftigen Aufnahme Spaniens in die Nato. Augenblicklich, so wurde bedauernd festgestellt, sei der Zeitpunkt, wegen der nach wie vor bestehenden Reserve einiger Nato-Staaten gegenüber der Franco-Diktatur wie vor allem Belgiens und Norwegens, noch nicht gekommen.

Ungeachtet dessen unterstrich das Positionspapier aber die Notwendigkeit, Spanien künftig als vollwertiges Mitglied in die Verteidigungsgemeinschaft zu integrieren, „weil hierdurch das politisch-militärische Potential der NATO wesentlich gestärkt werden könnte "137. Im Auswärtigen Amt wurde das diktatorische Regime Francos, trotz einiger Zweifel an seiner innenpolitischen Stabilität ${ }^{138}$, zunehmend als ein strategisch bedeutsamer Partner gegen den „weltweiten Kommunismus“ wahrgenommen. Unausgesprochen spielte dabei wohl auch der fortschreitende Dekolonisationsprozeß - vor allem in Afrika - eine gewichtige Rolle.

Vor diesem Hintergrund sollte Spanien für eine an Europa orientierte Politik wirtschaftlicher Kooperationssysteme wie die Organisation für europäische wirtschaftliche Zusammenarbeit (OEEC) und später die EWG bzw. die Freihandelszone gewonnen werden. Allerdings stand dieses Integrationsprojekt unter dem generellen Vorbehalt einer Annäherung zwischen Frankreich und Spanien ${ }^{139}$. Eine derartige Lotsentätigkeit könne für

136 Ministerialdirektor von Welck (Leiter der Länderabteilung) an Ministerialdirektor Berger, 23.9. 1957, PA/AA, Ref.506, Bd. 714. Politische Gründe für einen möglichst baldigen Abschluß der Vermögensverhandlungen. Hier auch das Folgende. Dieses Positionspapier kann als grundlegend für die Formulierung der bundesdeutschen Spanienpolitik in den folgenden Jahren angesehen werden.

137 Ebenda.

138 Vgl. ebenda. Hintergrund waren soziale Unruhen in den Jahren 1956 und 1957, die sich in Streiks und studentischen Demonstrationen ausdrückten.

139 Die französische Reserve gegenüber der Franco-Diktatur - erinnert sei nur an die Schließung der Grenze zwischen 1946 und 1948 und die gegen das Regime gerichteten Aktivitäten der in Frankreich lebenden Exilspanier - schwächten sich erst mit der Regierungsübernahme de Gaulles 1958 entscheidend ab. 
Bonn, so hoffte von Welck, überdies auch von politischem Nutzen sein: „Eine positive Einstellung der Bundesrepublik gegenüber Spanien in dem oben angeführten Sinne würde durchaus auch im Sinne unserer Verbündeten, nicht zuletzt im Interesse der Vereinigten Staaten liegen und gleichzeitig unsere eigene Stellung innerhalb des westlichen Bündnissystemes stärken. "140 Das Positionspapier beschrieb Westdeutschland als europäischen Juniorpartner der USA, der seine Spanienpolitik an der westlichen Führungsmacht orientierte, dabei aber die Hypothek, die die deutsch-spanische Vergangenheit für Politik und Öffentlichkeit im westlichen Ausland darstellte, vollkommen ausblendete.

Insgesamt verfehlte dieser politische Appell seine interne Wirkung im Auswärtigen Amt nicht, zumal selbst die zuständige Rechtsabteilung inzwischen davon ausging, daß der Eigentumskonflikt nur noch politisch gelöst werden konnte. Auch Botschafter Knappstein betonte in der Lagebesprechung Ende September besonders das außenpolitische Interesse der Bundesrepublik an Spanien. Seit dem Kabinettswechsel im Februar zeichne sich dort eine Öffnung gegenüber Europa ab, die von der Bundesrepublik honoriert werden müsse. Die Vermögensverhandlungen dürften diesen Trend nicht stören, da „Deutschland für Spanien in Europa von jeher der erstrebenswerteste Partner"141 sei.

Angesichts solcher Zukunftserwartungen verfolgte Bonn nun in der Vermögensfrage eine gegenüber Madrid verständnisvolle Politik, die das Franco-Regime nicht überfordern wollte. In seiner Zwischenbilanz konnte Knappstein zufrieden resümieren, daß jetzt alle Zeichen auf eine Einigung deuteten. In der Frage der Wiederbeteiligung der enteigneten Unternehmen, die für die deutschen Wirtschaftsinteressen von elementarer Bedeutung war, hatte die Bundesregierung notgedrungen bereits in früheren Verhandlungen ihr ursprüngliches Ziel, den Status quo ante, aufgegeben. Mittlerweile ging es nicht mehr um die Forderung einer quasi automatischen Wiederbeteiligung, sondern auf Vorschlag der spanischen Regierung nur noch darum, jeden von der Bundesrepublik vorgetragenen Einzelfall wohlwollend zu prüfen. Diese rechtlich unverbindliche Willenserklärung sollte dem deutsch-spanischen Vermögensabkommen in Form eines Briefwechsels beigefügt werden.

Im Grunde handelte es sich dabei um eine bloße kosmetische Maßnahme, die mit Blick auf die innenpolitische Optik der Bundesrepublik zwar von Bedeutung war, de facto aber waren durch die in der Vergangenheit mit stillschweigender Billigung des Franco-Regimes vollzogenen illegalen Neuinvestitionen der deutschen Altbesitzer bereits Tatsachen geschaffen worden. Mit der vom Auswärtigen Amt angestrebten Aufhebung des Madrider Abkommens sollten jetzt auch legale wirtschaftliche Investitionen möglich werden. Botschafter Knappstein wies in Bonn auf das weiterhin bestehende Industrieschutzgesetz in Spanien hin, das den Rahmen der Investitionen im Normalfall allerdings auf eine 25-Prozent-Quote begrenze. Daher sollten keine „unerfüllbaren“ Forderungen gestellt werden, über den möglichen Minimalkonsens hinaus sei nicht mehr zu erreichen: Mit dem von Madrid vorgeschlagenen Briefwechsel könne man sich um so eher zufrieden geben, „als ,in der ganzen Sache nichts mehr drinstecke' und durchaus damit zu rechnen sei, daß die spanische Regierung Anträge deutscher Unternehmer auf Wiederherstellung des Status quo ante, der ohnehin in vielen Fällen auf Umwegen oder illegal bereits erreicht sei, positiv entscheide"142.

\footnotetext{
1.40 Ebenda.

14 Aufzeichnung Ressortbesprechung Spanien am 26.9. 1957, PA/AA, Ref. 506, Bd. 714.

142 Ressortbesprechung im Auswärtigen Amt über das deutsche Vermögen in Spanien, 26. 9. 1957, HA, Bd. 4638 .
} 
Unausgesprochen spielte bei diesen Überlegungen die mit der Regierungsumbildung in Spanien - unter anderem standen an der Spitze des Finanz- und Handelsministeriums jetzt Protagonisten einer neoliberalen Wirtschaftspolitik ${ }^{143}$ - verbundene Hoffnung auf eine mögliche Neuorientierung der franquistischen Wirtschaftspolitik gleichfalls eine gewisse Rolle ${ }^{144}$. Insofern räumte das Auswärtige Amt dem Briefwechsel zur Wiederbeteiligung angesichts der möglichen Abkehr Spaniens von der Autarkiepolitik keine allzu große Bedeutung ein.

Da sich auch in der Frage der Markenrechte und Patente eine Einigung abzeichnete und Spanien bei einigen ehemaligen deutschen Immobilien Rückgabebereitschaft signalisiert hatte, erhielt Knappstein vom Auswärtigen Amt „grünes Licht“, auf dieser Grundlage die Verhandlungen baldmöglichst abzuschließen. Während die Vermögensgespräche in der Vergangenheit einem „Tauziehen“ geglichen hatten, überwog nun beiderseits der Wunsch nach einer raschen Einigung. Dementsprechend unspektakulär verlief die letzte Phase, so daß in der Tat wenige Monate später das Enteignungsthema zu den Akten gelegt werden konnte. Die am 8. April 1958 getroffenen Vereinbarungen mit der bezeichnend euphemistischen Überschrift „Abkommen über gewisse Auswirkungen des zweiten Weltkrieges“145 und dem Abkommen über die „Wiederherstellung gewerblicher Schutzrechte“ setzten den Schlußpunkt unter ein Kapitel, das das deutsch-spanische Nachkriegsverhältnis insbesondere atmosphärisch belastet hatte.

Aus dem Bündel der beiden Verträge seien hier nur die besonders interessierenden Absprachen hervorgehoben. So wurde vor allem das 1948 im Madrider Abkommen festgelegte Wiedererwerbsverbot - allerdings im Rahmen der spanischen Gesetzgebung ${ }^{146}$ - ausdrücklich aufgehoben. Die Voraussetzung hierfür war das Einverständnis der westlichen Alliierten, das Madrider Abkommen nunmehr zu liquidieren ${ }^{147}$.

14. Siehe zur grundlegenden Bedeutung der Kabinettsreform Zelinsky, Spaniens wirtschaftspolitische Wende von 1959, S. $291 \mathrm{ff}$.

${ }^{144}$ Schon im April hatte die Bundesregierung den westlichen Alliierten gegenüber derartige Spekulationen geäußert. Gemeinsam war ihnen allen das Interesse an einer erleichterten Beteiligung von Auslandskapital in Spanien. Anders als dies Petra-Maria Weber vermutet, wäre ein unbeschränktes Rückkaufrecht im deutsch-spanischen Abkommen auch nicht auf den Widerstand der Drei Mächte gestoßen. Vgl. dies., Spanische Deutschlandpolitik 1945-1958, S. 157. Vielmchr hätten die USA, England und Frankreich sich selbst gern auf diesen von der Bundesrepublik nicht durchzusetzenden Präzedenzfall bezogen: „Hätte man im gegenwärtigen Zeitpunkt die deutsche Forderung erfüllt, so wäre wahrscheinlich die amerikanische Botschaft am nächsten Morgen im Außenministerium vorstellig geworden, um gleiche Wünsche auch für die Vereinigten Staaten anzumelden. Vermutlich wären auch England und Frankreich auf diesem Wege gefolgt." Vgl. Schlußunterredung mit den Vertretern der Drei Mächte, 5. 4. 1957, PA/AA, Ref. 506, Bd. 713 .

145 Dieser Titel entsprach dem Wunsch der spanischen Regierung, die offensichtlich den Reizbegriff „deutsches Vermögen“ partout vermeiden wollte. Der deutsche Vorschlag „Abkommen über deutsche Vermögenswerte in Spanien und die Behandlung spanischer Staatsangehöriger beim deutschen Lastenausgleich zwischen der Bundesrepublik Deutschland und Spanien" konnte nicht durchgesetzt werden. Vgl. Fernschreiben Werz, Botschaft Madrid, an Ministerialdirektor Berger, Auswärtiges Amt, 18. 2. 1958, PA/AA, Ref.506, Bd.714. Vgl. zum deutschen Abkommensentwurf, 7.1.1958, PA/AA, Ref. 506, Bd. 714 .

146 Durch den bereits erwähnten Briefwechsel zum Abkommen war der Bundesregierung von Spanien eine wohlwollende Behandlung von Beteiligungsanträgen zugesagt worden.

147 Dieser verabredete Schritt wurde schließlich am 8. August 1958 in einem Protokoll fixiert. Vgl. Denkschrift zu den Abkommen, Deutscher Bundestag, 3. Wahlperiode, Drucksache 764. 
Außerdem wurden alle noch vorhandenen, bisher gesperrten deutschen Vermögenswerte freigegeben. Darunter fielen etwa 13 Unternehmen, der private Grundbesitz sowie die Bankguthaben deutscher Privatgläubiger. Ferner gingen mit den Abkommen einige der in den Besitz des spanischen Staates übergegangenen Schulen bzw. Schulgrundstücke in das Eigentum der Bundesrepublik über ${ }^{1 / 4}$.

In Bonn wurde das vorliegende Verhandlungsergebnis unterschiedlich beurteilt. Ein Positionspapier des Bundeswirtschaftsministeriums bewertete die erreichte Übereinkunft als im großen und ganzen zufriedenstellend: Das „betrübliche Kapitel der Behandlung deutschen Vermögens wird abgeschlossen, die sich hieraus ergebende Belastung der beiderseitigen Beziehungen weggeräumt. Die Vorteile für die deutschen Unternehmen liegen in der Aufhebung des Rückerwerbsverbots; außerdem ist es ihnen jetzt möglich, aus der Illegalität wieder herauszutreten, soweit sie - unter Umgehung der einschlägigen spanischen Vorschriften - ihre ehemaligen Vermögenswerte unter Einschaltung von Strohmännern bereits früher zurückerworben haben. "149 Kritisch angemerkt wurde jedoch das „unbefriedigende" Resultat in der Wiederbeteiligungsfrage, bei der Spanien lediglich eine „wohlwollende“ Behandlung zugestanden habe.

Das Auswärtige Amt hingegen bezeichnete in seiner Analyse das getroffene Arrangement sogar als die unter den gegebenen Umständen „optimale“ Lösung. Rückblickend hob man erleichtert hervor, daß es gelungen sei, die spanischen Reparationsforderungen abzuwenden, die die Vermögensgespräche doch erheblich erschwert hätten ${ }^{150}$. Ansonsten richtete sich der Blick nach vorn; zukünftig - so die Hoffnung - werde es möglich sein, den beiderseitigen Wirtschaftsaustausch auf dieser Grundlage zu verstärken.

Den politischen Gewinn sah man darin, daß die von der Bundesrepublik gewünschte Annäherung Spaniens an die europäischen Organisationen nicht weiter durch diesen bilateralen Dauerkonflikt überlagert wurde. Nachdem der bisherige "Stein des Anstoßes“ beiseite geräumt war, eröffneten sich nun neue Perspektiven für das deutsch-spanische Verhältnis.

Damit wurde die Idee eines Besuchs auf Außenministerebene wieder aktuell, die 1955 noch verworfen worden war. Botschafter Prinz. Adalbert hatte damals eine Spanienreise von Außenminister Brentano ventiliert, war aber intern auf deutlichen Widerspruch gestoßen. Sein Stellvertreter, Botschaftsrat von Keller, hatte gegenüber dem Leiter der Länderabteilung, von Welck, grundsätzlich den Sinn eines solchen Vorhabens bezweifelt. In den Augen von Keller hätten die deutsch-spanischen Beziehungen dadurch ein Gewicht erhalten, „das ihnen in Wirklichkeit nicht zukommt. Spanien treibt keine ,europäische“ und - unbeschadet seiner antikommunistischen Einstellung - auch keine , westliche' Poli-

148 Die Zahl der freigegebenen Firmen wird selbst in den offiziösen Kommentaren immer nur als ungefähre Größe angegeben. Neben den sechs Schulimmobilien crhielt die Bundesrepublik ein Grundstück in Madrid zurück, um dort ein Botschaftsgebäude zu errichten. Ungenau die Schilderung bei Niehus, die davon spricht, daß das beschlagnahmte deutsche Eigentum an seine Besitzer zurückgegeben worden sei. Niehus, Außenpolitik im Wandel, S. 464.

149 Stellungnahme zur Kabinettsvorlage des Bundesministers des Auswärtigen, Abt. VI, Bundeswirtschaftsministerium, 3. 3. 1958, BA, B 102, Bd. 24873.

150 Spanien war erst von seinen Ansprüchen endgültig abgerückt, nachdem die Bundesrepublik ihrerseits den noch nicht verteilten Liquidationserlös von ca. 6,7 Mill. DM dem spanischen Widerpart überlassen hatte. Vgl. Vorlage der Rechtsabteilung für die Kabinettssitzung, 5. 3. 1958, PA/AA, Ref. L 1, Bd. 185. 
tik. Was das Regime anstrebt, sind Prestige nach innen und außen sowie Hilfe beim Aufbau seiner Wirtschaft. Was es, in internationalen Kategorien gemessen, bieten kann, ist recht wenig; was es geben will: nichts"15!.

Im Bonner Außenamt waren die Meinungen damals geteilt. Während die Länderabteilung aus „politischen Gründen“ einen Spanienbesuch befürwortete, hielt die Rechtsabteilung einen derartigen Schritt vor dem Abschluß der Vermögensverhandlungen nicht für opportun ${ }^{152}$. Der Eigentumskonflikt hatte auch eine Anfang 1957 diskutierte Spanienreise von Bundeskanzler Adenauer verhindert. Nach dem Einwand des Auswärtigen Amts, den Reisetermin nicht mit dem Verhandlungsabschluß zu verbinden, der zu diesem Zeitpunkt kurzfristig möglich schien ${ }^{153}$, verschob der Kanzler seine geplante Visite auf unbestimmte Zeit.

Im Frühjahr 1958 hatte sich die Konstellation allerdings grundlegend verändert, jetzt konnte Bundesaußenminister Brentano auf eine bereits seit längerem vorliegende Einladung zurückkommen ${ }^{154}$. Neben Madrid stand auch Lissabon auf seinem Reiseprogramm; angesichts der gegenseitigen Empfindlichkeiten der iberischen Nachbarn wäre ein jeweils isolierter Besuch nicht in Frage gekommen ${ }^{155}$. So bot der gleichzeitige Abschluß der deutsch-portugiesischen und deutsch-spanischen Vermögensverhandlungen und die Unterzeichnung der Abkommen Bonn die willkommene Gelegenheit, den Kontakt mit beiden iberischen Ländern zu intensivieren.

Im April 1958 reiste Außenminister Brentano zur Vertragsunterzeichnung nach Madrid. Für Botschafter Knappstein war dieser Besuch der erfolgreiche Abschluß seiner Mission

151 Privatdienstliches Schreiben Keller an Welck, 3. 12. 1955, Privatarchiv Keller.

152 Welck betonte in seiner Antwort, daß dieses ungelöste Thema ein ernstes Hindernis für einen Besuch bilde. Ansonsten stünden allgemeine „politische Rücksichten“ dem kaum noch entgegen. Vgl. Welck an Keller, 23. 12. 1955, Privatarchiv Keller. Eine für das Jahr 1956 zunächst in Aussicht genommene Spanienreise wurde Anfang 1956 infolge der restriktiven Haltung Spaniens in der Enteignungsfrage verworfen. Vgl. Vermerk betr.: Mögliche Reise des Herrn Bundesministers des Auswärtigen nach Madrid und Lissabon, 4. 1. 1956, PA/AA, Ref. 506, Bd. 57.

153 Adenauer war an 10. Januar 1957 von der spanischen Regierung eingeladen worden. Das Auswärtige Amt äußerte „ernste Bedenken“ gegen den Zeitpunkt: „Nachdem Spanien den größten Teil des deutschen Vermögens liquidiert hat, können die Auswirkungen eines deutsch-spanischen Vermögensabkommens nur sehr bescheiden sein und müssen sich im wesentlichen auf die Beseitigung von Hindernissen für die künftige wirtschaftliche Betätigung beschränken. Es kann daher dem Herrn Bundeskanzler nicht zugemutet werden, ein Abkommen dieser Art persönlich zu unterzeichnen. Dies um so weniger, als das deutsch-schweizerische Vermögensabkommen, durch das Vermögenswerte von nahezu 1/2 Milliarde DM freigegeben wurden, im Jahre 1952 durch einen höheren Beamten des Finanzministeriums unterzeichnet wurde [...]." Aufzeichnung Gnodtke, 7. 2. 1957, PA/AA, Ref. 506, Bd. 712.

154 Eine offizielle Einladung war crstmals am 5. Dezember 1956 von der spanischen Regierung ausgesprochen worden. Vgl. Aufzeichnung über Besuch des Bundesministers des Auswärtigen, 26. 2. 1958, PA/AA, Ref. 203, Bd. 473.

155 Brentano bedauerte in einem Brief an Adenauer, er habe den Besuch in Lissabon bisher mit Rücksicht auf die Empfindlichkeit der spanischen Regierung zurückstellen müssen, obwohl die Beziehungen gerade zu Portugal sich sehr gut entwickelt hätten. Brentano an Adenauer, 26. 3. 1958, PA/AA, Ministerbüro, Bd. 17. Schon im Oktober 1957 hatte der deutsche Botschafter in Lissabon, Seelos, Brentano darauf hingewiesen, daß Portugal sich gegenüber Spanien von Bonn zurückgesetzt fühle. Im Gegensatz zu Spanien habe Portugal das deutsche Eigentum konserviert. Deshalb trat Seelos für einen separaten Portugal-Besuch Brentanos ein. Der Nato-Partner sei wohl außer Island der einzige europäische Nato-Staat, der noch nicht von einem Bundesminister besucht worden sei. Seelos an Brentano, 30. 10. 1957, PA/AA, Ministerbüro, Bd. 60 . 
und zugleich sein Abschied aus Madrid, da er als Stellvertreter des Staatssekretärs in das Auswärtige Amt wechselte ${ }^{156}$.

Die Bedeutung der ersten Spanienreise eines westdeutschen Außenministers lag vor allem darin, daß sie überhaupt zustande gekommen war. In der spanischen Hauptstadt ging es für beide Seiten darum, der eingetretenen Klimaverbesserung symbolischen Ausdruck zu verleihen. Charakteristisch für die Gespräche Brentanos mit seinem Amtskollegen Castiella und mit Staatschef Franco waren weniger konkrete Inhalte als vielmehr eine allgemein gehaltene außenpolitische Tour d'horizon. Ein greifbares Ergebnis war indes die an Castiella übermittelte Einladung zu einem Gegenbesuch in Bonn. Der deutsche Botschafter sah das international nach wie vor nur halbherzig akzeptierte Regime durch den Aufenthalt Brentanos entscheidend aufgewertet. Spanien habe bislang kaum bedeutsame Staatsbesuche erlebt: „Denn die zahlreichen Besuche orientalischer Herrscher und Minister wurden vom spanischen Volk nicht als echte Staatsbesuche empfunden. Der Umstand, daß der Außenminister der in der Welt geachteten und in Europa eine wesentliche Rolle spielenden Bundesrepublik Spanien besuchte, ist deshalb bis in die untersten Volksschichten mit Genugtuung verzeichnet worden “157, bemerkte Knappstein; dieser „Wendepunkt“ könne für Spanien die Tür zu engeren Beziehungen mit Europa öffnen. Der Wendepunkt war aber erst mit dem Abschluß der Vermögensfrage möglich geworden. Mit der Unterzeichnung der Abkommen am 8. April 1958 durch die beiden Außenminister ging ein jahrelanges zähes Ringen zu Ende, „eine Art Friedensschluß“158 war vollzogen.

Obwohl dieser Konflikt in seiner materiellen Dimension eher unbedeutend war, hatte er doch die bilateralen Beziehungen maßgeblich bestimmt. Für die junge Bundesrepublik war das international isolierte Spanien anfangs nur von untergeordnetem Interesse, so daß die Eigentumsfrage, die andernorts eher ein Nebenschauplatz war, auch mangels anderer politisch substantieller Themen im deutsch-spanischen „Freundschaftsverhältnis“ bis in die zweite Hälfte der 50er Jahre zwangsläufig den Hauptschauplatz bildete.

\section{Bonn als Fürsprecher Spaniens im europäischen Integrationsprozeß}

Selbst der spannungsreiche Konflikt um das enteignete deutsche Auslandsvermögen hatte an der grundsätzlichen Wertschätzung Bonns für den antikommunistischen Bündnispartner Spanien nichts geändert. Nach der anfänglichen Unsicherheit über die Zukunft des Franco-Regimes registrierte die Adenauer-Regierung mit Zufriedenheit dessen wachsende

${ }^{156}$ Brentano holte den ihm nahestehenden Knappstein in sein Ministerium, weil er auf der Führungsebene verstärkt Personen seines Vertrauens um sich haben wollte; durch eine neue Personalstruktur sollte die „Ära Brentano“ eingeläutet werden. Dahingehend äußerte sich Botschafter a. D. Guido Brunner, der im Rahmen seiner diplomatischen Ausbildung zwischen 1956 und Oktober 1957 in Madrid eng mit Knappstein zusammengearbeitet hatte. So Brunner im Gespräch mit dem Verfasser, 30. 5. 1990 (Madrid). $\mathrm{Zu}$ dem Bestreben Brentanos in der Außenpolitik gegenüber Adenauer eigene Akzente zu setzen, siehe die Studie von Kosthorst, Brentano und dic deutsche Einheit. Knappsteins Nachfolger in Madrid wurde Wolfgang Freiherr von Welck, der seit 1953 die Länderabteilung im Auswärtigen Amt geleitet hatte.

${ }^{157}$ Bericht Knappstein an das Auswärtige Amt über Spanienbesuch des Bundesministers von Brentano, 14. 4. 1958, PA/AA, Ref. 206, Bd. 163.

${ }^{158}$ So kommentierte der Westdeutsche Rundfunk am Tage der Vertragsunterzeichnung die Entcignungsregelung. Vgl. die Presseauswertung des Bundespresseamtes o. D., PA/AA, Ref. 206, Bd. 163. Dic Abkommen traten im Juni bzw. Juli 1959 in Kraft. Vgl. BGBl. 1959, II, S. 246 ff. 
internationale Akzeptanz. Mit dem Beitritt des einstmals geächteten iberischen Staates zu den Vereinten Nationen im Dezember 1955 schienen aus Bonner Sicht auch die bisherigen historisch begründeten Empfindsamkeiten des westlichen Auslands gegenüber der dortigen Diktatur in den Hintergrund getreten zu sein ${ }^{159}$. Den damit größer werdenden Spielraum ihrer Außenpolitik wollte die Bundesregierung nutzen, um dem Land den Weg in die europäische Integration zu ebnen.

In den weitgehend vom Ost-West-Konflikt bestimmten europapolitischen Vorstellungen Konrad Adenauers hatte das Spanien Francos seinen festen Platz. Bonn konnte in der zentralen Frage der Deutschlandpolitik davon ausgehen, in Madrid einen zuverlässigen Verbündeten für seinen Anspruch auf Alleinvertretung und Wiedervereinigung ohne Vorbedingungen zu haben ${ }^{160}$. Nicht von ungefähr bemühte sich der Kanzler bei seinem italienischen Parteifreund, dem christdemokratischen Ministerpräsidenten Antonio Segni, zu Beginn des Jahres 1956 darum, größere Aufmerksamkeit auf das in Europa nach wie vor politisch abseits stehende Land zu lenken. Adenauer warf die Frage auf, „weshalb man sich nicht mehr um Spanien kümmere. Franco habe dem Lande eine gewisse Stabilität gegeben, und Spanien sei für Europa zu wertvoll, um es auf die Dauer zu vernachlässigen. In der OEEC würde gegenwärtig dieses Problem diskutiert. Überall jedoch, besonders in England machten sich Widerstände bemerkbar, während man Tito wie einen König empfange"161. Mit seiner Wertschätzung für Franco sah sich Adenauer in Europa aber weitgehend isoliert und unverstanden. Bei dem ihm politisch nahestehenden Segni warb er für ein diktatorisches Regime, das ihm angesichts seiner häufigen Klagen, daß der Westen „uneinig und machtlos“ sei ${ }^{162}$, als Garant antikommunistischer Stabilität erschien. Nach dem Preis dieser "Stabilität“, der innenpolitischen Repression einer nicht-demokratischen Regierung ${ }^{163}$, fragte der Kanzler indes nicht. Sein Interesse war in erster Linie sicherheitspolitisch motiviert. Vor dem Hintergrund des Trends zur Dekolonisation in Nordafrika, der von beiden Politikern als kommunistisch gelenkt interpretiert wurde, sahen Adenauer

159 In diesem Sinne siehe die Instruktion für Botschafter Knappstein, 7. 9. 1956, PA/AA, Ref. 206, Bd. 38.

160 Das dezidiert antikommunistische Regime in Spanien wurde in dieser Frage vom Auswärtigen Amt sozusagen als ein natürlicher Partner der Bundesregierung wahrgenommen. Ebenda. Bei Besuchen spanischer Politiker gehörte es zum diplomatischen Standard Bonns, dankbar die im Rahmen der Vereinten Nationen gezeigte Unterstützung Madrids herauszustellen. Vgl. unter anderem Bulletin der Bundesregierung zum Besuch des spanischen Außenministers Castiella, 10. 11. 1959.

${ }_{161}$ Aufzeichnung eines Gesprächs Adenauers mit Segni, 8. 2. 1956, StBkAH III 54. Hier auch das Folgende. $\mathrm{Zu}$ danken ist der Stiftung Bundeskanzler-Adenauer-Haus (Rhöndorf) für die Offenlegung. Die Bundesregierung war bis zum Abbruch der diplomatischen Beziehungen mit Belgrad im Oktober 1957 selbst außerordentlich um Jugoslawien bemüht gewesen, das der DDR bis dahin die Anerkennung versagt hatte. Dies wog um so schwerer, als das Jugoslawien Titos eine wichtige Rolle in der Gruppe der blockfreien Staaten spielte, in der der Alleinvertretungsanspruch der Bundesrepublik unterschiedlich gesehen wurde. Siehe dazu Anic de Osona, Die erste Anerkennung der DDR. Ferner: Kosthorst, Brentano und die deutsche Einheit, S. 191-203; Nebelin, Adenauer, Tito und die Hallstein-Doktrin, S. 219-226.

$162 \mathrm{Zu}$ Adenauers Credo von der unabdingbaren „Geschlossenheit des Westens" vgl. Niedhart, „Damit noch eine neue Macht da ist.", S. 27-42.

16:3 Das Regime des „Caudillo" Franco bezog seine eigentliche Legitimation aus dem Sieg im offiziell 1939 beendeten Bürgerkrieg. Die Sieger vertieften bewußt die Gräben weiter, indem sie in der Nachkriegszeit „ungeheucrliche“ Vergeltung übten, „die blutige Repression erreichte im ersten Jahrzehnt nach 1939 einen in der spanischen Geschichte wohl einmaligen Höhcpunkt“. Bernecker, Krieg in Spanien, S. 213. Schätzungen gehen davon aus, daß bis zum Ende des Zweiten Weltkriegs etwa 200000 Menschen dem franquistischen Justizmord zum Opfer fielen. Vgl. Jackson, Annäherung an Spanien, S. 129. 
und Segni Europa machtpolitisch noch zusätzlich gefährdet. Gegenüber dem italienischen Ministerpräsidenten betonte Adenauer, „daß Spanien mit seinen 4-500 000 gut ausgerüsteten Soldaten für die europäische Sicherheit wichtig sei, auch wenn seiner Ansicht nach ein heißer Krieg nicht drohe"164.

Angesprochen auf das deutsch-spanische Verhältnis räumte der Kanzler ein, die Beziehungen seien augenblicklich wegen des beschlagnahmten deutschen Eigentums „etwas schwierig“. Adenauer führte dafür gleichsam entschuldigend auch den fehlenden außenpolitischen Einfluß seiner Regierung in den vergangenen Jahren an. Denn „während der Besatzungszeit, als die Bundesrepublik keine eigene Außenpolitik habe führen können, hätten sich die Franzosen und Engländer einer Pflege der deutsch-spanischen Beziehungen widersetzt"165. Mit der inzwischen erreichten Souveränität sah er nun die Chance gekommen, durch eine selbständige, von äußeren Restriktionen freie Politik das zwischenstaatliche Verhältnis zu verbessern.

Auf der europäischen Bühne ging es Adenauer zu diesem Zeitpunkt darum, hinter den Kulissen für das isolierte Spanien zu werben. Dafür fand er in seinem italienischen Kollegen einen Verbündeten. Der Gedankenaustausch mit Segni blieb aber im Ergebnis noch unverbindlich, konkrete politische Initiativen wurden nicht vereinbart. Nach weiteren $\mathrm{Ab}$ sprachen kam es allerdings im Sommer 1956 zu einem deutsch-italienischen Vorstoß, Spanien an den „Sechsergesprächen“ über die gerade entstehende „Europäische Wirtschaftsgemeinschaft" (EWG) zu beteiligen. Die gemeinsame Fürsprache zugunsten des Regimes weckte aber offenbar bei den Partnerländern unliebsame Assoziationen an die Intervention Deutschlands und Italiens im Spanischen Bürgerkrieg. Das Vorhaben stieß an politische Grenzen und blieb, wie Adenauer mit Bedauern feststellen mußte, „ohne Erfolg“166.

Einen politisch unverfänglicheren Rahmen für die von der Bundesregierung befürwortete Annäherung Spaniens an die europäischen Institutionen bot die „Organization for European Economic Cooperation“ (OEEC), in deren Gremien zur selben Zeit über einen spanischen Beitritt diskutiert wurde. Die OEEC ${ }^{167}$ mit Sitz in Paris war im April 1948 als Ko-

Auch wenn sich das Herrschaftssystem in Spanien im Lauf der Zcit graduell wandelte, die diktatoriale Struktur - Fehlen allgemeiner freier Wahlen, Einheitspartei des „Movimiento Nacional“, Führerprinzip, Zensur der Massenmedien etc. - blieb dauerhaft.

164 Gespräch Adenauer mit Segni, 8. 2. 1956, StBkAH III 54.

163 Ebenda.

166 Vgl. dazu Adenauer, Erinnerungen, S. 261. Näheren Aufschluß zu dieser „Spanien-Initiative“ könnten erst die für die allgemeine Forschung bis heute unzugänglichen Quellen aus dem Adenauer-Nachlaß sowie dem Bestand „Büro Staatssekretär“ im Auswärtigen Amt bieten. Obwohl der hohe Aussagewert der Adenauer-Memoiren bekannt ist, wird dieser Nebenstrang seiner Europapolitik in der Literatur nicht gewürdigt, was seinen Grund darin haben mag, daß Spanien im Rahmen der europäischen Nachkriegsgeschichte bislang nur wenig Beachtung gefunden hat. Auch Hans-Peter Schwarz, der eben dieses SpanienEngagement zwar berücksichtigt und als „Bild selbstbewußter Insensibilität gegenüber der jüngsten Vergangenheit" beschreibt, stützt sich bei seiner Interpretation allein auf die Erinnerungen Adenauers. Vgl. Schwarz, Adenauer. Der Staatsmann, S. 290. Henning Köhler geht auf diesen Aspekt der Europapolitik Adenauers nicht ein. Vgl. Köhler, Adenauer. Eine politische Biographie. Spanien bemühte sich seinerseits erst seit den sechziger Jahren um eine Annäherung an den „Gemeinsamen Markt“, 1962 erfolgte ein Antrag auf Assoziation an die EWG, der im Jahre 1970 lediglich zu einem Präferenzabkommen führte. Vgl. dazu Hommel, Spanien und die Europäische Wirtschaftsgemeinschaft.

167 In der Bundesrepublik wurde die Pariser Organisation offiziell zunächst als „Organisation für europäische wirtschaftliche Zusammenarbeit“ bezeichnet, scit Ende 1951 als „Europäischer Wirtschaftsrat“. In der Praxis blieb man meist bei der englischen Bezeichnung. 
ordinationsorgan der Marshallplanhilfe gegründet worden und sollte darüber hinaus - ohne jedoch supranationale Befugnisse zu haben - eine gemeinsame Wirtschaftspolitik ihrer 17 Mitgliedstaaten entwickeln. Dieser europäische Zusammenschluß hatte Westdeutschland nach Kriegsende die Möglichkeit eröffnet, auf internationaler Ebene die ersten außenpolitischen Gehversuche zu unternehmen ${ }^{168}$. Dagegen blieb Spanien wegen seines undemokratischen Regierungssystems von dem Wiederaufbauprogramm ausgeschlossen. Die Annäherung an die Pariser Organisation wurde durch die „Konferenz landwirtschaftlicher Absatzmärkte“ (KLA) eingeleitet, an der sich Spanien seit 1953 zusammen mit den Staaten der OEEC beteiligte. Die KLA war im Juli 1954 übereingekommen, ihre Arbeit innerhalb der OEEC als „Ministerausschuß für Ernährung und Landwirtschaft“ fortzusetzen. Durch diese „Hintertür" gelangte Spanien schließlich im Januar 1955 auch in den Kreis der OEEC. Zwei Monate später genehmigte der Ministerrat der OEEC die Bildung einer ständigen Vertretung Spaniens ${ }^{169}$. Damit stand die Frage einer möglichen Mitgliedschaft im Raum.

Während der Kanzler die Anbindung Spaniens an die europäischen Institutionen in erster Linie unter sicherheitspolitischen Vorzeichen betrachtete, lavierte die Bonner Regierung hier zwischen politischer Unterstützung und der Sorge vor der Hereinnahme eines weiteren „armen “Landes in die „geschlossene Gesellschaft" der OEEC ${ }^{170}$. Überdies herrschte die Sorge, die strukturellen Unterschiede in der Wirtschaftspolitik seien noch nicht miteinander zu vereinbaren: „Es ist schlechterdings nicht möglich, ein Land mit grundsätzlich dirigistischer Wirtschaftspolitik in eine völkerrechtliche Vereinigung von Ländern mit wirtschaftlich liberaler Grundtendenz aufzunehmen, deren Zweck und Ziel zudem die Herbeiführung der vollen Freiheit des Handels- und Zahlungsverkehrs ist, es sei denn, das aufzunehmende Mitgliedsland stellt seine gesamte Wirtschaftspolitik auf die Grundregeln der völkerrechtlichen Vereinigung um." ${ }^{171}$ Diese Hoffnung erfüllte sich jedoch erst im Jahre 1959. Auf dem Weg dahin stand die Bundesregierung Spanien allerdings zur Seite. Trotz aller Skepsis förderte sie weiter den Beitritt des südeuropäischen Landes, der nach ihrer Überzeugung "politisch und geographisch eine wünschenswerte Abrundung"172 der OEEC bedeute.

Die politische Struktur des Franco-Regimes war hingegen für den „Internationalen Bund Freier Gewerkschaften“ (IBFG) Grund genug zu intervenieren. Im Januar 1956

168 Siehe zu den außenpolitischen Anfängen der Bundesrepublik Bührer, Auftakt in Paris, S. 529-556; ders., Westdeutschland in der OEEC. Schon bevor die Bundesrepublik am 31. Oktober 1949 offiziell Mitglied wurde, hatten deutsche Repräsentanten gemeinsam mit Engländern und Amerikanern die Vertretung der Bi-Zone bei der OEEC gebildet. Zum „European Recovery Program“ siehe Hardach, Der Marshall-Plan.

169 Vgl. entsprechend Viñas u. a., Política comercial exterior en España (1931-1975), 2 Bde., Bd. 2, S. 834. Bis auf Island waren an der KLA alle OEEC-Staaten beteiligt.

170 Bundesfinanzministerium an Bundesministerium für wirtschaftliche Zusammenarbeit betr. Aufnahme Spaniens in die OEEC, 2. 12. 1955, BA, B 146, Bd. 734. Auch das Auswärtige Amt äußerte wirtschaftliche Bedenken, es wurde warnend an das wirtschaftlich schwache OEEC-Mitglied Türkei erinnert. Vgl. Niederschrift Ressortbesprechung im Bundesministerium für wirtschaftliche Zusammenarbeit betr. einen etwaigen Beitritt Spaniens, 6. 12. 1955, BA, B 146, Bd. 734. Das Bundesministerium für wirtschaftliche Zusammenarbeit besaß die Federführung in OEEC-Fragen. Es war 1953 aus dem Marshallplanministerium hervorgegangen.

171 Bundesfinanzministerium an Bundesministerium für wirtschaftliche Zusammenarbeit, 2. 12. 1955, BA, B 146, Bd. 734.

172 Niederschrift Ressortbesprechung im Bundesministerium für wirtschaftliche Zusammenarbeit, 6. 12. 1955, BA, B 146, Bd. 734. Damit begründete Staatssckretär Dahlgrün die positive Haltung seines Ministeriums. 
drohten die Gewerkschaften, im Falle einer engeren Kooperation der OEEC mit Spanien ihre Mitarbeit in den Gremien der Organisation einzustellen ${ }^{173}$. Die deutsche Vertretung ging zwar von einer unveränderten Position der Bundesregierung aus, bat aber dennoch um Weisung, wie zukünftig zu verfahren sei. Für Bonn war denn auch der gewerkschaftliche Protest kein Anlaß, von seiner spanienfreundlichen Haltung abzurücken. Nach einem Kabinettsbeschluß wurde die deutsche Delegation im Februar angewiesen, die bisherige Politik fortzuführen ${ }^{174}$. Die Einwände des IBFG blieben insgesamt folgenlos, die Außenminister der OEEC-Staaten betonten im Exekutivausschuß, die spanische Frage sei eine ,politische Entscheidung“, die allein von den Regierungen getroffen werden müsse ${ }^{175}$. Dort stand nicht mehr das $\mathrm{Ob}$, sondern nur noch das Wie zur Diskussion.

Gelegenheit zu weiterer Klärung gab es in Paris am 5. Oktober 1956 in einer Sitzung des OEEC-Rats. Auf der Grundlage eines von Spanien selbst angeregten Berichts der OEEG über die wirtschaftliche Situation des Beitrittsaspiranten entspann sich ein grundsätzlicher Meinungsaustausch über die Form, in der sich das Land der Pariser Organisation anschließen sollte. Die dem Rat vorliegende Alternative der OEEC-Arbeitsgruppe lautete „Assoziation“ oder „Vollmitgliedschaft"176. Politische Bedenken gegen das Franco-Regime spielten in diesem Gremium nur eine untergeordnete Rolle. Die entscheidende Frage war für die Mehrheit, wie und in welchem Tempo Spanien in die multilaterale europäische Wirtschaftsstruktur integriert werden könnte. Allein die Niederlande ${ }^{177}$ und Belgien lehnten bereits eine Assoziation ab. Sie wollten Spanien lediglich den vollen Beobachter-Status einräumen. Der belgische Delegierte erinnerte in einer persönlichen Stellungnahme an die politischen Differenzen mit Spanien. Eine Partnerschaft sei vor allem aufgrund des noch schwebenden Falles Léon Degrelle ${ }^{178}$ in der OEEG nicht ohne weiteres vorstellbar.

173 Vertretung der Bundesrepublik Deutschland bei der OEEC an Bundesministerium für wirtschaftliche Zusammenarbeit betr. Zusammenarbeit mit den internationalen Gewerkschaften, 21. 1. 1956, BA, B 146, Bd. 734 .

174 Vertretung der Bundesrepublik Deutschland bei der OEEC an Bundesministerium für wirtschaftliche Zusammenarbeit, 8.8. 1956, BA, B 146, Bd. 734. Die Frage war am 8. Februar im Kabinett erörtert worden. Dabei hatte man sich der Auffassung von Vizekanzler Franz Blücher angeschlossen, daß es nicht angehe, Spanien im „Hinblick auf den Einspruch des Internationalen Gewerkschaftsbundes in der OEEC auszuschließen“. Vgl. Die Kabinettsprotokolle der Bundesregierung, Bd. 9, 1956, S. 172 f.

${ }_{175}$ Vertretung der Bundesrepublik Deutschland bei der OEEC an Bundesministerium für wirtschaftliche Zusammenarbeit betr. Exekutivausschuß auf Ministerebene, 2. 3. 1956, BA, B 146, Bd. 734.

176 Bericht der Vertretung der Bundesrepublik Deutschland bei der OEEC über die 341. Sitzung des Rates vom 5. 10. 1956, PA/AA, Ref. 412, Bd. 246. Hier auch das Folgende.

177 Bei den Vorbehalten in den Niederlanden gegen das Regime in Spanien spielten atmosphärisch wohl auch historische Ressentiments eine Rolle. Ursache dafür war die gemeinsame Geschichte beider Länder, vor allem der Aufstand der protestantischen Niederlande gegen das sie beherrschende katholische Spanien im 16. Jahrhundert.

${ }_{178}$ Belgien hatte sich wiederholt ohne Ergebnis um die Auslieferung des in Spanien lebenden Gründers der faschistischen „Rex-Bewegung“ bemüht. Degrelle war in Belgien in Abwesenheit zum Tode verurteilt worden. Siehe dazu Wippermann, Europäischer Faschismus im Vergleich 1922-1982, S. $149 \mathrm{ff}$. Zu seinem Werdegang nach 1945 vgl.: Der Spiegel, Nr. 43, 21. 10.1959, S. 72 ff. Das im Zweiten Weltkrieg wie die Niederlande von Deutschland überfallene Land lehnte das Franco-Regime grundsätzlich als Geschöpf der faschistischen Partner Deutschland und Italien ab. Belgien war neben Mexiko - das viele republikanische Flüchtlinge beheimatete - der einzige Staat, der sich 1955 bei der Aufnahme Spaniens in die UNO der Stimme enthalten hatte. Außenminister Spaak begründete seine Haltung mit der Zusammenarbeit Spaniens mit Hitler und Mussolini während des Krieges. Adenauer an Bundesminister für wirtschaftliche Zusammenarbeit Blücher, 22. 2. 1956, BA, B 136, Bd. 6385 (Bd. 2). 
Auch sei das Ziel einer Vollmitgliedschaft Spaniens in Brüssel gegenwärtig „unerwünscht“. Demgegenüber plädierte die Bundesrepublik ebenso wie die meisten Mitgliedstaaten für eine enge Zusammenarbeit, die angesichts der wirtschaftlichen Situation Spaniens zunächst jedoch nur als Assoziation vorstellbar sei. Das eigentliche Ziel aber blieb aus deutscher Sicht die volle Mitgliedschaft Spaniens. Bevor daran gedacht werden konnte, galt es zunächst, die Modalitäten einer engeren Verbindung zu untersuchen. Eine Arbeitsgruppe der OEEC sollte gemeinsam mit Madrid die politischen und wirtschaftlichen Voraussetzungen für eine Assoziation ausloten. Die im Januar 1957 begonnenen Gespräche mündeten dann in Verhandlungen. Am 10. Januar 1958 wurde in Paris schließlich ein Assoziationsabkommen unterzeichnet, das Spanien dazu verpflichtete, die von der OEEC angestrebten wirtschaftlichen Ziele zu übernehmen ${ }^{179}$. Damit war das Ende der Autarkiepolitik nähergerückt.

In der OEEC ging man davon aus, daß Spanien erst allmählich in die wirtschaftlichen Strukturen der Gemeinschaft hineinwachsen würde. Dagegen forcierten marktwirtschaftlich orientierte Kreise des Franco-Regimes das Integrationstempo, indem sie die prekäre wirtschaftliche Lage des Landes als Argument nach innen und außen nutzten. Die politisch konservativen, aber wirtschaftlich „neoliberalen“ Technokraten, deren Einfluß mit der Kabinettsumbildung im Februar 1957 größer geworden war ${ }^{180}$, gingen davon aus, daß die Stabilisierung und der von ihnen beabsichtigte ökonomische Kurswechsel nur mit Hilfe des Auslands gelingen könne. Daher strebten sie eine rasche Vollmitgliedschaft in der OEEC an. In der Bundesregierung fanden die Wirtschaftsreformer einen Verbündeten. Bei seinem Deutschlandbesuch traf der spanische Handelsminister Alberto Ullastres, einer der Exponenten einer marktwirtschaftlichen Politik, im Juni 1958 auf viel Verständnis. Die Frage des OEEC-Beitritts stand im Mittelpunkt der Gespräche mit Bundeswirtschaftsminister Erhard. Bonn reagierte auf den Wunsch nach einer Finanzhilfe entgegenkommend, verwies aber auf den multilateralen Rahmen der Pariser Organisation. Erhard sicherte seinem Gast zu, es sei das Bestreben der Bundesregierung, „Spaniens Bemühungen um einen möglichst reibungslosen Übergang vom bilateralen zum multilateralen Handelsverkehr zu unterstützen und innerhalb der OEEC ihr Gewicht für eine Kredithilfe geltend zu machen “181. Aus der Unterstützung für die Wirtschaftsreformer leitete Bonn zunächst aber keine Hoffnungen auf einen politischen Wandel in Spanien ab ${ }^{182}$.

179) $\mathrm{Zu}$ den einzelnen Schritten im Verhältnis zwischen Spanien und der OEEC vgl. Hommel, Spanien und die Europäische Wirtschaftsgemeinschaft, S. 109-135.

180 Zur Bedeutung des Revirements für den wirtschaftspolitischen Wandel und der Rolle des katholischen Laienordens „Opus Dei“ als einer Modernisierungselite des spanischen Regimes siehe Zelinsky, Spaniens wirtschaftspolitische Wende von 1959, S. 288-294.

${ }_{181}$ Vermerk über Besprechungen zwischen Erhard und Ullastres, 18. 6. 1958, HA, Bd. 7526.

182 Aus den deutschen Quellen wird zwar Sympathie für die "Reformer“ in Madrid deutlich, weitergehende Schlußfolgerungen aus dem sich abzeichnenden ökonomischen Kurswechsel wurden dabei aber nicht gezogen. Das später in der öffentlichen Diskussion um Spanien häufig verwendete Argumentationsmuster, daß auf die wirtschaftliche Liberalisierung zwangsläufig eine Demokratisierung des politischen Systems folgen müsse, läßt sich gegen Ende der 50er Jahre für die Bundesrepublik noch nicht nachweisen. Walther L. Bernecker weist darauf hin, daß diese Annahme im Fall Spanien, wie auch in anderen autoritären Regimen, ohnehin auf einer falschen Prämisse beruhe: „Zu lange wurde übersehen, daß die Teilliberalisicrungen der 60er Jahre und die Beschleunigung des wirtschaftlichen Wachstums nicht auf die Überwindung des Autoritarismus, sondern gerade auf seine Stabilisierung zielten." Bernecker, Ein Interpretationsversuch: Der Franquismus - ein autoritäres Modernisierungsregime?, S. 411. 
Die von Spanien benötigte finanzielle Unterstützung setzte aus Sicht der OEEC allerdings eine radikale Wende der spanischen Wirtschaftspolitik voraus. Auf dieser Geschäftsgrundlage verdichteten sich zwischen Herbst 1958 und Frühjahr 1959 die Kontakte auf der Expertenebene ${ }^{183}$. Dabei nutzten die neoliberalen Kräfte in Spanien die Analysen der internationalen Sachverständigen als „Hebel“, um die innenpolitischen Widerstände namentlich von Staatschef Franco zu brechen ${ }^{184}$. Durch dieses Zusammenspiel konnte ein Sanierungsprogramm auf marktwirtschaftlicher Basis entwickelt werden, das der OEEC als „Stabilisierungsplan" im Juni 1959 vorgelegt wurde. Das spanische Autarkiemodell fand somit nach zwanzig Jahren sein Ende, die sogenannte kopernikanische Wende des Franquismus war vollzogen.

Nun konnte Spanien, das am 16. Mai 1959 einen Antrag auf Vollmitgliedschaft gestellt hatte, mit finanzieller Starthilfe rechnen. Gedacht war an ein Kreditvolumen von 200-220 Millionen US-Dollar, das von dem Internationalen Währungsfonds, amerikanischen Privatbanken sowie einer Gruppe europäischer Länder, darunter auch der Bundesrepublik, aufgebracht werden sollte ${ }^{185}$. Am 20.Juli 1959 stimmte der OEEC-Ministerrat dem Aufnahmeantrag Spaniens zu. Der Leiter der deutschen OEEC-Vertretung begrüßte das neue Mitglied mit Pathos: „Anschließend gab ich der Befriedigung der Bundesregierung über den Beitritt Spaniens Ausdruck, durch den erst der Europäische Wirtschaftsrat seinen Namen einer Organisation europäischer wirtschaftlicher Zusammenarbeit verdiene. Spanien gehöre kulturell, wirtschaftlich und politisch zu Europa, das insgesamt aus den wechselseitigen Beziehungen nur Nutzen ziehen könne. "186

\section{Die Idee des "christlichen Abendlandes" als Faktor deutsch-spanischer Gemeinsamkeit}

Die Überzeugung, daß das Spanien Francos zur Wertegemeinschaft des „freien Westens“ gehöre, gründete sich auf das christlich-abendländische Gedankengut, von dem im konservativen Spektrum der frühen Bundesrepublik häufig die Rede war. Dabei knüpfte man an die Abendland-Diskussion nach dem Ersten Weltkrieg an ${ }^{187}$. Der von Oswald Spengler diagnostizierte „Untergang des Abendlandes“(1918/1922) hatte damals unter Intellektuellen eine Debatte entfacht, in der vor allem die katholische Publizistik für eine christliche Erneuerung Europas eingetreten war.

\footnotetext{
183. Missionen der OEEC und des IWF, dem Spanien im Mai 1958 beigetreten war, reisten in rascher Folge nach Madrid. Vgl. zu diesem permanenten Dialog Hommel, Spanien und die Europäische Wirtschaftsgemeinschaft, S. 124-133.

184 Vgl. Zelinsky, Spaniens wirtschaftspolitische Wende von 1959, S. $296 \mathrm{ff}$. So berichtete auch die deutsche Botschaft in Madrid im April 1959: „Es bleibt spanischer Regierung kaum anderer Weg akute Zahlungsbilanzschwierigkeiten zu überwinden, als Beitritt zur OEEC. Unzweifelhaft bestanden starke Widerstände gegen von OEEC und IWF geforderte Maßnahmen, die vor allem auf Franco, Ministerpräsident Suances und Interessentenkreise zurückgingen." Botschaft Madrid an Auswärtiges Amt, 7.4.1959, PA/AA, Ref. 401, Bd. 346.

185 Bericht des Leiters der Außenwirtschaftsabteilung im Bundeswirtschaftsministerium Reinhardt an Minister, 9. 7. 1959, PA/AA, Ref. 401, Bd. 346.

${ }_{186}$ Bericht der Vertretung der Bundesrepublik Deutschland bei der OEEC, 23. 7. 1959, BA, B 102, Bd. 1150.

187 Vgl. zur Kontinuität der Diskussion Hürten, Der Topos vom christlichen Abendland in Literatur und Publizistik nach den beiden Weltkriegen, S. 131-154.
} 
Nach der vom Nationalsozialismus pervertierten Nationalstaatsidee hatte in der Zeit des Kalten Krieges in Westdeutschland ein Europabild Konjunktur, das Europa bzw. das mit ihm gleichgesetzte Abendland vor allem als Bollwerk gegen den Kommunismus ansah. Nach dem Ende des Zweiten Weltkrieges wurde die Parole „Christliches Abendland“ zum ideologischen Leitbegriff einer ,weltanschaulich durch den Antibolschewismus bestimmten Europapolitik vorwiegend katholischer Prägung"188. Konrad Adenauer, einer der maßgeblichen Protagonisten dieser Politik, beanspruchte 1949 für die Arbeit der von ihm geführten Regierung „den Geist christlich-abendländischer Kultur"189. Außenpolitisch bedeutete das für ihn, daß der Abwehrwille gegen den Weltkommunismus gestärkt werden müsse. Nur wenn sich Europa zusammenschließe ${ }^{190}$, „könne es ein Damm gegen die rote Flut sein "191, mahnte er im Februar 1951 seine Partei. Der Abendland-Begriff bot dabei ein Vehikel für eine gegen den Kommunismus gerichtete „Sammlungspolitik“, die auch autoritäre Regime einschließen konnte. Mit der Beschwörung der Gefahr, die Europa durch den aggressiven Bolschewismus drohe, konnte Adenauer auf bereits seit den zwanziger Jahren bekannte antibolschewistische Denkmuster zurückgreifen. Schon die durch den Spanischen Bürgerkrieg seit 1936 verstärkte antisowjetische NS-Propaganda fand für ihre Losung „Deutschland - das antibolschewistische Bollwerk des Abendlandes"192 ein wohlbestelltes Terrain vor. Als Bestandteil des weithin verbreiteten Antibolschewismus half das vieldeutige Schlagwort vom „Abendland“ dem NS-Regime bei der geistigen Mobilmachung der deutschen Gesellschaft gegen die Sowjetunion ${ }^{193}$. So recht-

188 Vgl. den Abendland-Artikel von Wolf, in: Die Religion in Geschichte und Gegenwart Bd. 1, S. 9. Nach der Auffassung von Wolf fehlte diesem Terminus jede präzise Bestimmung. Gerade diese inhaltliche Vagheit machte ihn „aus dem Nenner für eine mehr empfundene als nachweisbar geistig-religiöse Einheit zum ideologischen Leitwort einer ,christlichen' und ,europäischen' Politik". Ebenda. Vgl. außerdem den ausführlichen Beitrag von Oskar Köhler, in: Theologische Realenzyklopädie Bd. 1, S. 17-42. Zum Abendland-Gedanken auf protestantischer Seite, namentlich bei dem konservativen Publizisten Hans Zehrer, siehe Schildt, Deutschlands Platz in einem "christlichen Abendland", S. 344-369. Zum Stellenwert der Abendland-Idee im „Geist der 50er Jahre“" Schwarz, Die Ära Adenauer. Gründerjahre der Republik, S. $455 \mathrm{f}$. Aus ideengeschichtlicher Sicht: Faber, Abendland. Ein „politischer Kampfbegriff“; Grebing, Konservative gegen die Demokratie, S. 263-282.

${ }^{189}$ Adenauer, Erinnerungen, S. 243. Zur „abendländischen“ Haltung Adenauers siehe: Schwarz, Adenauer und Europa, S. 476 f; Weidenfeld, Konrad Adenauer und Europa; Doering-Manteuffel, Rheinischer Katholik im Kalten Krieg, S. 237-246.

${ }^{190}$ In der frühen Bundesrepublik wurde der spanische Philosoph José Ortega y Gasset vielfach öffentlich als bedeutsamer Prophet einer europäischen Einigung gewürdigt. Seine große Popularität vor allem in den 50er Jahren - das Buch „Aufstand der Massen“ ist eines der wohl meistgelesenen wissenschaftlichen Werke in der Bundesrepublik - verdankte Ortega nicht nur seinem Europäertum. Der Verehrer Deutschlands übernahm in seinem Alter - 1949 war er 68 Jahre alt - gewissermaßen die Rolle des „Lehrmeisters", der nicht „das schlechte Gewissen und die Strafangst (verkörperte), vor denen die Deutschen sich verkrochen. Er machte keine Vorwürfe, sondern Mut". König, Ortega und die Bundesrepublik, S. 244. Schildt, Moderne Zeiten, S. 327 f.

191 Adenauer vor dem Parteiausschuß der CDU, 12. 2. 1951, vgl. Weidenfeld, Konrad Adenauer und Europa, S. 178.

192 Ruffmann, Schlüsseljahre im Verhältnis zwischen dem Deutschen Reich und der Sowjetunion, S. 7.

193 Reinhard Rürup weist in dem Begleitband zur Ausstellung „Der Krieg gegen die Sowjetunion 1941-1945“ darauf hin, daß die Sowjetunion „für die große Mehrheit der Bevölkerung das ,Feindbild Nr. 1': cine Gefahr für Staat und Gesellschaft, für Religion und Kultur, für Familie und Jugend" gewesen sei. Rürup, Der Krieg gegen die Sowjetunion, S. 12; siehe auch Wette, Ideologien, Propaganda und 
fertigten auch Teile des katholischen Episkopats den deutschen Überfall im Juni 1941 als „Befreiungskrieg“, ein Bischof übernahm gar die nationalsozialistische Terminologie, wenn er von einem europäischen „Kreuzzug“ gegen den Bolschewismus sprach ${ }^{194}$. Dieses Argumentationsmuster wandelte sich notgedrungen mit dem militärischen Verlauf des Krieges.

Unter dem Eindruck des Menetekels von Stalingrad wurde in der NS-Propaganda seit Anfang 1943 der „Befreiungskrieg“ zum „Verteidigungskrieg“ uminterpretiert. Von nun an galt es aus taktischen Gründen, die „Abwehr des Bolschewismus“ zu mobilisieren, um mit einer neuen Sinngebung den Krieg zu rechtfertigen. Dabei griff der NS-Chefpropagandist Joseph Goebbels in seiner „Sportpalast“-Rede wiederum zu dem Abendland-Topos, der jetzt für den „totalen Krieg“ instrumentalisiert wurde. „Das Abendland ist in Gefahr"195, behauptete Goebbels. Knapp drei Wochen zuvor hatte der Propagandaminister an derselben Stelle seine Zuhörer beschworen, der Kampf gegen die Sowjetunion sei nicht nur „ein Ringen um die Freiheit und Sicherheit der deutschen Nation, sondern eine gigantische Auseinandersetzung um das künftige Schicksal Europas - ja des ganzen zivilisierten Abendlandes" 1966 .

Die antikommunistischen Stereotypen der Nachkriegszeit blieben dieser Tradition verhaftet, vermittelten aber durch ihren defensiven Charakter „eine nach 1945 unvermeidbare Distanzierung vom offensiv-kriegerischen Antikommunismus und Antisowjetismus des „Dritten Reiches“197. Zugleich konnte direkt an die seit 1943 verbreiteten Bedrohungsperzeptionen angeknüpft werden, ohne jedoch die deutsche Aggression von $1941 \mathrm{zu}$ benennen. Die in der dezidiert antikommunistisch geführten politischen und publizistischen Debatte der frühen 50er Jahre häufig als „Mission des Abendlandes“ apostrophierte Frontstellung Westdeutschlands gegen den Weltkommunismus festigte ideologische Affinitäten mit Franco-Spanien. So fand das autoritäre Regime, das sich nach 1945 verstärkt auf seinen „vorbildlichen Katholizismus“ berief und Staatschef Franco zum „Wächter des Abendlandes" 198 stilisierte, zumindest im konservativen Spektrum der Bundesrepublik rege und wohlwollende Aufmerksamkeit.

Dies galt vor allem für das bildungsbürgerliche katholische Lager um die seit 1946 in Augsburg erscheinende Zeitschrift „Neues Abendland“. Aus diesem Kreis ging 1951 in München die „Abendländische Aktion“ hervor. Die auf Initiative von Fürst Georg von Waldburg zu Zeil und Trauchburg, dem Finanzier des „Neuen Abendlandes“, entstandene

Innenpolitik als Voraussetzungen der Kriegspolitik des Dritten Reiches, S. 25-166; Sywottek, Mobilmachung für den totalen Krieg:

${ }_{194}$ Zum Rußlandbild der katholischen Kirche siehe Smolinsky, Das katholische Rußlandbild in Deutschland nach dem Ersten Weltkrieg und im „Dritten Reich“, S. 348-355.

195 Goebbels-Rede am 18.2. 1943 im Berliner Sportpalast, auszugsweise in: Rürup, Der Krieg gegen die Sowjetunion, S. 182.

196 Rede anläßlich des 10. Jahrestages der „Machtergreifung“ am 30. 1. 1943 im Berliner Sportpalast, zitiert nach Elvert, „Germanen“ und „Imperialisten“, S. 164-184.

197 Albert/Niedhart, Vom System- zum Machtkonflikt: Dic Sowjetunion in der westcleutschen Bedrohungswahrnehmung, S. 73.

${ }_{198}$ Vgl. dazu Fusi, Franco, S. 98-123. Der nach 1945 mehr in den Vordergrund gerückte Katholizismus des Franco-Regimes und die damit verbundene Abendland-Ideologie trugen maßgeblich zu seiner internationalen Aufwertung bei. Vgl. Bernecker, Spanien. Zwischen Isolation und Integration, S. $151 \mathrm{ff}$. 
Aktion strebte „eine Erneuerung der in Verfall geratenen abendländischen Welt aus dem Geiste christlichen Glaubens“199 an. Dazu wollte sie ,alle Kräfte zusammenfassen, die einem weiteren Vordringen von Atheismus, Nihilismus und Bolschewismus entgegenzutreten entschlossen sind"(Paragraph 1 der Satzung). Der Blick der Abendländer war rückwärts gerichtet. Die alte christlich-universale Ordnung sollte durch ein „abendländisches Kaisertum" nach dem Vorbild des Heiligen Römischen Reiches wiederhergestellt werden. Die Befürworter der kaiserlichen Restauration hatten es vermocht, diesen Gedanken im „Manifest“ der Aktion festzuschreiben. Es forderte als „ein Ziel abendländischer Erneuerung die Wiederherstellung kaiserlicher Gewalt“. Zum Kern der etwa 80 Gründer aus dem Inund Ausland gehörte neben anderen Mitgliedern des Hochadels auch Otto von Habsburg, der von seinen Anhängern als erster Anwärter auf diesen Thron betrachtet wurde. Die Praxis zeigte allerdings, daß das monarchistische Element nicht in den Vordergrund gerückt wurde. Vielmehr sollte der solchen Reichsvisionen übergeordnete geistige Kampf gegen Atheismus und Bolschewismus in Europa eine möglichst breite Basis finden.

Zu diesem Zweck wurde 1952 von derselben Initiative die „Abendländische Akademie“ in München gegründet. Sie wollte durch Vorträge, Diskussionsabende und Tagungen den „Menschen, die sich zum Geist des Abendlandes bekennen, eine Arbeitsstätte und eine sichtbare Heimat" bieten ${ }^{200}$. Der exklusive Gesprächskreis um Aktion und Akademie sah, geprägt von seinem christlich überhöhten Geschichtsverständnis, in dem spanischen Weltreich des 16. und 17. Jahrhunderts ein historisches Vorbild der ihm vorschwebenden übernationalen Reichsordnung. Eben dieses diffuse Ideal sorgte dafür, daß Spanien im abendländischen Milieu in vielfacher Weise gewürdigt wurde. So stellte der konservativ-katholische Schriftsteller Reinhold Schneider, dessen Erzählung „Las Casas vor Karl V.“ in der Nachkriegszeit zur westdeutschen Schullektüre gehörte, die imperiale Vergangenheit des „Siglo de Oro“ in den Mittelpunkt seines Werkes. Darin entwarf der Autor ein idealisiertes Bild der tragischen Größe Spaniens, das die Werte der einheitlichen religiös-politischen Einheit - verkörpert im Katholizismus und der Monarchie - gegen den individualistischen Protestantismus zu verteidigen suchte. Schneider sah diese Epoche auch als eine „mahnende Alternative zur eigenen, dem Modernismus und der religiösen Bindungslosigkeit verfallenen Gegenwart"201.

Spaniens prägende Bedeutung für das vergangene und künftige Europa stellte vor allem die Zeitschrift „Neues Abendland“ heraus. Dort sah Otto von Habsburg 1957 Spanien an der Spitze eines „unsichtbaren Reiches“. Das Land habe im Gegensatz zum britischen

199 Bericht Valjavec über: Beschwörung des „Heiligen Römischen Reiches“, 26. 7. 1954, PA/AA, Abt. 3, Ref. 304, Bd. 28. Die 58 Seiten umfassende Aufzeichnung liefert erhellende Hintergrundinformationen über Träger und Ziele der exklusiven abendländischen Zirkel. Professor Fritz Valjavec war Direktor des Südost-Instituts in München. Zu danken ist Dr. Matthias Pape (Bonn) für den Hinweis auf den ValjavecBericht. Das Folgende z. T. wörtlich nach Valjavec.

200 Seit 1952 fanden jährlich als Hauptereignis mehrtägige Tagungen in Eichstätt statt. Themen waren u. a. 1952: Werte und Formen im Abendland; 1953: Der Mensch und die Freiheit; 1954: Staat, Volk, übernationale Ordnung.

${ }_{201}$ Tietz, Das alte und das neue Spanien bei Reinhold Schneider und Lion Feuchtwanger, S. 86. Schneiders literarische und öffentliche Bedeutung in der frühen Bundesrepublik spiegelt sich auch darin, daß er 1956 mit dem „Friedenspreis des Deutschen Buchhandels“ ausgezeichnet wurde. Vgl. zum Gedanken der „Vorbildlichkeit“ Spaniens für Europa in der Nachkriegszeit Briesemeister, Die Iberische Halbinsel und Europa, S. 13-27. 
Empire eine "geistige transzendente Sendung“, die er als die für ganz Europa zentrale Verbindung Spaniens mit Lateinamerika beschrieb. In seiner eurozentrischen Sicht verstieg sich Otto von Habsburg zu der Behauptung: „Iberoamerika ist nichts anderes als ein überseeisches Europa“. Als lebendiges Bindeglied der beiden Hemisphären der christlichabendländischen Welt könne Spanien ,jene Kraft vermitteln, die allein den Sieg unserer europäischen Gemeinschaft über den modernen Barbaren aus dem Osten gewährleisten wird"202.

Nicht nur deutschsprachige Autoren präsentierten hier ein Zerrbild spanischer „Allmacht“. Auch dem Franco-Regime bot dieses Forum häufig Gelegenheit zur Selbstdarstellung. Marqués de Valdeiglesias, einer seiner Apologeten, erhob Spanien zum Vorbild für Europa. Es biete dem Ausland „das durch Humanismus, Rationalismus und Liberalismus unterdrückte Leitbild einer christlich-universalen Weltordnung “203. Das in der Nachkriegszeit anfangs völlig isolierte franquistische Regime sah in der Zustimmung aus dem Abendland-Kreis eine Möglichkeit zur eigenen außenpolitischen Aufwertung. Zum organisatorischen Vehikel dieser Politik wurde das ebenfalls seit 1952 bestehende "Centro Europeo de Documentación e Información (CEDI). Das zumindest bis 1957 aus dem Etat des spanischen Außenministeriums finanzierte CEDI war nach dem Urteil des deutschen Botschafters von Welck mit dem Ziel gegründet worden, „in den Ländern des westlichen Europas zu werben und der Propaganda der spanischen Emigration entgegenzutreten “204. Diese Hoffnungen des Franco-Regimes speisten sich aus dem Umstand, daß vor allem in den Reihen der deutschen „Abendländer" bekannte Namen aus dem parteipolitisch organisierten Konservativismus vertreten waren.

In der Bundesrepublik bewegten Abendländische Aktion und Abendländische Akademie, das Pendant zum CEDI, die politische Phantasie. Die Öffentlichkeit nahm Notiz von ihnen, weil die gegen das pluralistische System und die parlamentarische Demokratie gerichtete nebulöse Programmatik von prominenten Politikern aus der Bonner Regierung mitgetragen wurde ${ }^{205}$. In Vorstand, Kuratorium und Beirat der Akademie hatten sich 1955 zahlreiche Mitglieder aus den Parteien der Koalition versammelt: $u$. a. Bundesaußenminister Heinrich von Brentano (CDU), Bundesratsminister Hans-Joachim von Merkatz (DP), Bundesvertriebenenminister Theodor Oberländer (CDU), Bundesfamilienminister FranzJosef Wuermeling (CDU) sowie der Vizepräsident des Bundestages Richard Jaeger (CSU). An Spanien interessiert zeigten sich vor allem Richard Jaeger und Hans-Joachim von Merkatz.

Zwischen der Abendländischen Akademie und dem CEDI kam es schon bald nach dessen Gründung zu einem kontinuierlichen Austausch. Gelegenheit zu intensiveren Kontak-

202 Otto von Habsburg, Spanien und Europa, S. 299.

${ }^{203}$ De Valdeiglesias, Beitrag Spaniens, S. 286. Der spanische Staatsrat schrieb hier noch weitere Aufsätze, die stets die Vorbildfunktion des franquistischen Staates für das übrige Europa betonten.

204 Bericht Botschaft Madrid betr. VII. Tagung des Europäischen Dokumentationszentrums, 25. 6. 1958, ACDP, NI. von Merkatz, I-148, Bd. 083/1. Dort auch weiteres Material zur Geschichte dieser Institution, die in der Bundesrepublik als Europäisches Dokumentationszentrum bezeichnet wurde. Zur Gründung des CEDI und seiner weiteren Entwicklung ausführlich bei Weber, Spanische Deutschlandpolitik 1945-1958, S. 240 ff.

205 Vgl. die Kritik an den programmatischen Vorstellungen der Abendländischen Aktion und der Mitarbeit prominenter deutscher Politiker in Aktion und Akademie, in: Der Spiegel, Nr. 33, 10.8. 1955, S. 12-14. 
ten gaben die seit 1953 meist an geschichtsträchtiger Stelle durchgeführten internationalen Jahrestagungen des CEDI. In „El Escorial“, unweit der spanischen Hauptstadt, diskutierten Repräsentanten verschiedener europäischer Länder aus Politik und Kultur über jeweils aktuelle, aber sehr weitgespannte Fragen ${ }^{206}$. Dieser christlich-abendländische ElitenDialog, der das Franco-Regime in die Wertegemeinschaft des „freien Westens“ integrieren sollte, fand vor allem in der Bundesrepublik großen Anklang. Möglicherweise auch durch touristische Interessen beeinflußt, war sie stets mit großen und repräsentativen Delegationen in Spanien vertreten ${ }^{207}$. Hinter den Kulissen ging es auch um das politische Tagesgeschäft. Auf der deutsch-spanischen Agenda der Jahre 1954 und 1955 standen die spanischen Bemühungen um einen Adenauer-Besuch. In einer Zeit, in der offizielle Kontakte spärlich und politisch heikel waren, boten die CEDI-Tagungen einen Ort, an dem FrancoSpanien wohlgesonnene deutsche Politiker informell mit Mitgliedern des Regimes zusammentreffen konnten.

Als Spanien-Lobbyist betätigte sich insbesondere Bundestagsvizepräsident Richard Jaeger, der 1954 erstmals an einem CEDI-Kongreß teilnahm. Sein von Sympathie getragenes Engagement äußerte sich auch publizistisch. In einem vom spanischen Informationsministerium später nachgedruckten Artikel für den „Rheinischen Merkur“ bejahte Jaeger im Herbst 1954 mit geschichtlichen Argumenten die Zugehörigkeit Spaniens zur europäischen Wertegemeinschaft. Angestoßen durch die Veröffentlichung in Spanien und das Interesse diplomatischer Kreise in Madrid publizierte das Bonner Presse- und Informationsamt seinerseits in Auszügen die Thesen Jaegers und verlieh ihnen damit offiziösen Charakter.

Bezogen auf das deutsch-spanische Verhältnis rückte Jaeger das verbindende Element des Anti-Bolschewismus pathetisch in den Vordergrund. Offenbar unter Anspielung auf den 17. Juni 1953 und den Spanischen Bürgerkrieg erklärte er beide Länder zu Opfern des Bolschewismus: „Haben nicht beide Völker in jüngster Vergangenheit, wenn auch unter verschiedenen Formen die Grausamkeit des Bolschewismus an sich selbst gespürt? Deutschland und Spanien sind heute auf Grund ihrer bitteren Erfahrungen immuner gegen die Gefahr des Bolschewismus als irgendein anderes Volk. "208 Der CSU-Politiker erhob damit das diktatorische Regime Francos zum vorbildlichen Bündnispartner in der Auseinandersetzung mit dem das „Böse“ verkörpernden Kommunismus. Die Frage der Staatsform war deshalb für ihn unbedeutend, ja es sei sogar sehr gefährlich, Außenpolitik ,in Übereinstimmung mit Ideologien zu betreiben“. Statt dessen mahnte er, Deutschland habe sicherlich keinen Grund, „einen seiner wenigen Freunde in der Welt zurückzustoßen, weil dieser in seiner eigenen, von unserer verschiedenen politischen Form lebt“.

\footnotetext{
206 Wie umfassend die Themen formuliert waren, zeigt eine kleine Auswahl: Aufbau des föderativen und christlichen Europa (1954); Europa vor dem Problem der Koexistenz (1955); Europa im Atomzeitalter (1956).

${ }^{207}$ Bericht Botschaft Madrid betr. VII. Tagung des Europäischen Dokumentationszentrums, 25. 6. 1958, ACDP, Nl. von Merkatz, I-148, Bd.083/1. Zum deutschen Teilnehmerkreis gehörten auch regelmäßig Journalisten konservativer Couleur wie Otto Roegele vom Rheinischen Merkur oder Alfons Tomicic-Dalma, der für den Münchner Merkur schrieb. Darüber hinaus nahmen regelmäßig Vertreter aus Portugal, Italien, Belgien sowie den Niederlanden und der Schweiz teil.

${ }^{208}$ Vgl. die vom Presse- und Informationsamt der Bundesregierung dokumentierten Auszüge des Artikels „Spanien und Europa“, 6. 10. 1954, PA/AA, 210-01/70, Bd. 2, dort auch die folgenden Zitate.
} 
Davon war Bonn auch weit entfernt. Ein offenes Nein auf die von Außenminister Artajo gegenüber Jaeger wiederholt ausgesprochene Einladung Adenauers wäre in der Tat eine Brüskierung gewesen. So kleidete Bonn seine zögerliche Haltung in eine Form des ,Ja, aber", die Madrid kaum verstimmen konnte ${ }^{209}$. Einer Adenauer-Visite stand aus deutscher Sicht vor allem der Vermögenskonflikt zwischen beiden Staaten im Wege. Adenauer selbst, von Jaeger persönlich unterrichtet, zeigte wenig Berührungsängste gegenüber dem Franco-Regime. Er habe prinzipiell aufgeschlossen reagiert ${ }^{210}$, der nichtdemokratische Charakter der spanischen Regierung war für ihn offenbar eher nebensächlich. Als müsse er seine politische Eigenständigkeit demonstrieren, bekundete Adenauer gegenüber dem italienischen Ministerpräsidenten Segni im Februar 1956 geradezu trotzig, er wäre mit Franco zusammengetroffen, wenn er sich für die Kanarischen Inseln als Urlaubsziel entschieden hätte ${ }^{211}$. Es waren aber nicht primär die von ihm suggerierten privaten Motive, die gegen seine ursprüngliche Wahl des Urlaubsortes gesprochen hatten ${ }^{212}$.

Mit den Kanarischen Inseln waren vielmehr politische Implikationen verbunden. Angesichts der international überwiegend negativen Beurteilung der Franco-Diktatur wäre selbst ein Ferienaufenthalt des deutschen Regierungschefs in Spanien eine hochpolitische Angelegenheit gewesen, die zu Irritationen bei den westlichen Verbündeten geführt hätte. Dies war der eigentliche Grund dafür, daß es auch nach dem Abschluß der Vermögensfrage im Jahre 1958 nicht zu einem offiziellen Spanienbesuch Adenauers kam. Notgedrungen mußte die Bundesregierung akzeptieren, daß der Spielraum ihrer eigenen Spanienpolitik wesentlich durch das internationale Umfeld und dessen Verhältnis zu Spanien bestimmt wurde. Die meisten europäischen Bündnispartner beobachteten das mit einer historischen Hypothek belastete deutsch-spanische Verhältnis stets mit Argwohn. Solange das autoritäre Regime noch unter „Besuchsquarantäne“ stand, war ernsthaft nicht an ein Treffen zwischen Adenauer und Franco zu denken. Ein internes Papier des Auswärtigen Amtes brachte die Konstellation 1959 auf den Punkt: Es dürfte „sich mit Rücksicht auf unsere westlichen Verbündeten, bei denen Erinnerungen an das frühere enge Verhältnis zwischen dem Francound dem Hitlerregime wachgerufen werden könnten, empfehlen, die Durchführung der

209 Ein beredtes Beispiel hierfür ist das Schreiben von Jaeger an Artajo, in welchem er im Juli 1955 das Ergebnis seiner Mission mitteilt. Darin heißt es, daß der Bundeskanzler einem Spanien-Besuch gegenüber sehr aufgeschlossen sei und nach Abschluß der Vermögensfrage der Reise nichts mehr im Wege stehc. Jaeger an Artajo, 16. 7. 1955, Privatarchiv Richard Jaeger. Im nachhinein interpretierte Jaeger den Brief so, daß er „zum Wohle der deutsch-spanischen Beziehungen formuliert" gewesen sei und die eher dilatorische Haltung Adenauers beschönigt habe. Gespräch mit Dr. Richard Jaeger, 14. 6. 1989 in Bonn.

210 Gespräch mit Dr. Richard Jaeger, 14.6. 1989.

211 Gespräch Adenauer mit Segni, 8. 2. 1956, StBkAH III 54.

212 Die für die zweite Februarhälfte 1956 vorgesehene Erholungsreise war für das Bundeskanzleramt unerwartet zu einem Politikum geworden. Der zunächst direkt geplante Hinflug war aber selbst mit einer gecharterten Maschine aus technischen Gründen nicht möglich. Darauf machte jedenfalls die Botschaft Madrid aufmerksam und warnte vor einem „völligen Übergchen“ der spanischen Behörden. Botschaft Madrid an Auswärtiges Amt, 21. 12. 1955, PA/AA, Ref. 206, Bd. 39. Nachdem auch vom Auswärtigen Amt der Hinweis gegeben worden war, Spanien würde es als eine „ausgesprochene Unhöflichkeit“ ansehen, wenn der Bundeskanzler bei einer Zwischenlandung dem spanischen Staatschef „nicht wenigstens einen kurzen Höflichkeitsbesuch abstatten würde“, setzte das Nachdenken über die politischen Konsequenzen ein. Aufzeichnung von Welck an Staatssekretär betr. eventuellen Besuch des Herrn Bundeskanzlers, 23. 12. 1955, PA/AA, Ref. 206, Bd. 39. Im Januar 1956 wurde der spanischen Regierung mitgeteilt, daß Bundeskanzler Adenauer auf Anraten seiner Ärzte von seinem geplanten Erholungsurlaub auf den Kanarischen Inseln zu seinem Bedauern absehen müsse. Vermerk, 17. 1. 1956, PA/AA, Ref. 206, Bd. 39. 
Einladung nach Spanien [. . . ] nicht zu übereilen. Da bisher kein anderer Regierungschef eines größeren westlichen Landes Spanien nach dem Zweiten Weltkrieg einen Besuch abgestattet hat, wäre es wünschenswert, wenn der Staats- oder Regierungschef eines verbündeten westlichen Landes Spanien vor dem Herrn Bundeskanzler besuchen würde“213.

Der besorgte Blick auf das Ausland hatte schon 1955 die deutsche Botschaft in Madrid dazu veranlaßt, vor einer allzu großen Beteiligung prominenter politischer Persönlichkeiten an den CEDI-Tagungen zu warnen. Daraufhin sah Außenminister Brentano von einer Teilnahme $\mathrm{ab}^{214}$. Gleichwohl waren die Botschaft wie das Auswärtige Amt, das sich den Bedenken angeschlossen hatte, grundsätzlich aber an den Kontaktmöglichkeiten und inoffiziellen Kanälen durch das CEDI interessiert.

Die abendländisch inspirierten Politiker wie Jaeger und Merkatz empfanden sich als Pioniere im deutsch-spanischen Nachkriegsverhältnis. Ihnen ging es darum, Spanien auf die Agenda der westdeutschen Außenpolitik zu bringen. Mit der Souveränität der Bundesrepublik sah der Vizepräsident des Bundestages, Jaeger, die Zeit gekommen, bei Adenauer für eine aktive deutsche Spanienpolitik zu werben. Unter Verweis auf seine jüngsten Gespräche mit „verantwortlichen Kreisen“ der USA, die eine engere deutsch-spanische Zusammenarbeit und ein Hereinwachsen Spaniens in die NATO nicht ungern sähen, plädierte Jaeger im Juni 1955 dafür, jetzt „die bisher vielleicht berechtigte, nunmehr aber nicht mehr notwendige allzu starke Zurückhaltung gegenüber Spanien fallenzulassen und deutscherseits eine konstruktive Spanienpolitik zu beginnen“215. Die Bundesregierung könne seiner Ansicht nach sogar dem an einer engeren Beziehung interessierten FrancoRegime signalisieren, daß der Preis dafür ein Entgegenkommen in der Eigentumsfrage sei. Damit überschätzte er sicherlich die deutschen Möglichkeiten und das spanische Interesse an der Bundesrepublik. Der Vermögenskonflikt erschwerte jedenfalls bis zu seiner Regelung im Frühjahr 1958 den von Jaeger erhofften intensiveren deutsch-spanischen Dialog. Insgesamt verhallte das pro-spanische Plädoyer des CSU-Politikers aber nicht ungehört. Obwohl nach seinem Eindruck Spanien für Adenauer außenpolitisch nur eine „Quantité négliable“ gewesen sei ${ }^{216}$, deutet doch der Anfang 1956 eingeleitete, aber erfolglos geblie-

213 PA/AA, Ref. 206, Bd. 7627, o. D. Anlaß dieser Überlegungen war der im November 1959 stattfindende Deutschlandbesuch des spanischen Außenministers Castiella, bei dem man damit rechnete, daß Castiella erneut eine Einladung an Adenauer aussprechen werde. Von der „Besuchssperre“ für Spanien war das Salazar-Regime im angrenzenden Portugal indirekt gleichfalls betroffen. Ebenso wie bei anderer Gelegenheit, nahm die westdeutsche Diplomatie auch hier Rücksicht auf die wechselseitigen Empfindsamkeiten der iberischen Nachbarn. Eine bereits vorliegende Einladung der portugiesischen Regierung an Bundeskanzler Adenauer konnte deshalb nur hinhaltend beantwortet werden.

214 Tagung des Europäischen Dokumentations- und Informationszentrums in Madrid, 30.5.1956, PA/AA, Ref. 206, Bd. 42. Die Aufzeichnung verweist auf die von der Botschaft Madrid ein Jahr zuvor mitgeteilten Vorbehalte. Der eigentliche als „Geheim“ eingestufte 18seitige Bericht der Botschaft über das CEDI aus dem Jahre 1955 wurde vom Auswärtigen Amt nicht offengelegt. Vgl. Schreiben an den Verfasser, 8. 5. 1991. Immerhin hatten 1955 u. a. Jaeger, Merkatz und Bundestagspräsident Eugen Gerstenmaier an der CEDI-Tagung teilgenommen.

215 Jaeger an Adenauer, 16. 6. 1955, PA/AA, Ref. 206, Bd. 23.

216 So kennzeichnete Richard Jaeger rückblickend den Stellenwert, den Spanien in Adenauers außenpolitischem Denken besaß. Jaeger selbst war nicht nur von abendländischer Emphase umgetrieben, seinen Vorstoß bei Adenauer begründete er auch mit dem Wunsch nach Profilierung, denn als jüngerer Politiker habe er etwas bewegen wollen. Hinzu kamen für den langjährigen Vorsitzenden des Bundestagsausschusses für Verteidigung sicherheitspolitische Motive. Nach seiner Überzeugung mußte Spanien NATOMitglied werden. Gespräch mit Dr. Richard Jaeger, 14.6. 1989 in Bonn. 
bene Versuch des Kanzlers, Spanien in den europäischen Integrationsprozeß einzubinden $^{217}$, darauf hin, daß Jaeger bei Adenauer wohl ein offenes Ohr gefunden hatte.

Gegen Ende der 50er Jahre verlor die „abendländische Begegnung“ allmählich ihre exklusive Gesprächsfunktion. Je mehr sich das bilaterale Verhältnis u. a. durch die Einigung im Eigentumskonflikt verbesserte, desto häufiger wurden die offiziellen Kontakte und machten das informelle Diskussionsforum CEDI nach und nach entbehrlich. Hinzu kam, daß der Zeitgeist sich gleichfalls gewandelt hatte. Inzwischen war in der Bundesrepublik weniger von „Abendland“ die Rede. Im Zuge einer allgemeinen „Entideologisierung“ (Axel Schildt) fand das programmatische Organ der Abendland-Diskussion offenbar keine Resonanz mehr, es wurde 1958 eingestellt ${ }^{218}$. Die Konjunktur der abendländischen Idee war vorüber. Mehr und mehr hatte sich eine westdeutsche „Identität“ herausgebildet, die sich weniger an christlichen Wertgrundlagen, sondern an der wirtschaftlichen Leistungsfähigkeit und „Modernität“ der liberaldemokratischen Ordnung orientierte.

Das Spanienbild der Adenauer-Regierung war durch die im westdeutschen Konservativismus verbreitete abendländische Grundstimmung jedoch wesentlich geprägt worden. Die Propagandisten des „christlichen Abendlandes“ hatten immer wieder auf die zeitlosen Werte des „wahren und ewigen“ Spanien verwiesen. Ihre auf die ferne Vergangenheit gerichteten Projektionen blendeten die politische und soziale Gegenwart Franco-Spaniens weitgehend aus und förderten damit die Unkenntnis der dortigen innenpolitischen Verhältnisse. Es war kennzeichnend für die deutsche Spanienpolitik der Nachkriegszeit, weit in die Geschichte zurückzugreifen, wenn bei offiziellen Anlässen historische Gemeinsamkeiten beschworen werden sollten. So wurde Karl V., dessen 400. Todestag sich 1958 jährte, bei dem Spanienbesuch von Außenminister Brentano zur willkommenen Symbolfigur deutsch-spanischer Freundschaft ${ }^{219}$.

Die jüngste Vergangenheit wurde aber nicht immer ausgespart. Bei einem Gespräch zwischen Staatschef Franco und Bundesratsminister von Merkatz am Rande der CEDITagung 1956 funktionierte der deutsche Gast den 1936 erfolgten Militärputsch gegen die spanische Republik und den nachfolgenden Bürgerkrieg in eine antikommunistische Pionierleistung um. Ohne das deutsche Eingreifen in den Bürgerkrieg zu erwähnen, machte sich Merkatz die franquistische Rechtfertigungsstrategie zu eigen: „Deutschland und Europa schuldeten Spanien Dank dafür, daß es im Jahre 1936 den Kampf gegen den Kommunismus aufgenommen und diesen siegreich zu Ende geführt habe. "220 Seine Eloge auf das Franco-Regime krönte er mit einem weichgezeichneten Bild des spanischen Diktators, der auf ihn „weniger den Eindruck eines hohen Militärs oder eines Diktators als den eines patriarchalisch großväterlichen Staatsmanns" mache.

217 Gemeinsam mit seinem italienischen Kollegen Segni hatte Adenauer eine derartige Initiative gestartet. 218 Vgl. zum „Zeitgeist“ am Ënde der 50er Jahre: Schildt, Moderne Zeiten, S. 449.

219 Vgl. die Tischrede von Brentano anläßlich seiner Zusammenkunft mit dem spanischen Außenminister Castiella, PA/AA, Ref. 206, Bd. 163, o. D.

220 Bericht Botschaft Madrid betr. Gespräch Franco mit Merkatz, 27.6. 1956, PA/AA, Ref. 206, Bd. 36. Dort auch das folgende Zitat. Hans-Joachim von Merkatz war von 1938 bis 1945 (unterbrochen von seiner Wehrdienstzeit zwischen 1939 und 1941) Generalsekretär des Ibero-Amerikanischen Instituts in Berlin gewesen. Das aus dem Etat des Propagandaministeriums finanzierte Institut verfügte vor allem durch seinen Direktor, den ehemaligen Botschafter bei Franco, General Faupel, über sperifische Kenntnisse der innerspanischen Entwicklung. Vgl. dazu Ruhl, Spanien im Zweiten Weltkrieg, S. 62. 
Daß ein solch verklärter Blick nicht allein abendländisch gesinnten Politikern wie von Merkatz vorbehalten war, zeigt ein Vorgang, der ein Schlaglicht auf die diplomatische Berichterstattung der spanischen Innenpolitik wirft. Im Dezember 1959 erreichte Staatssekretär Globke im Bundeskanzleramt ein Brief des Kölner Verlegers Franz Carl Bachem. Sein Inhalt, eine ungeschminkte Schilderung der wirtschaftlichen, sozialen und politischen Situation in Spanien, sorgte bei Globke vor allem aufgrund der Persönlichkeit des mit Adenauer bekannten Verfassers für besondere Aufmerksamkeit. Bachem, katholisch, mit einer Spanierin verheiratet und gewiß keiner politisch linken Neigungen verdächtig, war ein genauer Beobachter des Landes, das er bereits seit vier Jahrzehnten kannte ${ }^{221}$. Ihm war bewußt, daß seine Eindrücke nicht der „offiziellen Version“ des Franco-Regimes entsprachen. Sein mehrere Seiten umfassender Bericht prangerte u. a. den „Krebsschaden“ der Vetternwirtschaft an, die von „ganz oben“ ausgehe: „Die vielen Madrilener ,Señoritos", die auf staatlichen Gehaltslisten geführt werden, die große Baufirma oder die Aktiengesellschaft, die in 2 Jahren durch eine betriebsfremde Personalpolitik mit aufwendiger Geschäftsführung ruiniert wird [...]."222 Jeder wisse das, aber aus Angst oder Resignation werde nicht offen darüber gesprochen. Nach dem Bürgerkrieg sei auf Kosten der Landwirtschaft die von einem Staatskartell gesteuerte Schwerindustrie unnötig ,aufgebläht" worden, was zu sozialen Verwerfungen und einer ungesunden Landflucht geführt habe. Am Beispiel der vom Franco-Regime politisch wie kulturell unterdrückten Region Katalonien - die katalanische Sprache war öffentlich verboten - sprach Bachem vom ,verewigten Bürgerkrieg“. Die spanische Gesellschaft habe nach seinem Eindruck politisch resigniert: „Warum Franco sich hält?, sagte mir ein höherer Beamter, weil wir alle nicht wissen, was nach ihm kommt."

Für Adenauer fiel der Brief Bachems mit seiner Klage über das „so miserabel regierte“ Land offensichtlich aus dem Rahmen dessen, was ihn ansonsten an Informationen über Spanien erreicht hatte. Der Kanzler wurde hier mit einem Bild konfrontiert, das im krassen Gegensatz zu einer diplomatischen Berichterstattung stand, welche die inneren Probleme des iberischen Staates nur unscharf wahrnahm. Nur so wird seine erstaunte Reaktion verständlich. Er wollte vom Auswärtigen Amt wissen: „Hat unser Botschafter jemals einen derartigen Bericht geschickt? "223 Dort löste diese Frage augenscheinlich gewisse Irritationen aus. Das Bundeskanzleramt mußte nach mehr als einem halben Jahr registrieren, daß selbst zahlreiche Rückfragen bei den zuständigen Referaten im Auswärtigen Amt ergebnislos geblieben waren. Die abschließende Stellungnahme des Spanien-Referats er-

221 Bachem hatte seine Spanien-Beobachtungen auf Bitten seines Freundes Rafael Calvo Serer zu Papier gebracht. Unklar ist, ob Calvo Serer Bachem selbst gebeten hatte, diese Schilderung an das Bundeskanzleramt weiterzuleiten, oder ob Bachem dies auf eigene Veranlassung tat. Jedenfalls schickte Bachem den Brief an Globke mit der Bitte um Weiterleitung an Adenauer. Vgl. Schreiben von Bachem an Globke, 30. 11. 1959, BA, B 136, Bd. 3652. Der Philosophieprofessor Calvo Serer galt als der ideologische Vordenker der in Spanien einflußreichen katholischen Organisation „Opus Dei“, die auf der Basis eines betont starken Arbeits- und Pflichtethos wirtschaftstheoretisch neoliberale Ziele verfolgte und seit Ende der 50er Jahre zum wichtigsten Bestandteil des franquistischen Elitensystems avancierte. Serer sollte sich im Laufe der Jahre vom „reaktionären Restaurationsideologen“ zum nach damaligen Vorstellungen in Spanien „liberalen“ Oppositionspolitiker wandeln. Vgl. dazu Bernecker, Spaniens Geschichte seit dem Bürgerkrieg, S. $112 \mathrm{ff}$.

${ }_{222}$ Bachem an Globke, 30. 11. 1959, BA, B 136, Bd. 3652. Dort auch die folgenden Zitate.

223 Ebenda; handschriftliche Anmerkung Adenauer. 
hebt gar die unkritische Berichtspraxis zum Prinzip, da man das Land eben mit anderen Maßstäben messen müsse: Es „sei allgemein bekannt, daß es in Spanien Rückständigkeiten und Mißstände gebe, wie sie im übrigen Mitteleuropa unbekannt seien. Die Berichte der Botschaft versuchten jedoch immer, eine ausgewogene Darstellung der Verhältnisse zu vermitteln, und verzichteten darauf, die einem Besucher aus Mitteleuropa auffallenden negativen Seiten so stark in den Vordergrund zu rücken "2224. Die Antwort ist ein Beleg dafür, wie sehr die westdeutsche Perspektive auf Spanien in den 50er Jahren von einem unkritischen Wohlwollen geprägt war. Die christlich-abendländische Idee als Bestandteil des Antikommunismus hat zu einer derartigen Haltung wesentlich beigetragen.

\section{Kulturelle Beziehungen - Offizielle Kulturpolitik ohne Inhalt?}

Die weltanschauliche Komponente fehlte auch nicht bei der Entwicklung der deutschspanischen Kulturpolitik. Schon im Februar 1951, kurz nach dem Ende des UNO-Boykotts gegen das Franco-Regime, teilte Bundeskanzler Adenauer dem spanischen Missionschef in Bonn, Aguirre, auf Anfrage mit, daß die Bundesregierung sich von einer erneuerten und vertieften kulturellen Zusammenarbeit nicht nur für beide Länder, sondern darüber hinaus auch für die „abendländische Kulturgemeinschaft“ eine wertvolle Bereicherung erhoffe ${ }^{225}$.

Mit dem von Spanien angeregten Kulturabkommen betrat man allerdings Neuland, da es trotz der von Adenauer gerühmten „langen Tradition freundschaftlicher Beziehungen " bisher eine entsprechende Vereinbarung zwischen Deutschland und dem tatsächlich doch fernen Spanien nicht gegeben hatte. Nach den Vorstellungen Bonns sollte das Verhältnis in Abkehr von der nationalsozialistischen Kulturpropaganda auf einer „vollkommen unpolitischen Ebene" ${ }^{226}$ ausgebaut werden. Im Bundeskanzleramt betrachtete man das iberische Land als „eine außerordentlich wichtige Durchgangsstel$1 e^{\text {"227 }} \mathrm{zu}$ den intellektuellen Kreisen Lateinamerikas. Diese Brückenfunktion mag auch das Interesse deutscher Hochschulen an einem direkten Kontakt mit spanischen Uni-

224 Vermerk Deutz für Staatssekretär Globke, 25. 7. 1960, BA, B 136, Bd. 3652. Als Ausgleich für das bislang spärliche Wissen über dic innerspanischen Verhältnisse wurde Globke bei Bedarf ein Bericht der Botschaft über die oppositionellen Kräfte und die Hauptansatzpunkte ihrer Kritik in Aussicht gestellt.

225 Adenauer an Aguirre, 13. 2. 1951, PA/AA, Ref. 600, Bd. 60. Zuvor hatte der spanische Gesandte am 31. Januar den Wunsch seiner Regierung übermittelt, die kulturellen Beziehungen wieder aufzunehmen. Erstc Gesprächc hatte es bereits seit September 1950 zwischen der spanischen Mission und dem Bundeskanzleramt gegeben.

226 Aufzeichnung Salat betr. kulturelle Beziehungen zwischen Deutschland und Spanien, 10. 10. 1950, PA/AA, 205-00/70, Bd. 1. Rudolf Salat leitete zwischen 1950 und 1954 zunächst im Bundeskanzleramt, später im Auswärtigen Amt die Kulturabteilung. Salat hatte ein besonderes Interesse an Spanien. Mit dem spanischen Außenminister Artajo verband ihn seit den dreißiger Jahren eine enge Freundschaft. Bei einem Spanien-Besuch von Salat im Mai 1951 erinnerte sich sein Duzfreund Artajo an frühere Verhandlungen über ein deutsch-spanisches Kulturabkommen nach 1933. Diese Gespräche - an denen Artajo für die „Katholische Aktion“ teilgenommen hatte - seicn damals an den nationalsozialistischen Propagandavorstellungen gescheitert. Mit dem „neuen Deutschland“ könnc nun ein „anders orientiertes Kulturabkommen" vereinbart werden. Vgl. Aufzeichnung Salat betr. Aussprache mit dem spanischen Außenminister, 4.5. 1951, PA/AA, Ref. 600, Bd. 60.

227 Aufzeichnung Salat, 10. 10. 1950, ebenda. 
versitäten gefördert haben. Die Erfahrungen, die einige deutsche Studenten dabei mit dem rechtsextremen, ganz durch die NS-Zeit bestimmten Deutschlandbild ihrer spanischen Kommilitonen machten, wurden vom Auswärtigen Amt allerdings mit Sorge registriert. So beklagte sich der Leiter der Kulturabteilung Rudolf Salat Anfang November 1951 bei der spanischen Botschaft über den ,peinlichen Eindruck “228, den manche Studenten in Spanien gewonnen hätten. Dort gebe es anscheinend in der Jugend nach wie vor starke Sympathien für das NS-Regime. In einem Colegio in Barcelona hänge beispielsweise noch heute in jedem Zimmer ein Hitler-Bild. Außerdem seien viele spanische Studenten davon überzeugt, „daß die rechtsradikalen Parteien in Westdeutschland über eine große Anhängerschaft verfügen, die sich nur deshalb nicht nach außen kundtun könne, weil die Besatzungsmächte es verhindern "'229. Salat sah die gesamte kulturelle Kooperation von einem „Rückschlag“ bedroht, falls der Presse in der Bundesrepublik derartige Erfahrungen bekannt würden ${ }^{230}$. Die von ihm befürchtete „Pressekampagne“ blieb jedoch aus. Politisch wie atmosphärisch nahmen die vorbereitenden Gespräche über ein Kulturabkommen zwischen dem Auswärtigen Amt und der spanischen Botschaft keinen Schaden.

Beide Seiten konnten sich rasch auf die Grundlinien einer allgemein formulierten Rahmenvereinbarung einigen, die allerdings mehr einer Absichtserklärung gleichkam ${ }^{231}$. Die konkrete Ausgestaltung des Kulturabkommens sollte eine jährlich zusammenkommende deutsch-spanische Kommission übernehmen. Im September 1951 lag dem Auswärtigen Amt bereits ein spanischer Entwurf vor.

Die Aussicht auf eine mögliche Einigung stellte Bonn allerdings vor außenpolitische Probleme. Die Erinnerungen im Ausland an die deutsch-spanische Verbindung vor 1945 und das schwierige Verhältnis zwischen den Westmächten und dem eben noch geächteten Franco-Regime machten selbst die als unpolitisch verstandenen kulturellen Beziehungen der Bundesrepublik mit Spanien zu einem Politikum. Denn zur gleichen Zeit - teilweise hatten die bilateralen Gespräche schon vorher begonnen - verhandelte die Bundesregierung auch mit den Vereinigten Staaten, Frankreich, Großbritannien und Italien über kulturelle Vereinbarungen. Ein deutsch-spanisches Vorpreschen hätte gegenüber diesen Staaten einen Affront bedeutet, den Bonn nicht riskieren wollte ${ }^{232}$. Die Rücksicht auf das westliche Ausland bestimmte also das Tempo im Kulturdialog mit Spanien. Ein Jahr später, im Herbst 1952, hoffte die Kulturabteilung dann, daß „nunmehr auch der Vertrag mit Spanien energisch vorwärts getrieben werden kann"'233.

Neben den staatlichen Bemühungen um einen kulturellen Dialog setzte Bonn auch früh auf private Initiativen, wie die von ihr finanziell unterstützte Deutsch-Spanische Ge-

228 Vermerk Salat über den Besuch des spanischen Kulturattachés Castro-Rial, 2. 11. 1951, PA/AA, Ref. 600 , Bd. 60 .

229 Salat an Castro-Rial, 29. 10. 1951, PA/AA, Ref. 600, Bd. 60.

230 Ebenda.

231 Aufzeichnung betr. deutsch-spanisches Kulturabkommen, 16. 4. 1951, PA/AA, Ref. 600, Bd. 60. Da der Bund angesichts der Kulturhoheit der Länder wenig an konkreten Verpflichtungen eingehen konnte, war der Inhalt überwiegend allgemeiner Natur. Dies galt ebenso für andere Kulturabkommen mit dem Ausland.

${ }^{232}$ Vgl. Aufzeichnung Salat, betr. Aussprache mit dem spanischen Außenminister, 4.5. 1951, PA/AA, Ref. 206, Bd. 43.

${ }^{233}$ Instruktion für Botschafter Prinz Adalbert, 15.9. 1952, PA/AA, 210-01/70, Bd. 1. 
sellschaft ${ }^{234}$. Die Ende September 1950 in München gegründete Institution wollte den kulturellen und wirtschaftlichen Austausch zwischen beiden Ländern fördern ${ }^{235}$. In der Bundesrepublik entwickelte die von Prinz Adalbert von Bayern, dem späteren deutschen Botschafter in Madrid, geleitete Gesellschaft rasch einen Monopolanspruch gegenüber anderen deutsch-hispanischen Kulturvereinen. Den Kreisen und Zirkeln, die an verschiedenen Orten entstanden waren, bot sie sich als Dachorganisation an ${ }^{236}$. Da die Kulturabteilung im Auswärtigen Amt eine Zersplitterung der deutsch-ausländischen Kulturgesellschaften vermeiden wollte, gab es ursprünglich ähnliche Interessen. Doch das Vorgehen des umtriebigen Geschäftsführers Hüffer löste bald Befremden aus: „Die Kulturabteilung kann auch nicht verhehlen, daß die Form, in der Dr. H. [üffer] die Durchführung dieser Zusammenarbeit zu erzwingen versuchte, manchmal nach ,Geichschaltung، aussah [...]. Unter diesen Umständen hat die Kulturabteilung schwere Bedenken, einer von der Münchner Gesellschaft gelenkten Dachorganisation zuzustimmen."237

Nicht nur der ungehemmte Expansionsdrang der Deutsch-Spanischen Gesellschaft, sondern auch die ungelöste Frage nach ihrem Gegenüber in Spanien führten zu Spannungen. Anfangs hatten die Deutsch-Spanische Gesellschaft wie auch das amtliche Bonn auf eine Zusammenarbeit mit der bereits vor 1945 aktiven „Asociación Hispano Germana“ in Madrid gehofft. Die Wiederbelebung dieser „theoretisch immer noch bestehen$\mathrm{de}[\mathrm{n}]$ und anscheinend wieder etwas aktiv werdende[n] Spanisch-Deutsche[n] Gesellschaft ${ }^{\text {"238 }}$ scheiterte aber am fehlenden Interesse der Franco-Regierung, die mit diesem Produkt der faschistischen Ära in der Nachkriegszeit wohl nicht mehr identifiziert werden wollte. Als daraufhin der ohnehin bereits in der Kritik stehende Hüffer die Idee einer „unabhängigen“ Spanisch-Deutschen Gesellschaft in Sevilla ins Spiel brachte, ging das Auswärtige Amt zunehmend auf Distanz. Die Madrider Botschaft hatte sich vehement gegen dieses Projekt ausgesprochen, da die Gefahr bestehe, daß es in die Hände von Spaniern und Deutschen gelangen könnte, die mit dem Nationalsozialismus sympathisierten. In Spanien müsse „unbedingt klar gemacht werden, daß die Bundesrepublik ein neues Deutschland sei, grundverschieden von dem vergangenen Regime. Deshalb müsse man auch den Personen gegenüber stark bleiben, die mit den Nazis verbunden

${ }_{234}$ Zumindest im Haushaltsjahr 1951/52 erhielt die Deutsch-Spanische Gesellschaft einen Zuschuß aus dem Kulturfonds. Vgl. Salat an Hüffer (Geschäftsführer der Deutsch-Spanischen Gesellschaft), 19.10. 1951, PA/AA, Ref. 600, Bd. 111.

235 Vgl. Paragraph 1 der Satzung. Die Gesellschaft wurde am 29. September 1950 gegründet. Eine Deutsch-Spanische Gesellschaft gab es bereits zwischen 1929 und 1945 in Berlin. Darüber hinaus existierten in Leipzig, Frankfurt a. M. und in München Zweiggesellschaften.

${ }^{236}$ Hüffer an Salat, 10.11.1952, PA/AA, Ref. 600, Bd.111. Hüffer, der mit diesem Schreiben Salat als neues Kuratoriumsmitglied begrüßte, bat sogar darum, das Auswärtige Amt möge diesen Anspruch gegenüber anderen Organisationen autorisieren.

${ }_{237}$ Kulturabteilung an Botschaft Madrid, 26.11.1952, PA/AA, Ref.600, Bd. 111. Dic 1952 vereinbarte Kooperation der Deutsch-Spanischen Gesellschaft mit dem Ibero-Amerikanischen Verein in Hamburg war bereits \%wei Jahre später an der Person Hüffers gescheitert.

238 Instruktion für Botschafter Prinz Adalbert, 15. 9. 1952, PA/AA, 210-01/70, Bd. 1. Die Asociación Hispano Germana war Ende 1941 unter dem Vorsitz von General Moscardó geschaffen worden. Ihre Existenz, von Reichsaußenminister Ribbentrop inspiriert, gründete sich auf das Interesse des NS-Regimes an einem intensiveren Dialog mit Spanien. Zugleich sollte damit eine Nachrichten- und Informationsbörse aufgebaut werden. Vgl. Ruhl, Spanien im Zweiten Weltkrieg, S. 55. 
waren“239. Damit war vor allem Hüffer gemeint. Gegen den früheren Kulturreferenten an der Botschaft in Madrid waren mittlerweile Vorwürfe wegen seiner nationalsozialistischen Vergangenheit laut geworden ${ }^{240}$ - für das Auswärtige Amt Anlaß genug, um die weitere Zusammenarbeit mit der Deutsch-Spanischen Gesellschaft in Frage zu stellen. Hüffer sollte in den Hintergrund treten. Falls dies nicht erreicht werden könne, sei an eine weitere Unterstützung nicht mehr zu denken, „um nicht [den] bekannten Vorwürfen gegen die Bundesregierung Nahrung zu geben “241. Mit dem Rücktritt ihres Präsidenten Prinz Adalbert von Bayern im Frühjahr $1953^{242}$ verlor die Gesellschaft weiter an Prestige. Der nur wenige Monate zuvor ernannte Botschafter wollte vor allem auch wegen der Problematik um die Person Hüffer Loyalitätskonflikten aus dem Wege gehen.

Die hochfliegenden Ambitionen Hüffers auf eine maßgebliche Rolle der Gesellschaft im deutsch-spanischen Kulturaustausch erfüllten sich nicht. In einem Überblick des Auswärtigen Amtes vom Oktober 1954 über die deutsch-ausländischen Kulturgesellschaften wurde ihr nur noch eine marginale Rolle zugeteilt: „Als Auffang- und Betreuungsstelle für Besucher aus den iberischen und ibero-amerikanischen Ländern hat die Gesellschaft jedoch eine nützliche und auch im öffentlichen Interesse liegende Funktion zu erfüllen, so daß eine bescheidene finanzielle Unterstützung auch in Zukunft vertretbar erscheint." ${ }^{243}$

Auf der zwischenstaatlichen Ebene nahm das geplante Kulturabkommen Anfang 1953 konkrete Gestalt an. Zwischen der spanischen Botschaft und dem Auswärtigen Amt war jetzt grundsätzlich eine Klärung über das Vertragswerk erzielt worden, das nun aber erst noch in der Bundesrepublik politisch mit den Bundesländern abgestimmt werden mußte. Denn Bonn war aufgrund der Kulturhoheit der Länder auf deren Zusammenarbeit angewiesen, was die Kulturabteilung auch gelegentlich klagen ließ: „Die größte Schwierigkeit ist ja nicht die Einigung mit dem ausländischen Partner, sondern die Notwendigkeit, in ständiger Fühlungnahme mit den Kultusministern zu bleiben, die für die Kulturangele-

${ }^{239}$ Aufzeichnung betr. deutsch-spanische Kulturbeziehungen, 21.4.1953, PA/AA, Ref. 600, Bd. 112. Grundlage war ein Gespräch mit Botschaftsrat Schlitter in Bonn über Fragen der kulturellen Zusammenarbeit.

2.10 Vermerk Deubner betr. Geschäftsführer der Deutsch-Spanischen Gesellschaft Dr. Hüffer, 15. 11. 1952, PA/AA, Ref. 600, Bd. 111. Danach war Hüffer während des „Dritten Reiches“ ein sehr aktiver Nationalsozialist. Deshalb habe es der Kulturreferent der Botschaft Madrid, Bauer, auch abgelehnt, der DeutschSpanischen Gesellschaft beizutreten. Der Vorsitzende der Gesellschaft, Prinz Adalbert von Bayern, war zunächst über Hüffers Vergangenheit nicht informiert. Der Historiker Hüffer hatte im Jahre 1942 die „Blaue Division“ als „Vormauer und Hort unserer verjüngten Kulturgemeinschaft“ beschrieben. Vgl. Briesemeister, Die Iberische Halbinsel und Europa, S. 20.

241 Ebenda, Vermerk Deubner.

242 Aufzeichnung betr. deutsch-spanische Kulturbeziehungen, 21. 4. 1953, PA/AA, Ref. 600, Bd. 112. Botschaftsrat Schlitter sprach lediglich davon, daß Prinz Adalbert „vor kurzem“ seinen Rücktritt als Präsident erklärt habe. In Prinz Adalberts Memoiren wird die Münchner Einrichtung nur am Rande erwähnt. ${ }_{213}$ Aufzeichnung Rumpf, 14.10.1954, PA/AA, Ref.600, Bd. 112. Zu diesem Zeitpunkt waren in der Deutsch-Spanischen Gesellschaft mit ihren Niederlassungen in Berlin und Köln 500 Mitglieder organisiert. Allerdings lebe sie überwiegend von dem „Ehrgeiz und Betätigungsdrang von Herrn Hüffer“. Inwieweit die Gesellschaft später noch eine Rolle im Kulturaustausch spielen konnte, muß aufgrund der spärlichen Quellenüberlieferung nach 1954 offenbleiben. Die Akten der Kulturabteilung aus den 50er Jahren sind in einem nicht unerheblichen Umfang kassiert worden. Unterlagen der Deutsch-Spanischen Gesellschaft stehen nicht mehr zur Verfügung. Vgl. Schreiben der heutigen Deutsch-Hispanischen Gesellschaft, 22.6. 1989 . 
genheiten primär zuständig sind. “" ${ }^{44}$ Dem Sonderausschuß der Kultusminister-Konferenz lag seit Februar 1953 ein deutsch-spanischer Entwurf vor. Rücksicht mußte das Auswärtige Amt dabei sowohl auf die von der SPD geführten Bundesländer als auch auf die immer noch nicht abgeschlossenen Verhandlungen mit anderen Staaten nehmen. Zu diesem Zeitpunkt war noch kein anderes Vertragswerk unterschriftsreif, so daß der deutsch-spanische Entwurf, ungeachtet seiner möglichen Billigung durch die Bundesländer, nicht weiter vorangetrieben werden konnte. Es sei „ausgeschlossen“, wurde die deutsche Vertretung informiert, „als erstes Kulturabkommen der Bundesrepublik das deutsch-spanische zu unterzeichnen "245. Das von außenpolitischen Rücksichten bestimmte Zögern dauerte also an.

Aber auch innenpolitisch mußte mit Einwänden gerechnet werden. Bonn lehnte deshalb im Februar die Anregung der Madrider Vertretung ab, die noch ausstehenden Gespräche in der spanischen Hauptstadt fortzuführen. Das Kulturreferat befürchtete nämlich, daß die ohnehin schon vorhandenen Vorbehalte der SPD-Kultusminister bei einem Wechsel des Verhandlungsorts neue Nahrung finden könnten. In diesem Fall käme sofort die Vermutung auf, „die Verhandlungen würden allzusehr unter den Einfluß der FrancoRegierung gelangen, wenn ausgerechnet für das deutsch-spanische Kulturabkommen die bisherige Übung aufgegeben würde, sie in Bonn zu führen" ${ }^{246}$. Schwierigkeiten mit den Bundesländern gab es ohnehin. Auch die grundsätzliche Frage der Zustimmungsbedürftigkeit der Länder war noch ungeklärt. Ohne das vorherige Einverständnis ihrer Kabinette sahen sich die Minister in der Kultusminister-Konferenz jedenfalls außerstande, ihre endgültige Zustimmung zu geben. Bei den USA war dies unproblematisch gewesen. Während das deutsch-amerikanische Kulturabkommen bereits von sämtlichen Länderkabinetten gebilligt worden war ${ }^{247}$, konnte im Falle Spanien nicht mit einem einhelligen Votum gerechnet werden, obwohl die Kultusminister-Konferenz keine inhaltlichen Einwände mehr hatte. Die prinzipiellen Vorbehalte einiger SPD-Kultusminister ließen aber ernste Zweifel an der Billigung aller Länder aufkommen ${ }^{248}$. Deshalb schlug die Kulturabteilung Staatssekretär Hallstein vor, die Ratifizierung durch einen bloßen Notenwechsel zu umgehen ${ }^{249}$.

244 Salat an Botschaft Madrid, 5.2.1953, PA/AA, Ref.600, Bd. 158. Die Botschaft wurde über einen grundsätzlichen Kompetenzkonflikt zwischen Bund und Ländern informiert. Es bedurfte langwieriger Diskussionen, um die Kultusminister davon zu überzeugen, daß allein dic Bundesregicrung befugt sei, Kulturabkommen mit dem Ausland zu schließen. Die Länderkompetenzen galten z. B. für die Lehrplänc an den deutschen Auslandsschulen, das Hochschulwesen und die Anerkennung von Schul\%eugnissen.

24.5 Salat an Botschaft Madrid, 23. 2. 1953, PA/AA, Ref. 600, Bd. 158.

246 Ebenda.

247 Vorlage der Kulturabteilung für Staatssckretär Hallstein betr. Ratifizierung der deutsch-ausländischen Kulturabkommen, 19.5.1953, PA/AA, Ref. 600, Bd. 158.

248 In der Konferenz der Kultusminister war man nicht zu einer einheitlichen Auffassung über die „Notwendigkeit" eines deutsch-spanischen Vertrages gekommen. Vgl. Schreiben der Ständigen Konferenz der Kultusminister der Länder (KMK) an Salat, 22.4. 1953, PA/AA, Ref. 600, Bd. 158.

249 Vorlage der Kulturabteilung für Staatssekretär Hallstein, 19.5. 1953, PA/AA, Ref. 600, Bd. 158. Hallstein wurde gebeten, die Frage der Ratifikation von Kulturabkommen grundsätzlich zu regeln, da Unsicherheit darüber herrsche, was im Falle eines negativen Votums eines oder mehrerer Länder zu geschehen habe. Denn die Rechtsabteilung im Auswärtigen Amt hatte in einem Gutachten vom 24. Februar darauf hingewiesen, daß ,jede einzelne Landesregierung dem Abschluß eines Kulturabkommens mit dem Bund durch ausdrücklichen Beschluß zustimmen und diese Zustimmung dem Auswärtigen Amt mitteilen muß“. Schreiben der KMK an Salat, 22. 4. 1953, PA/AA, Ref. 600, Bd. 158. 
In dieser innen- wie außenpolitisch unklaren Situation ging es im bilateralen Verhältnis vor allem darum, Zeit zu gewinnen. Insofern kam der Bundesregierung das Angebot der spanischen Botschaft im Juni 1953 sehr gelegen, alles zu tun, um dem Kanzler bei den bevorstehenden Bundestagswahlen im September zu helfen ${ }^{250}$. Diese unverhoffte Geste nutzte das Auswärtige Amt zu einem Aufschub. Der Leiter der Kulturabteilung, Salat, machte aus seiner politischen Präferenz keinen Hehl: Der Beamte wollte auch aus wahltaktischen Gründen die Unterzeichnung zurückstellen. Kurz vor den Wahlen erschien es ihm nicht angebracht, ausgerechnet mit dem umstrittenen franquistischen Regime das erste deutsch-ausländische Kulturabkommen ${ }^{251}$ abzuschließen. Dies wäre, so Salat gegenüber der Madrider Botschaft, einer Einladung an die Opposition gleichgekommen: „Es bedarf keiner großen Phantasie, um sich vorzustellen, wie ein derartiger Akt von den politischen Gegnern des Herrn Bundeskanzlers im Wahlkampf ausgenützt würde. Es wäre auch sehr bedauerlich, wenn damit auch ein internationales Abkommen in parteipolitische Kämpfe hineingezogen würde. “252

Als Bonn aber auch nach der Bundestagswahl keine Anstalten machte, den anhaltenden Schwebezustand zu beenden, kam die deutsche Vertretung in Madrid mehr und mehr in argumentative Schwierigkeiten. Nach fast einem Jahr, klagte Botschafter Prinz Adalbert im Mai 1954, wachse in Spanien die Verstimmung darüber, daß der Vertrag von der Bundesrenpublik nach wie vor hinausgezögert werde. Die vorher genannten innenpolitischen Überlegungen seien bis zu den Wahlen hier verständnisvoll akzeptiert worden. Außerdem bezweifelte er, daß die juristischen Probleme zwischen Bund und Ländern immer noch nicht geklärt seien. Die außenpolitischen Rücksichten auf andere Länder könne er nicht offenlegen, denn dies „hätte die Spanier erst recht vergrämt“"253. Der Botschafter versprach sich von dem baldigen Abschluß auch eine positive Wirkung auf die Eigentumsfrage. Während die Kulturabteilung das Plädoyer Prinz Adalberts unterstützte ${ }^{254}$, blieb die politische Führung des Auswärtigen Amtes dabei, aus außenpolitischen Gründen weiter abzuwarten ${ }^{255}$. Die bereits ausgeräumten verfassungsrechtlichen Bedenken ${ }^{256}$ mußten weiterhin als Argument gegenüber Spanien herhalten ${ }^{257}$.

Neuen Bewegungsspielraum erhielt Bonn im Oktober 1954 mit dem Abschluß des deutsch-französischen Kulturabkommens ${ }^{258}$. Damit war der Weg für das deutsch-spanische Pendant frei. Am 10. Dezember 1954 wurde es schließlich von Bundeskanzler Adenauer

${ }^{250}$ Aufzeichnung Salat über sein Gespräch mit dem stellvertretenden Kulturattaché der spanischen Botschaft Suárez, 23. 6. 1953, PA/AA, Ref. 600, Bd. 159.

${ }_{251}$ Strenggenommen war das deutsch-amerikanische Kulturabkommen das erste seiner Art. Die Vereinbarung vom 9. April 1953 erfolgte aber lediglich als Notenaustausch und wurde deshalb vom Auswärtigen Amt nicht als „richtiges" Kulturabkommen betrachtet.

${ }_{252}$ Salat an Botschaft Madrid, 23. 6. 1953, PA/AA, Ref. 600, Bd. 159.

${ }_{253}$ Prinz Adalbert an Auswärtiges Amt, 20.5. 1954, PA/AA, Ref. 600, Bd. 160.

${ }^{254}$ Stellungnahme der Kulturabteilung für Staatssekretär Hallstein, 31. 5. 1954, PA/AA, Ref. 600, Bd. 160.

25.5 Vermerk zum Ergebnis der Direktorenbesprechung, 25. 6. 1954, PA/AA, Ref. 600, Bd. 160.

256 Im Januar 1954 war die Rechtsabteilung im Auswärtigen Amt nach der Durchsicht der geplanten Kulturabkommen mit Frankreich, Großbritannien und Spanien jedenfalls davon überzeugt, daß die Unterzeichnung und Ratifikation ohne Beteiligung des Bundesrates erfolgen könne. Auch sei eine „informelle Zustimmung“ der Länderregierungen nicht notwendig. Vgl. Vermerk über Gespräch zwischen Kulturund Rechtsabteilung, 27. 1. 1954, PA/AA, Ref. 600, Bd. 160.

${ }^{257} \mathrm{Vgl}$. Aufzeichnung der Kulturabteilung für ein Gespräch zwischen Staatssekretär Hallstein und Botschafter Prinz Adalbert, 5. 8. 1954, PA/AA, Ref. 600, Bd. 34.

${ }_{258}$ Die Kulturabkommen mit Italien und Großbritannien wurden im Februar 1956 bzw. im Mai 1958 abgeschlossen. 
und dem spanischen Botschafter in Bonn unterzeichnet. Beide Seiten erklärten sich in allgemeiner Form, „die Kenntnis und das Verständnis der geistigen, wissenschaftlichen und künstlerischen Tätigkeit des anderen Landes zu erhalten und zu mehren "259. Inhaltlich war das Vertragswerk ein Katalog von allgemein gehaltenen Absichten, der in erster Linie die Zusammenarbeit und den Austausch in Forschung und Lehre umfaßte. Darüber hinaus sollte die Arbeit der Auslandsschulen gefördert werden. Auch auf künstlerischer Ebene sicherten sich die Vertragspartner Unterstützung zu. Politisch brisant konnte die Durchführung von Art. 8 werden. Dieser beinhaltete, daß die Regierungen sich um „die Berichtigung von Irrtümern bemühen, die durch Bücher, Artikel oder Nachrichten verbreitet werden und in denen die historischen Tatsachen zum Schaden eines der beiden Teile entstellt wiedergegeben sind “260. Umsetzen sollte all dies ein von beiden Ländern paritätisch besetzter Ausschuß, von „dessen Wirksamkeit“, wie Staatssekretär Hallstein im Juni 1955 prognostizierte, „der Erfolg [der Übereinkunft] abhängen wird“"261.

Der Abschluß des Kulturabkommens wurde in der westdeutschen Presse als Erfolg und Fortschritt in den beiderseitigen Beziehungen kommentiert. Die „Deutsche Zeitung und Wirtschaftszeitung“ etwa sprach von einem „Lichtblick in der Entwicklung einer Freundschaft, auf die in den letzten Jahren unnötigerweise der Schatten ideologischer Rücksichten auf dritte Länder gefallen war. Man möchte wünschen, daß es der Beginn einer neuen Spanienpolitik der Bundesregierung wird“262. Der Artikel übersah aber weitgehend, daß es auch hausgemachte Probleme im Verhältnis beider Länder gab. Selbst im Auswärtigen Amt war es umstritten, ob das Kulturabkommen wegen der ungelösten Enteignungsfrage politisch überhaupt in die Landschaft paßte. Noch einen Monat vor der Unterzeichnung hatte sich der für das Auslandsvermögen zuständige Referent gegen ein Kulturabkommen ausgesprochen. Ohne vorherige Zugeständnisse Spaniens, insbesondere in der Frage der beschlagnahmten Schulgebäude, sei eine solche Vereinbarung derzeit „untragbar“263. Aber die Bundesregierung entschied sich anders. Sie unterzeichnete zwar auf spanisches Drängen hin das Kulturabkommen, machte aber dem Vertragspartner deutlich, daß aus deutscher Sicht ein „moralisches Junktim“ mit der Vermögensfrage bestehe. Bonn sah das Kulturabkommen als Vorleistung, die im Gegenzug von Madrid durch die Rückgabe der beschlagnahmten Schulgebäude honoriert werden sollte.

Botschafter Prinz Adalbert wies Außenminister Artajo kurz nach der Unterzeichnung darauf hin, die Bundesrepublik erwarte nunmehr eine Rückgabe der Schulgebäude bzw. Schulgrundstücke ${ }^{264}$. Da Madrid keine Taten folgen ließ, trat zwar das Kulturabkommen

259 Vgl. Bulletin des Presse- und Informationsamtes der Bundesregierung, 11. 12. 1954.

260 Vgl. cbenda.

${ }^{261}$ Kabinettsvorlage des Auswärtigen Amtes zum dcutsch-spanischen Kulturabkommen, 13.6. 1955, PA/AA, L. 1, Bd. 178.

262 Deutsche Zeitung und Wirtschaftszeitung, 18. 12. 1954.

${ }^{263}$ Vermerk von Waldheim betr. Verhandlungen mit Spanien, 23.11.1954, PA/AA, Ref. 600, Bd. 160. Schon früher waren von Waldheim derartige Einwände geäußert worden. Vgl. Vermerk Rumpf, 28. 8. 1953, PA/AA, Ref. 600, Bd. 159.

${ }^{264}$ Prinz Adalbert an Auswärtiges Amt, 28. 12. 1954, PA/AA, Ref. 600, Bd.113. Staatssekretär Hallstein gab dem Bundestag im März 1956 Auskunft über die Lage der deutschen Schulen in Spanien. Danach waren seit 1949 zehn Schulen wiedercröffnet oder neu gegründet worden, die zur Zeit von etwa 2280 Kindern besucht werden. Die provisorische Unterbringung der Schulen in neu gemieteten Räumen sei „einigermaßen befriedigend“. Alle Schulen erhielten Unterstützung aus Bundesmitteln. Vgl. 2. Deutscher Bundestag, 133. Sitzung vom 8. 3. 1956, Stenographische Berichte, S. 6889 ff. 
am 14. März 1956 in Kraft, de facto aber legte es Bonn als Reaktion auf das fehlende Entgegenkommen auf Eis. So wurde das vorgesehene Arbeitsgremium, der „Ständige Gemischte Ausschuß“, erst gar nicht besetzt. Damit stand das Abkommen jahrelang bloß auf dem Papier.

Allerdings bemühte sich die deutsche Botschaft in Spanien darum, den Stillstand im Kulturaustausch durch eigene Aktivitäten zu kompensieren. Das Projekt einer deutschen Kulturwoche in Madrid wurde von Botschafter Knappstein, der im Oktober 1956 Prinz Adalbert von Bayern abgelöst hatte, engagiert vorangetrieben. Bei der Programmplanung galt es auch die spezifischen Bedingungen der franquistischen Kulturpolitik zu berücksichtigen. Knappstein erläuterte dem Auswärtigen Amt Ende 1956, daß etwa bei der Auswahl des Spielfilmangebots auf bestimmte inhaltliche Prämissen zu achten sei. Daher legte er Bonn eine Negativliste vor. Nicht in Frage kamen demnach: „Weltanschauliche Filme, Filme politischen Charakters, Filme mit tiefenpsychologischen Motiven, Filme, die schwere Familienkonflikte zeigen." ${ }^{265}$ Nach monatelangen Vorbereitungen konnte dann am 6. Oktober 1957 in Madrid die erste deutsche Kulturwoche nach dem Kriege eröffnet werden. Dem spanischen Publikum wurden unter anderem der für das Bild von Nachkriegsdeutschland nichtssagende, aber politisch unverfängliche Dokumentarfilm des Frankfurter Zoodirektors Grzimek „Kein Platz für wilde Tiere“ sowie ein Streifen über „Deutsche Sitten und Gebräuche" präsentiert ${ }^{266}$. Den Schwerpunkt bildete eine von Botschafter Knappstein selbst angeregte Werkschau des zeitgenössischen Malers Professor Georg Muche $^{267}$. Ein Konzert des Stuttgarter Kammerorchesters, eine Sammlung künstlerischer Publikationen sowie wissenschaftliche Vorträge rundeten die Kulturwoche ab.

Knappstein zog ein optimistisches Resümee. Trotz der vereinzelten Kritik in der deutschen Presse, die angesichts der nach wie vor ungelösten Eigentumsfrage den Zeitpunkt bemängelt hatte, bewertete er die Kulturwoche „als großen Erfolg“. Nach seiner Überzeugung werde dieses Ereignis nachhaltig wirken „und sich günstig auf die Beziehungen zwischen den beiden Nationen auswirken“268.

Derartige kulturelle Veranstaltungen blieben aber zunächst bloßes Dekor. Das politische Klima zwischen Westdeutschland und Spanien blieb weiterhin von dem Konflikt um das enteignete deutsche Vermögen bestimmt. Eine nachhaltige Veränderung war erst mit der im Frühjahr 1958 vereinbarten Eigentumsregelung möglich. Da sich Madrid hierbei auch zur Rückgabe von sechs Schulgebäuden bzw. Schulgrundstücken verpflichtet hatte, boykottierte Bonn das Kulturabkommen nun nicht länger. Knapp drei Jahre nach seinem Inkrafttreten fand schließlich im Februar 1959 die erste Arbeitstagung der deutsch-spani-

265 Knappstein an Auswärtiges Amt, 20. 12. 1956, PA/AA, Ref. 600, Bd. 197.

266 Bericht Botschaft Madrid betr. deutsche Kulturwoche in Madrid, 22. 10. 1957, PA/AA, Ref. 600, Bd. 197.

267 Knappsteins Idee einer Ausstellung moderner Malcrei war in Bonn anfangs aufgrund der Unkenntnis der spanischen Kulturpolitik nicht auf Gegenliebe gestoßen. Die vorhandenen "grundsätzlichen Bedenken" suchte er mit dem Hinweis auf bereits positiv aufgenommene Ausstellungen deutscher, italienischer und amerikanischer zeitgenössischer Künstler auszuräumen. Überdies sei die Annahme falsch, daß es in Spanien „wegen der besonderen politischen Struktur des Staates ähnliche Tendenzen gäbe, wie sie im Dritten Reich in dem Kampf gegen die sogenannte ,Entartete Kunst' zum Ausdruck kamen“. Die Bilder von Muche, einem Schüler Kandinskys, hielt Knappstein „wegen ihrer leuchtenden Farben und ihrer spielerischen Leichtigkeit für besonders geeignet, in Spanien gezeigt zu werden“. Vgl. Bericht Knappstein an Auswärtiges Amt, 20.3. 1957, PA/AA, Ref. 600. Bd. 197.

268 Bericht Botschaft Madrid betr. deutsche Kulturwoche in Madrid, 22. 10. 1957, PA/AA, Ref. 600, Bd. 197. Am Ende der Kulturwoche wurde das Deutsche Kulturinstitut in Madrid eröffnet. 
schen Kulturkommission ${ }^{269}$ statt. Ein Anfang zur inhaltlichen Ausgestaltung war damit. gemacht.

Der Nachfolger Knappsteins, Botschafter von Welck, kommentierte das Zusammentreffen der Kommission in Madrid denn auch erleichtert als einen „wesentlichen Abschnitt“ in den zwischenstaatlichen Kulturbeziehungen: „In deutschen wie in spanischen Kreisen gab es manche, denen bekannt war, daß das am 10. Dezember 1954 abgeschlossene deutsch-spanische Kulturabkommen leerer Buchstabe bleiben müsse, solange der Ständige Gemischte Ausschuß nicht zusammengetreten war." ${ }^{\text {"270 }}$

Die anfänglichen Hoffnungen Bonns, das Kulturabkommen könnte den Weg für eine wirkliche Annäherung bereiten, hatten sich nicht erfüllt. Solange der bilaterale Dauerkonflikt, die Enteignungsfrage, nicht gelöst war, blieb der staatliche Kulturaustausch inhaltsleer.

\section{Ein deutscher Pressekorrespondent in Spanien - Die „Berichtsfabrik" Heinz Barth}

Wie konfliktträchtig die Zusammenarbeit der beiden politisch unterschiedlichen Systeme war, zeigte sich bei der Vorbereitung auf die erste Sitzung der deutsch-spanischen Kulturkommission. Erst jetzt wurde der deutschen Seite bewußt, daß der Artikel 8 des Kulturabkommens Stoff für Kontroversen bot. Darin war nämlich vereinbart worden, man werde sich darum bemühen, „Irrtümer“, die durch „Bücher, Artikel oder Nachrichten verbreitet werden “'271, zu berichtigen. Eine solche Absichtserklärung wäre anderen, demokratischen Staaten gegenüber unverfänglicher gewesen.

Die deutsche Vertretung in Madrid befürchtete, es könnte angesichts unterschiedlicher Standpunkte zur jüngsten Geschichte zu einem dauerhaften Streit kommen: „Damit aber würde der Sinn des Kulturabkommens, dessen Aufgabe es ist, Reibungen zwischen den Nationen zu mindern, in sein Gegenteil verkehrt werden. "272 Der Botschaft bereitete nicht nur die mögliche Geschichtsdebatte Unbehagen. Sie sah vor allem die Gefahr, der Artikel 8 könne dem Franco-Regime die Handhabe für eine ständige Auseinandersetzung um mißliebige Presseberichte bieten. Unter Hinweis auf eine gerade in Spanien von der Zensur $^{273}$ verbotene „Spiegel“-Ausgabe wies Botschaftsrat Werz auf die seiner Meinung nach „oft sehr kritische Beurteilung des spanischen Staatschefs und seines Regimes in der deutschen Presse“274 hin. In seinem Kommentar „Beten für Franco“ hatte Moritz Pfeil (d.i. Rudolf Augstein) im Dezember 1958 die katholische Kirche in der Bundesrepublik daran

269 Der deutschen Kommission gehörten vier Mitglieder an. Neben einem Vertreter des Auswärtigen Amtes, des Bundesinnenministeriums und der Ständigen Konferenz der Kultusminister war auch der Bonner Romanist Professor Harri Meier vertreten. Den Vorsitz übernahm der stellvertretende Staatssekretär im Auswärtigen Amt Knappstein. Schreiben des Leiters der Kulturabteilung von Trützschler an Botschaft Madrid, 12. 9. 1958, PA/AA, Ref. 600, Bd. 135.

270 Bericht Botschaft Madrid betr. erste Sitzung der deutsch-spanischen Kulturkommission (25.-28. Februar), 14. 3. 1959, PA/AA, Bestand Botschaft Madrid, Bd. 7667.

271 Vgl. zum Wortlaut des Abkommens: Bulletin des Presse- und Informationsamtes der Bundesregierung, 11. 12. 1954.

272 Aufzeichnung Peiser, Botschaft Madrid, 8. 1. 1959, PA/AA, Bestand Botschaft Madrid, Bd. 7667.

273 Vgl. Lorenzen, Presse unter Franco.

274 Vermerk Werz, Botschaft Madrid, zur Deutsch-Spanischen Kulturkommission, 12. 1. 1959, PA/AA, Bestand Botschaft Madrid, Bd. 7667. 
erinnert, daß das Prinzip der Menschenrechte von Diktaturen in Ost und West gleichermaßen verletzt werde, und dabei eine Parallele zwischen Tito, Gomulka und Franco gezogen $^{275}$. Werz befürchtete, daß Madrid aus solchen Aussagen die Forderung nach Gegenmaßnahmen der Bundesregierung ableiten könne. Deshalb warnte der Botschaftsrat Bonn „dringend“ davor, diesen politisch heiklen Artikel des Kulturabkommens zu erörtern.

Das Auswärtige Amt sah die Dinge aber offenbar gelassener, einer entsprechenden Diskussion im gemeinsamen Kulturausschuß wollte man jedenfalls nicht von vornherein ausweichen. Die deutsch-spanischen Gespräche verliefen unproblematisch: Beide Seiten verständigten sich darauf, eine von Spanien gewünschte Revision der Schulgeschichtsbücher an das „Internationale Schulbuchinstitut“ in Braunschweig und sein Pendant das „Centro de Orientación Didáctica“ zu delegieren. Diese sollten ein gemeinsames Thesenwerk über die deutsche und spanische Geschichte vorlegen. Außerdem drängte Madrid darauf, die pittoresken Darstellungen Spaniens („Land der Esel, Zigeuner, Bettler“) in bundesdeutschen Völkerkunde- und Geographiebüchern zu beseitigen. Das Thema Pressezensur wurde überhaupt nicht angesprochen ${ }^{276}$. Dies mag auch daran gelegen haben, daß die spanische Regierung, abgesehen von der prinzipiellen Kritik aus dem linken Spektrum, mit dem von ihr in der Bundesrepublik gezeichneten Bild überwiegend zufrieden sein konnte. Zwar schieden sich publizistisch am Franco-Regime die Geister. Nicht nur „Der Spiegel“ oder die „Frankfurter Rundschau“ vertraten in ihrer sporadischen Berichterstattung über Spanien eine kritische Haltung. Aus ihrem antifaschistischen Selbstverständnis heraus prangerten ebenso die zahlreichen sozialdemokratischen Presseorgane ${ }^{277}$ beharrlich den undemokratischen Charakter des Regimes an. Das Gros der westdeutschen Medien stellte aber die franquistische Diktatur in einem milden Lichte dar.

Dafür sorgte vor allem die „Berichtsfabrik“ Heinz Barth ${ }^{278}$, der in den 50er Jahren zeitweilig mindestens fünfzehn bundesdeutsche Zeitungen und vier Radiostationen belieferte. Die Spanien-Berichterstattung lag damit nahezu in einer Hand, denn Barth schrieb auch für die meisten überregional bedeutsamen Blätter, wie die „Süddeutsche Zeitung“, „Welt“, „Tagesspiegel“, „Stuttgarter Nachrichten“ und die „Westdeutsche Allgemeine Zeitung“ - eine größere Reichweite hatte kein anderer deutscher Journalist ${ }^{279}$. Diese Omnipräsenz spiegelte einerseits das geringe Interesse an dem politisch isolierten Land wider,

27. Der Spiegel, Nr. 51, 17. 12. 1958, S. 7.

276 Vgl. Ergebnisprotokoll der ersten Sitzung des Ständigen Gemischten Ausschusses, 13.3. 1959, PA/AA, Bestand Botschaft Madrid, Bd. 7667.

277 Die traditionsreiche SPD-Presse umfaßte 1956 immerhin 26 Zeitungen. Vgl. zur Entwicklung der Presselandschaft in der Bundesrepublik die skizzenhafte Darstellung von Frei, Die Presse, S. 308.

278 So titulierte ihn der Leiter des Pressereferats im Auswärtigen Amt, Günter Diehl, Mitte der 50er Jahre. Vgl. das Schreiben Diehls an das Spanienreferat, 16.8. 1955, PA/AA, Ref. 203, Bd. 473.

279 Außerdem berichtete er über spanische Themen in: Frankfurter Neue Presse, Mannheimer Morgen, Düsseldorfer Nachrichten, Norddcutsche Zeitung, Schwäbische Zeitung, Westfälische Nachrichten, Weser-Kurier, Wuppertaler Generalanzeiger, Hamburger Abendblatt, Deutsche Zeitung und Wirtschaftszeitung. Überdies arbeite Barth, so die Madrider Botschaft, noch für weitere Zeitungen und Zeitschriften. Seinc Artikel für Die Welt schrieb er unter dem Pseudonym „Gottfried Grosse“, während er für die SZ die spanische Form seines Vornamens (Enrique) verwendete. An Rundfunkstationen vertrat er den Sender Freies Berlin, Radio Bremen, den Nordwestdeutschen Rundfunk und den Hessischen Rundfunk. Botschaft Madrid an Auswärtiges Amt, 13.6. 1955, PA/AA, Ref. 206, Bd. 33. 
das nur gelegentlich Aufmerksamkeit erfuhr ${ }^{280}$. Andererseits war die dominierende Position Barths auch Ausdruck des Neubeginns der westdeutschen Presse insgesamt.

Die Auslandsberichterstattung steckte noch in den „Kinderschuhen“, das Korrespondentennetz mußte nach dem Kriege erst wieder neu geknüpft werden. Ebenso wie andere Bereiche der westdeutschen Gesellschaft stand auch der Journalismus vor dem grundlegenden Problem, eine „neue“ demokratische Presse 281 überwiegend mit dem „alten“ Personal entwickeln zu müssen. Nicht nur für Barth galt, daß sich viele Journalisten bei ihrer Nachkriegskarriere gegenseitig halfen. So fanden sich u. a. in den Reihen der von den Briten gegründeten „Welt" mehrere Redakteure wieder, die wie Barth zuvor für die NSWochenzeitung „Das Reich“ geschrieben hatten. Daher war es nicht verwunderlich, daß auch der ehemalige Kollege Barth seit 1949 für „Die Welt“ arbeiten konnte ${ }^{282}$. Insgesamt kam es in der Publizistik zu einer „kollegiale[n] Zwangsgemeinschaft der wenigen Unbefleckten mit den vielen Halbverstrickten und Läuterungswilligen “283.

Heinz Barth (Jahrgang 1910), NSDAP-Mitglied seit $1936^{284}$, der von 1939 bis zu seiner Einberufung zur Wehrmacht 1944 für die „Deutsche Allgemeine Zeitung“ und die Wochenzeitung „Das Reich“ sowie das „Deutsche Nachrichtenbüro“ aus Spanien berichtet hatte, gehörte sicherlich zu den vielen „Halbverstrickten“. Als Buchautor pries er 1940 in einer von Paul Karl Schmidt, dem Chef der Nachrichten- und Presseabteilung im Auswärtigen Amt, herausgegebenen Propagandaschrift die faschistische „Revolution am Mittel-

280 Eine Darstellung zum Bild Spaniens in der westdeutschen Publizistik ist noch ein Desiderat der Forschung. Eine erste Annäherung an das Thema findet sich bei Briesemeister, Spanien in der deutschen Essayistik und Zeitungsberichterstattung der Jahre 1945 bis 1968, S. 83-90. Für die Zeit zwischen 1945 bis 1949 vgl. Aschmann, „Treue Freunde ..."?, S. 150-109.

281 Zum Neubeginn der Presse in Deutschland siehe: Hurwitz, Die Stunde Null der deutschen Presse; Koszyk, Pressepolitik für Deutsche; Hachmeister/Siering (Hrsg.), Die Herren Journalisten; Hodenberg von, Die Journalisten und der Aufbruch zur kritischen Öffentlichkeit; Weiß, Journalisten.

282 Vgl. dazu Frei, Stunde Null der deutschen Presse?, S. 187 f.

283 Ebenda, S. 189. In den von Peter Köpf untersuchten 151 Nachkriegsredaktionen der Jahre 1945-1949 fanden sich lediglich 25 Redaktionen ohne nationalsozialistische Vergangenheit. Über 500 Journalisten hatten bereits zwischen 1936 und 1945 in der Presse des „Dritten Reiches“ gearbeitet; Köpf, Schreiben nach jeder Richtung, S. 237. Siehe auch: Köhler, Unheimliche Publizisten. Die verdrängte Vergangenheit der Medienmacher. Diesem Buch liegt die bereits 1989 erschienene Studie Köhlers „Wir Schreibmaschinentäter" zugrunde. In der vollständig überarbeiteten Neufassung verzichtet der Autor ohne Angabe von Gründen auf das Kapitel zu Heinz Barth.

${ }^{284}$ Auskunft des Bundesarchivs, Außenstelle Berlin-Zehlendorf (früher Berlin Document Center). Die Barth in der Nachkriegszeit wiederholt unterstellte nachrichtendienstliche Tätigkeit für den Sicherheitsdienst (SD) der SS konnte vom Bundesarchiv nicht bestätigt werden. Dieses Gerücht geht auf Franz Heinrich Pfeifer, einen früheren Mitarbeiter Heydrichs, zurück. Pfeifer hatte 1945 unter dem Namen Heinrich Orb über die Spionagetätigkeit zahlreicher Auslandskorrespondenten berichtet. Vgl. Orb, Nationalsozialismus. Dreizehn Jahre Machtrausch. Siehe ebenfalls Köhler, Unheimliche Publizisten, S. 208. Auch das Auswärtige Amt hatte 1955 Aufklärungsbedarf. Es bat die deutsche Vertretung in Madrid, „streng vertraulich“ festzustellen, ob Barth mit Wissen der spanischen Behörden während des Krieges für den SD und nach 1945 für französische Sicherheitsbehörden gearbeitet habe. Vgl. Welck an Botschafter Prinz Adalbert, 24. 6. 1955, PA/AA, Ref. 203, Bd.473. Nach Recherchen bei den spanischen Behörden und einer „sonst zuverlässige[n] alliierte[n] Stelle“ konnte die Botschaft keine Anhaltspunkte für Barths geheimdienstliche Aktivitäten finden. Vgl. Botschafter Prinz Adalbert an Auswärtiges Amt, 26. 6. 1955, PA/AA, Ref. 203, Bd.473. Das „neutrale“ Spanien war im Zweiten Weltkrieg aufgrund seiner strategischen Lage ein für die deutsche Auslandsspionage begehrter Platz. Vgl. Höhne, Canaris. Patriot im Zwiclicht, S. 407 f.; Collado Seidel, Zufluchtsstätte für Nationalsozialisten?, S. 134-144. 
meer“285. Auch mit seinen Zeitungsartikeln fügte sich Barth damals harmonisch in die oberflächliche und klischeehafte Spanien-Berichterstattung der deutschen Medien ein, die von den ideologischen Maximen des NS-Weltbildes getragen war ${ }^{286}$. Seit dem Beginn des Zweiten Weltkrieges rückten dabei Retrospektiven auf den Bürgerkrieg und die Vorstellung von der antibolschewistisch inspirierten Freundschaft in den Vordergrund. Das Interesse an Francos Außenpolitik ließ allerdings mit dem Kriegsverlauf seit 1944 stark nach, die deutsch-spanische Gemeinsamkeit wurde öffentlich nur noch selten akzentuiert ${ }^{287}$.

Nach dem Kriege setzte Barth seine journalistische Karriere in vertrauter Umgebung fort. Er kehrte 1947 mit einem chilenischen Paß nach Madrid zurück ${ }^{288}$. Bevor Barth wieder verschiedene deutsche Blätter mit Eindrücken aus Spanien versorgte, schrieb er zunächst im Auftrag der faschistisch geprägten Staatspartei Falange propagandistische „Stimmungsberichte“, die im westlichen Ausland um Sympathie für das politisch isolierte Land werben sollten ${ }^{289}$. Das antikommunistische Klima in der frühen Bundesrepublik erleichterte es Barth, seine regimefreundliche Haltung in ähnlicher Weise auch dem deutschen Zeitungspublikum nahezubringen. Wie ein roter Faden durchzieht seine Artikel die Mahnung, die „alte, durch keinerlei historische Hypotheken belastete Freundschaft, die beide Länder miteinander verbindet" ${ }^{\text {"290, }}$ zu einer engeren Zusammenarbeit zu nutzen. Dabei trat der Korrespondent überwiegend als Sachwalter Spaniens auf. Das unterkühlte bilaterale Verhältnis war für ihn in erster Linie die Folge der außenpolitischen Rücksicht Bonns auf die antifranquistischen Vorbehalte anderer westlicher Staaten, die aus seiner Sicht immer fragwürdiger wurde. Nachdem die USA als „mächtigste Demokratie der Erde“291 gleichsam vorbildhaft zum „Bundesgenossen Francos“ geworden seien, habe diese „etwas übertriebene Vorsicht“ endgültig ihren Sinn verloren. So klagte er im März 1955, kurz bevor die Bundesrepublik in die Souveränität entlassen werden sollte, im „Mannhei-

${ }^{285}$ Köhler, Wir Schreibmaschinentäter, S. 243. Unter dem Namen Paul Carrell machte Schmidt in der Bundesrepublik später publizistisch Karriere. Zu seinem Werdegang vor und nach 1945 ausführlich: Benz, Paul Carell. Ferner: Köhler, Unheimliche Publizisten, S. 164-203.

${ }^{286} \mathrm{Zu}$ diesem Fazit kommt Peter, Das Spanienbild in den Massenmedien des Dritten Reiches, S. 224. Vgl. zu Barths idealisiertem Bild der spanischen Staatspartei Falange und der Person Francos S. 162.

287 Ungeachtet des außenpolitischen Lavierens Francos und der mit dem Kriegsverlauf wachsenden Entfremdung beider Diktaturen wurde in den deutschen Medien Spanien - im Gegensatz zu Italien - nie Verrat an der gemeinsamen Sache vorgehalten. Ebenda, S. 208.

288 Botschaft Madrid an Auswärtiges Amt, 26. 6. 1955, PA/AA, Ref. 203, Bd. 473. Nach Informationen der deutschen Botschaft in Madrid war Barth im Juli 1945 vom chilenischen Konsulat in Dresden ein provisorischer Paß ausgestellt worden. Seinen Angaben zufolge habe er ihn aber erst im März 1947 von dem jetzt in München lebenden früheren chilenischen Konsul in Dresden erhalten, der, so Barth, ,gegen Entgelt viel[e] derartige Dokumente erteilt habe". Nicht nur die genauen Umstände dieser Paßgeschichte, sondern auch die Beweggründe Barths bleiben im dunkeln. Möglicherweise wollte er mit seiner neuen Staatsangehörigkeit einem drohenden Entnazifizierungsverfahren aus dem Wege gehen. Die Madrider Botschaft hatte ihm nach Vorlage einer eidesstattlichen Erklärung, daß er keine fremde Staatsangehörigkeit besitze, 1953 einen deutschen Reisepaß ausgestellt.

289 Botschaft Madrid (Vertraulich) betr. Auslandskorrespondent Heinz Barth, 29.7. 1955, PA/AA, Ref. 206, Bd. 33. Barth, vom spanischen Informationsministerium als „besonderer Fall“ gekennzeichnet, erklärte dem Pressereferenten der Botschaft, er habe 8-9 Monate (Oktober 1947-Juni 1948) für den Artikeldienst der „Sección de Investigación e Información de la Falange“ gearbeitet. Da er aber jede nachrichtendienstliche Tätigkeit abgelehnt habe, sei ihm später gekündigt worden.

290 Stuttgarter Nachrichten, 31. 12. 1955.

291 Mannheimer Morgen, 2. 3. 1955. 
mer Morgen “ eine seiner Ansicht nach inzwischen überfällige Neuorientierung der Bonner Spanienpolitik ein: „Es ist offensichtlich, daß bei der Bundesregierung bis zur Stunde praktisch nichts vorhanden ist, was die Bezeichnung ,Spanienpolitik' verdienen würde. Allzu sorglos hat man in Bonn das Verhältnis am Boden schleifen lassen, weil man offenbar glaubte, die Bundesrepublik könne sich angesichts der ideologischen Vorbehalte, die in den westlichen Ländern gegen Spanien geltend gemacht wurden, nicht dem Verdacht einer neuen ,Achsenpolitik' aussetzen." ${ }^{292}$

Barths Ehrgeiz, auf die deutsche Spanienpolitik einzuwirken, beschränkte sich nicht allein auf das journalistische Feld. In der Bonner Regierung fand er für seine Kritik durchaus Verbündete. So bat Bundesratsminister von Merkatz, als „Abendländer“ an Spanien besonders interessiert, Barth um eine Analyse des bilateralen Verhältnisses. In dem „streng vertraulichen“ Hintergrundbericht an Merkatz kritisierte Barth im Oktober 1955 die Konzeptionslosigkeit der bisherigen Bonner Spanienpolitik. Sorgen bereitete ihm die mangelnde „Durchschlagskraft“ der deutschen Botschaft, die mit Prinz Adalbert, der große menschliche Sympathien genieße, bisher den Eindruck erweckt habe, daß die Bundesrepublik mehr dekorativ als politisch in Spanien vertreten sei. Diese Wahrnehmung habe vor allem die Spanier dazu ermutigt, die deutschen Forderungen in der Vermögensfrage „mit sorgloser Gleichgültigkeit zu behandeln“293.

Die in seinen journalistischen Beiträgen immer wieder dokumentierte Sympathie für das Franco-Regime erlaubte ihm - trotz der politischen Zensur ${ }^{294}$ - in der Auseinandersetzung um das enteignete deutsche Vermögen aber auch andere Töne anzuschlagen. Als „Gottfried Grosse“ kritisierte Barth für „Die Welt“ Anfang 1957 unverblümt spanische Reparationsforderungen mit der Schlagzeile: „Die Regierung Franco spannt den Bogen zu weit. " ${ }^{\text {"955 }}$ In der Sache sei das Regime bisher ,jeden Nachweis schuldig geblieben, wie es seine Forderungen begründen will“296. Wenn die deutsch-spanische Freundschaft diese „neue Prüfung“ überstehen solle, müsse, so forderte er, Madrid seine Position überdenken. Das Ende des jahrelangen Konflikts ließ Barth im Frühjahr 1958 dann wieder versöhnlich werden. Das Vermögensabkommen würdigte er in gewohnt konzilianter Weise. Wie so häufig arbeitete der Journalist auch hier in seinem Rückblick mit dem Stereotyp der völkerverbindenden Freundschaft: „Aber es verdient festgehalten zu werden, daß selbst auf dem Tiefpunkt der deutsch-spanischen Beziehungen die Mehrheit der spanischen Öffentlichkeit mit ihren Sympathien auf deutscher Seite stand. Sie hat das Unrecht der Enteignung aus innerster Überzeugung missbilligt. "297

Heinz Barth war durch seine langjährige Erfahrung als Spanien-Korrespondent und seine vielfältigen Kontakte eine Schlüsselfigur für das Bild des iberischen Landes in der

\footnotetext{
292 Ebenda.

293 Barth an von Merkatı, 11. 10. 1955, ACDP, Nl. von Merkatz, I-148, Bd. 009/1.

294 Ein anderer langjähriger deutscher Spanien-Korrespondent, Anton Dieterich (Kölner Stadtanzeiger, Rheinische Post, Kölnische Rundschau), der ebenfalls schon zwischen 1939 und 1944 aus Spanien berichtet hatte, beschrieb die Zensur in Gestalt des Informationsministeriums nach dem Kriege als nicht sehr rigide. Oftmals habe sic „wackelige Zähne“ gehabt. Jeder einzelne Bericht mußte aber vorgelegt werden. Hinzu kam nach den Worten Dieterichs die Kontrolle und indirekte Überwachung durch die spanische Botschaft in Bonn, die bei mißliebigen Artikeln entsprechende Berichte an das Informationsministerium schickte. Gespräch mit Anton Dieterich, 29.5. 1990 in Madrid.

295 Die Welt, 30.1. 1957.

296 Ebenda.

297 Die Welt, 13. 3. 1958.
} 
westdeutschen Presse. Um so mehr verwunderte es, daß Barth, der sich im Spanien Francos eingerichtet hatte, im Sommer 1955 unerwartete Schwierigkeiten mit dem Madrider Informationsministerium bekam. Ohne Angabe von Gründen wurde ihm mitgeteilt, daß sein Presseausweis nicht mehr wie bisher üblich ein halbes Jahr verlängert werde, sondern nur noch für einen Monat gelte und dann neu beantragt werden müsse ${ }^{298}$. Barth befürchtete, dieser Schritt sei als Vorstufe einer späteren Ausweisung gedacht. Er begriff sich als politisches Opfer der Pressezensur und sah in dieser Maßnahme „einen ungerechtfertig-

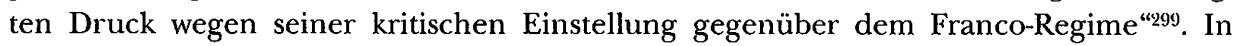
Bonn wurde diese Argumentation verwundert aufgenommen. Dem Spanien-Referenten im Auswärtigen Amt erschien es „unwahrscheinlich“, daß die „Berichterstattung Barths, die vom Länderreferat seit langem aufmerksam verfolgt wird, der Anlaß zu dieser Maßnahme gewesen sei “300. Deshalb erhielt die Botschaft in Madrid die Weisung, zunächst bei den spanischen Behörden zu ermitteln, und falls eine ungerechtfertigte „Diskriminierung“ vorliege, deren Rücknahme zu verlangen. Die Suche nach den wahren Motiven des Informationsministeriums erwies sich als Stochern im Nebel.

Die Botschaft konnte lediglich mit Vermutungen aufwarten, die auf atmosphärische Spannungen zwischen dem Informationsministerium und Barth hindeuteten. Demnach warf der Generaldirektor für Pressewesen, Aparicio, dem Journalisten enttäuscht „Gesinnungswandel“ vor, der ihn an der Loyalität Barths zu Spanien zweifeln lasse ${ }^{301}$. Der Leiter des Pressereferats im Auswärtigen Amt, Diehl, argwöhnte daraufhin, daß Barth sich durch seine engen Verbindungen zur Falange angreifbar gemacht habe und das Vorgehen des Informationsministeriums den Unmut über Barths wachsende Distanz zur Staatspartei widerspiegele: „Die eigentliche Ursache des Zerwürfnisses dürfte sein, daß Herr Barth tief in die spanische Innenpolitik verstrickt ist. Die Falange hat bis 1945 in Herrn Barth als Vertreter von ,Das Reich“ einen besonders zuverlässigen Vertrauens- und Verbindungsmann gesehen. Die Falange hat ihm in der Notzeit nach 1945 [...] geholfen, indem sie ihn in einem Nachrichtendienst beschäftigte. Die Falange hat Barth wohl auch ermöglicht, chilenische Papiere zu erhalten. Die Falange glaubt - ob zu Recht oder Unrecht, das bleibt dahingestellt - infolgedessen einen Anspruch darauf zu haben, daß Herr Barth ihr gegenüber ,treu“ ist." ${ }^{022}$ Inzwischen hatte sich ihr „Schützling“ aber offenbar politisch von ihr entfernt. Barth sah nun in der Rückkehr zum Monarchismus augenscheinlich die politische Zukunft Spaniens ${ }^{303}$.

Die Madrider Botschaft verwies in ihrem Ermittlungsbericht außerdem auf die herausgehobene Position, die Barth unter seinen Kollegen einnehme. Möglicherweise seien die aktuellen Probleme des „bestverdienenden deutschen Journalisten“304 auch von Intrigen und Mißgunst gefördert worden. Im Gegensatz zu den Pressevertretern aus den USA, Eng-

208 Botschaft Madrid betr: beschränkte Verlängerung der Akkreditierung des deutschen Journalisten Heinz Barth, 11. 6. 1955, PA/AA, Ref. 206, Bd. 33.

299 Presse- und Informationsamt an Auswärtiges Amt, 8. 6. 1955, PA/AA, Ref. 206, Bd. 33.

300 Aufzeichnung für den Bundesminister des Auswärtigen betr. Tätigkeit des deutschen Journalisten Heinz Barth, 28. 6. 1955, PA/AA, Ref. 206, Bd. 33.

301 Botschaft Madrid betr. Heinz Barth, 29. 7. 1955, PA/AA, Ref. 206, Bd. 33.

302 Diehl an Ref. 303, 16. 8. 1955, PA/AA, Ref. 203, Bd. 473.

303 Ebenda.

${ }^{304}$ Botschaft Madrid an Auswärtiges Amt, 26. 6. 1955, PA/AA, Ref. 203, Bd. 473. 
land oder Frankreich blieben die meisten deutschen Spanien-Korrespondenten lange im Lande ${ }^{305}$. Dadurch hatte sich ein System von Konkurrenz und Abhängigkeiten herausgebildet, das nach dem Eindruck der deutschen Botschaft mit einer vorurteilsfreien und unabhängigen Berichterstattung auf Dauer nicht vereinbar war. Denn die spanische Seite nutzte die Rivalitäten der Pressevertreter politisch in ihrem Sinne aus. Dies geschehe ,in zwei Richtungen“, urteilten die diplomatischen Beobachter: ,in der Ausübung von Druck auf [die] wegen ihrer Berichterstattung weniger beliebte [Seite] und in der Gewährung von Vorteilen - nach zuverlässigen, wenn auch nicht beweisbaren Angaben sogar finan-

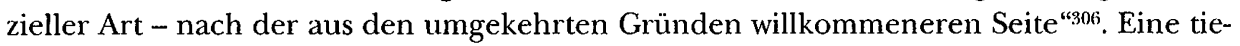
fergehende Beschreibung der innenpolitischen Verhältnisse in Spanien wurde von den deutschen Korrespondenten auch kaum geleistet. Heinz Barth, der von diesem „Sumpf“ offensichtlich bis dahin profitiert hatte, konnte den Disziplinierungsversuch dank der Unterstützung der deutschen wie auch spanischer Behörden bald abwenden. Nachdem sogar das Madrider Außenministerium den Alleingang des Informationsministeriums als „idiotische und dumme Maßnahme" die zeitliche Beschränkung im August 1955 wieder zurückgenommen ${ }^{308}$.

In Bonn war der „Fall Barth“ mit wachsendem Unbehagen verfolgt worden. Die zutage geförderten Informationen ließen das Auswärtige Amt auf Distanz gehen. Günter Diehl, der Leiter des Pressereferats, befürchtete angesichts der vielen Ungereimtheiten um Barth anhaltende Querelen, die auch in dessen Monopolstellung begründet seien: „Immerhin stellt sich die Frage, ob die Zusammenballung der Spanienberichterstattung der deutschen Presse in einer Hand, wie es bei der ,Berichtsfabrik' von Heinz Barth der Fall ist, pressepolitisch gesund ist. ${ }^{\text {"309 }} \mathrm{Ihm}$ wäre es deshalb lieber gewesen, wenn der umtriebige Korrespondent seine bisherige Wirkungsstätte, wie von Barth angekündigt, freiwillig verlassen hätte: „Wir haben von Amts wegen natürlich ein Interesse daran, daß die Sache ohne Prestigeverlust für uns ausgestanden wird. Aber der Fall Barth enthält Stoff für weitere Konflikte, und es wäre meines Erachtens das Beste, wenn Herr Barth seine mir gegenüber geäußerte Absicht wahr machen würde, in absehbarer Zeit sein Tätigkeitsfeld zu wechseln." 310 Dieser Wunsch sollte sich so schnell nicht erfüllen. Barth verließ seinen Arbeitsplatz Spanien erst im Jahre 1962. Zu seinem Abschied schrieb die Zeitung „Christ und Welt" treffend, aber ohne die gebotene Ironie: „Ein Vierteljahrhundert hindurch hat Barth das deutsche Spanien-Bild nachhaltig beeinflußt und sich in Madrid großer Wertschätzung erfreut." ${ }^{111}$

${ }^{305}$ Der Journalist Anton Dieterich beschrieb dieses Phänomen, das auch für ihn galt, mit den Worten: „Die Deutschen kamen und blieben." Gespräch mit Anton Dieterich, 29. 5. 1990 in Madrid. In der spanischen Hauptstadt waren 195514 deutsche bzw. deutschsprachige Journalisten akkreditiert. Darunter befand sich auch der Österreicher Josef Hans Lazar, der zwischen 1939 und 1945 als Presseattaché an der deutschen Botschaft in Madrid tätig gewesen war. Vgl. Botschaft Madrid, 21.9. 1955, PA/AA, Ref. 206, Bd. 33. Anders als etwa die Spanien-Berichterstatter der New York Times, Time und Le Monde wurde in den 50er Jahren kein deutscher Journalist des Landes verwiesen.

${ }^{306}$ Botschaft Madrid betr. Heinz Barth, 29. 7. 1955, PA/AA, Ref. 206, Bd. 33.

307 Aufzeichnung Klein betr. Vorgehen des spanischen Informationsministeriums gegen den Journalisten Heinz Barth, 29. 6. 1955, PA/AA, Ref. 206, Bd. 33.

308 Botschaft Madrid an Auswärtiges Amt, 1. 8. 1955, PA/AA, Ref. 206, Bd. 33.

${ }^{309}$ Diehl an Klein, 16. 8. 1955, PA/AA, Ref. 203, Bd. 473.

310 Ebenda.

311 Zitiert nach: Der Spiegel, Nr. 30, 21. 7. 1969, S. 109. 